\title{
Global Mindset, Networks and Trader Performance: A Study of the Global Grain and Oilseed Sector
}

\author{
By \\ Richard William Price \\ Supervised by \\ Dr. Revti Raman
}

A thesis submitted to the Faculty of Commerce and Administration, Victoria University of Wellington, in fulfilment of the requirements for the degree of Master of Commerce in International Business

Victoria University of Wellington, New Zealand 2015 



\section{Abstract}

As a result of globalisation of trade, the research on the role of global mindset (GM) in enhancing performance has gained momentum in the new millennium. Even though GM is considered as an essential prerequisite to performance in the current international business environment, the empirical evidence of the direct effects of GM on performance is mixed. One of the reasons for this mixed evidence is the existence of other mechanisms, such as mediators and moderators, which influence GM-performance relationships. This study focuses on one such mechanism, namely networks (NWs), and examines how NWs mediate the association between GM and the performance of the global grain and oilseed traders. The study argues that GM has little direct effect on trader performance (TP). Rather, GM strengthens network structure (NWS), which collectively leads to enhanced network leverage (NWL) and thus increased TP.

Based on a sample of 78 traders in the global grain and oilseed sector (GGOS), the study finds that both the network (NW) components - NWS and NWL mediate the association between GM and TP. The finding of full path mediation provides empirical evidence that superior GM leads to superior NWS, which results in superior NWL and thus superior TP. The method used in data analysis is Partial Least Square Structural Equations Modelling (PLS-SEM), using SmartPLS software.

This study makes two main contributions. Firstly, the study endorses the critical role of GM in enhancing the performance of traders in the GGOS. Secondly, the study provides a deeper understanding of how GM enhances performance; that is, the serial mediating roles of NWS and NWL. The current research has largely suggested single mediation of relationship quality. This study goes a step further and introduces NWL into the argument. The key implications of the study include the need to strengthen the GM and NWs of traders, as the interplay between the two is critical in enhancing their performance. The findings need to be interpreted carefully, as the study suffers from limitations of small sample size and single sector study. 


\section{Acknowledgements}

I will keep this brief, not to play down the importance of this section; rather to intensify my sincere gratitude and appreciation to a small number of key people who without their support this journey would not have been possible.

Firstly, to my wife, Theresa who has been equally committed to this process through the demands of raising four children with a regularly absent husband and never complaining, always supporting. I thank you with all my heart. To our four children: Carlos, Isabella, Mia and Eva, Dad has been absent and I am sorry you have had to endure my absence. I have ground to make up and this summer will be the summer of all summers, I promise. I love you all so very much, and I hope this effort will inspire each of you to pursue an academic journey of your own in the years to come.

Finally, Dr Revti Raman, my supervisor. I thank you so very much for all the time and guidance you have provided; you will always be the world's best supervisor to me and I wish you all the very best in the future. You encouraged me to travel down a statistical path that I never envisaged, and at first terrified me. But on reflection, I am so very pleased that you did, for it has been an immensely satisfying part of the journey. Your success in your own research, and your commitment towards your students is testament to the person you are. I wish you all the very best, and I look forward to following your publishing career, and will always feel very honoured to have worked under your supervision. 


\section{Table of Contents}

ACKNOWLEDGEMENTS

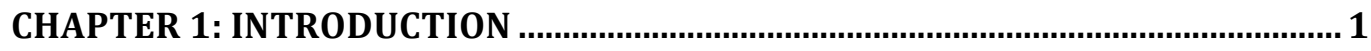

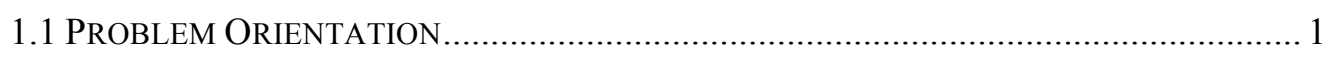

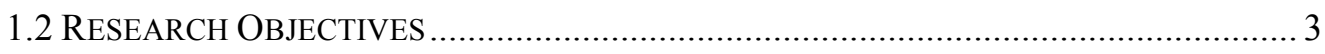

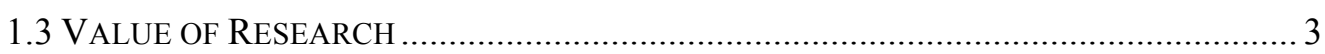

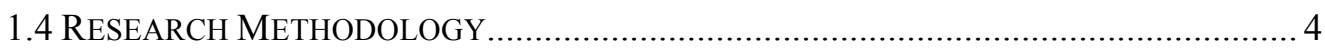

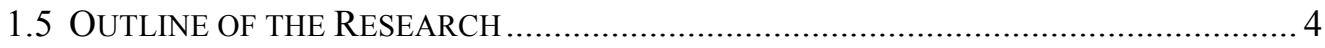

CHAPTER 2: UNDERSTANDING THE GLOBAL GRAIN AND OILSEED SECTOR ..... 6

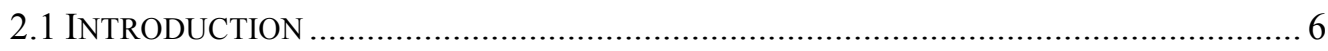

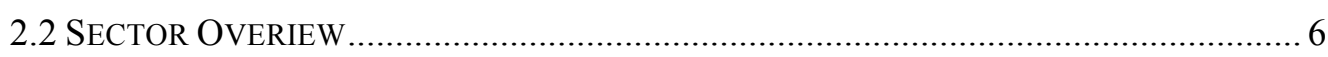

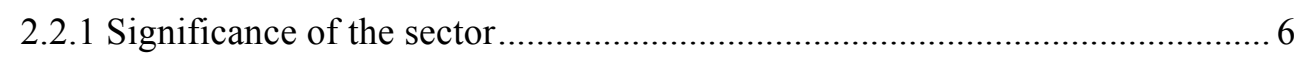

2.2.2 Challenges faced by the sector............................................................... 10

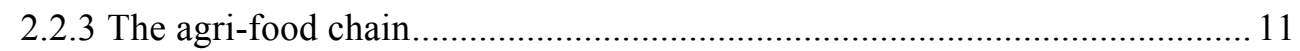

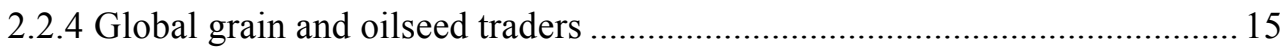

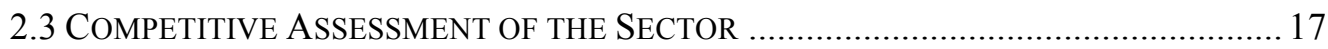

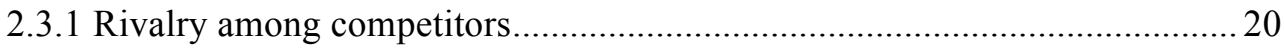

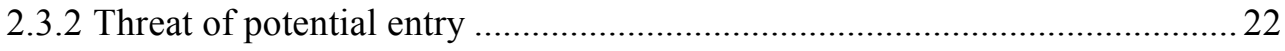

2.3.3 Bargaining power of buyers and suppliers ................................................ 24

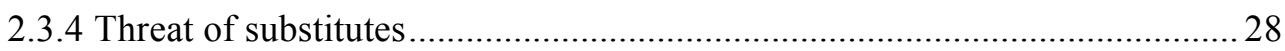

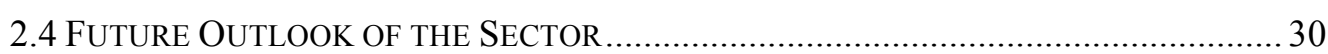

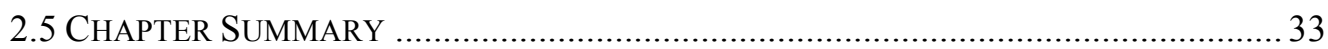




\section{CHAPTER 3: LITERATURE REVIEW AND THEORETICAL}

FRAMEWORK

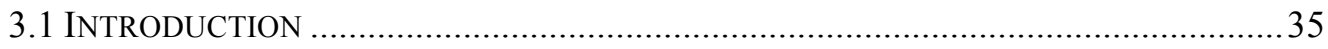

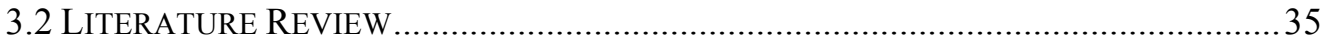

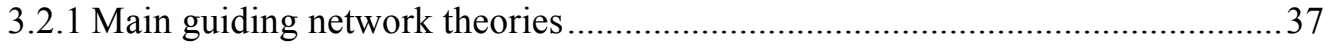

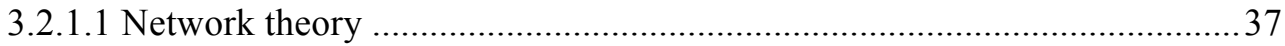

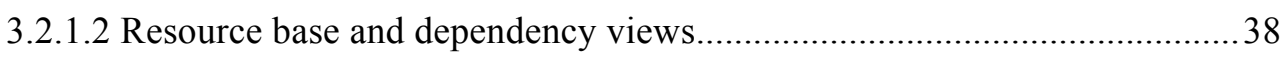

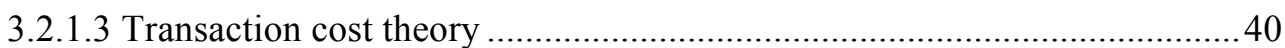

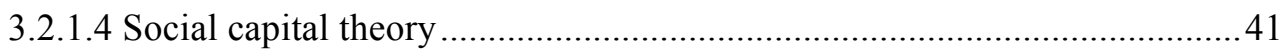

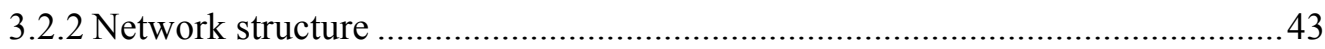

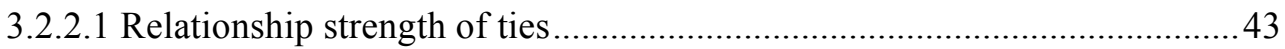

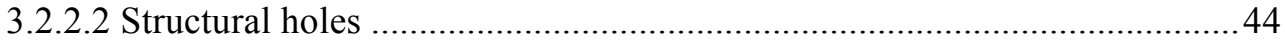

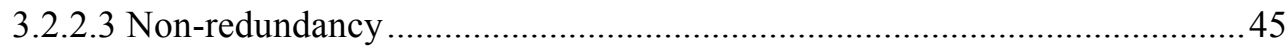

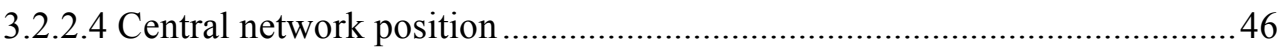

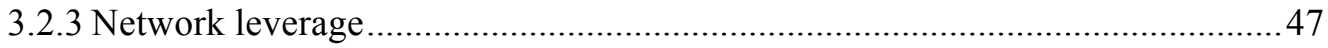

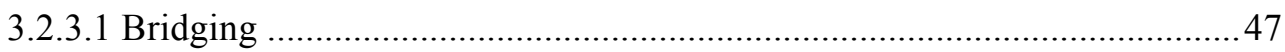

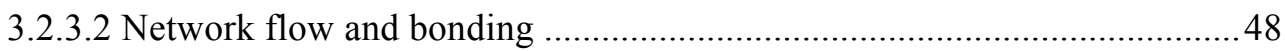

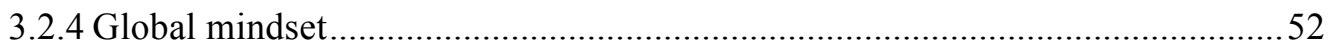

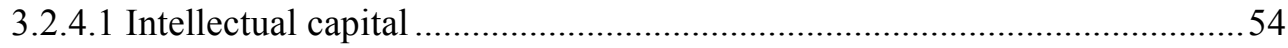

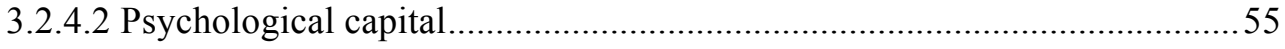

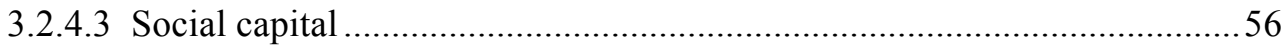

3.3 ConCEPTUAL Model AND HyPothesis DEVELOPMENT …….............................56

3.3.1 Global mindset, network structure and trader performance...........................58

3.3.2. Global mindset, network leverage and trader performance ...........................59

3.3.3 Network structure, network leverage and trader performance........................60

3.3.4 Global mindset, network structure, network leverage and trader

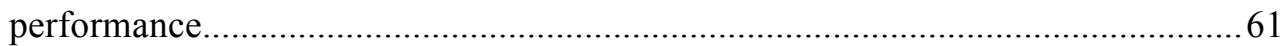

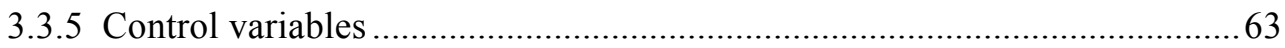

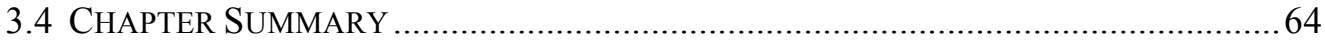

CHAPTER 4: METHODOLOGY

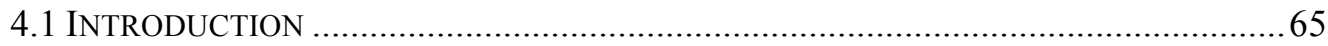

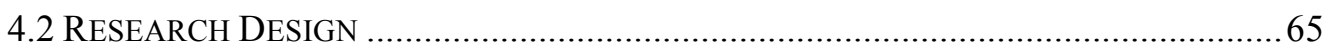

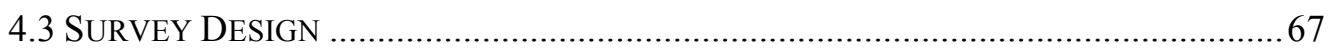

4.4 EXPLANATORY VARIABLES MEASUREMENTS........................................................68 


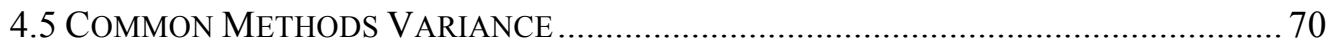

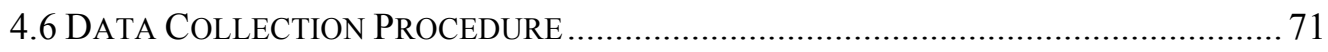

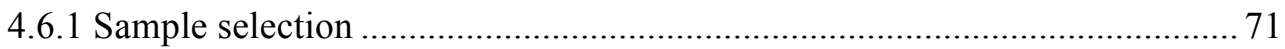

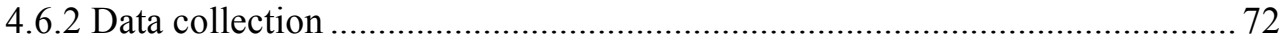

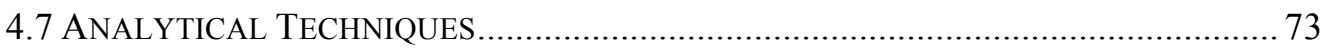

4.7.1 Exploratory and confirmatory factor analysis ............................................ 73

4.7.2 Path modelling and analysis using PLS-SEM ............................................. 76

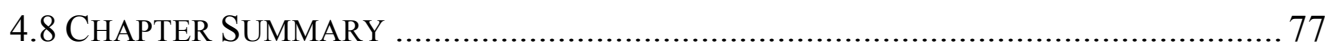

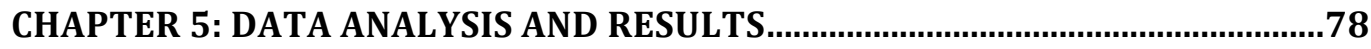

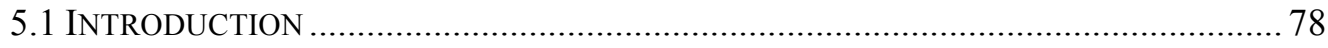

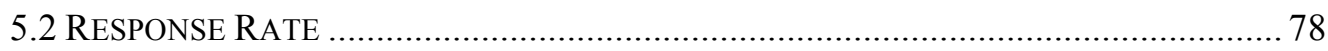

5.3 RESPONDENT AND DEMOGRAPHIC PROFILES ...................................................... 79

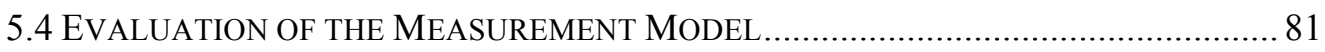

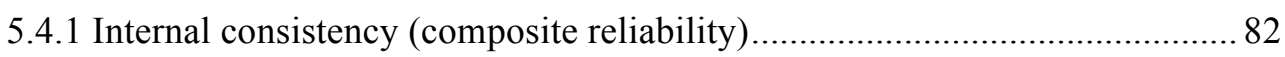

5.4 .2 Indicator reliability and convergent validity (average variance extracted) ... 82

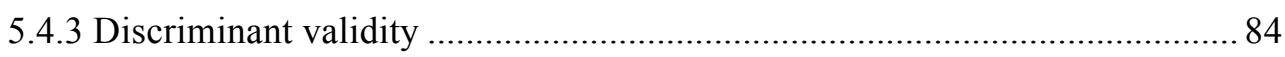

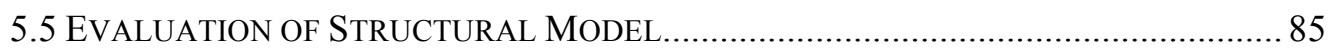

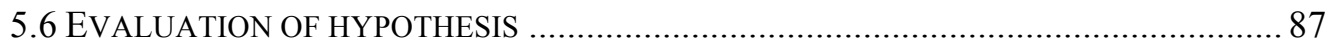

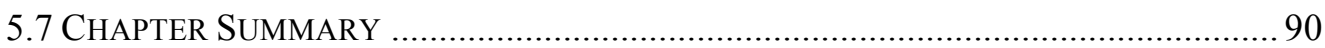

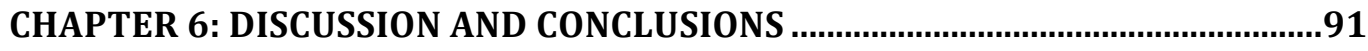

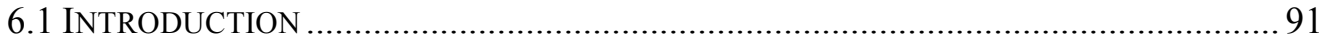

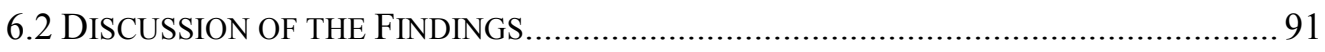

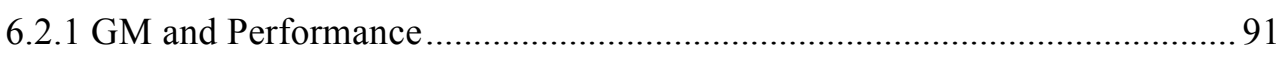

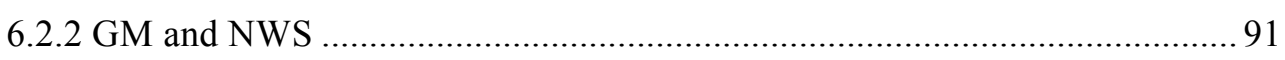

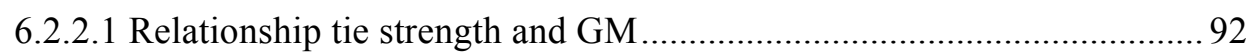

6.2.2.2 Central network position and GM ..................................................... 93

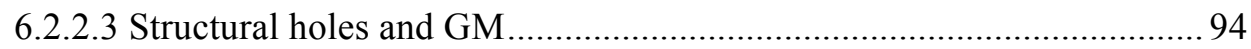

6.2.2.4 Non-redundant network contacts and GM ......................................... 94

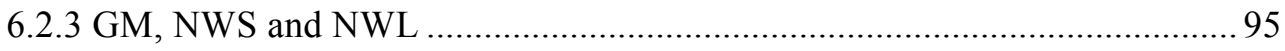

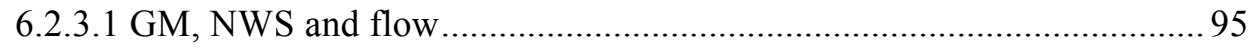

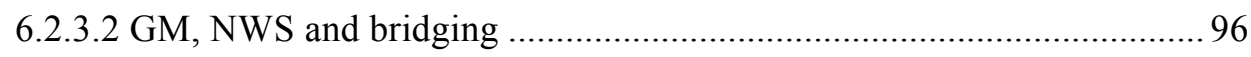

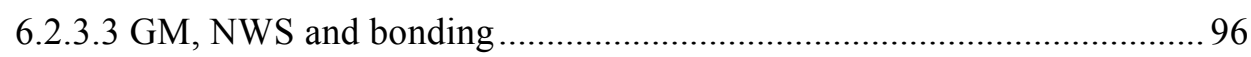

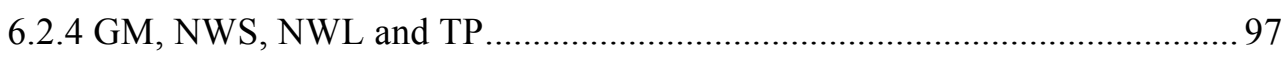

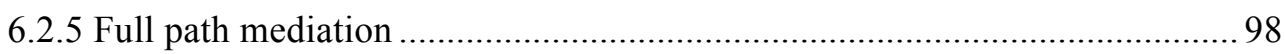

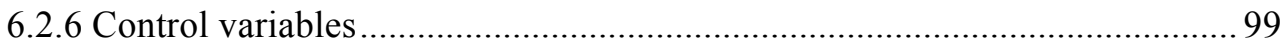




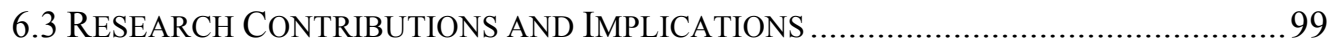

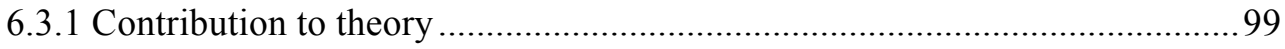

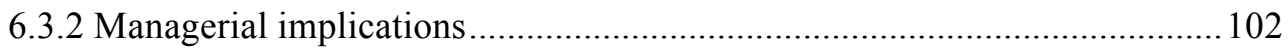

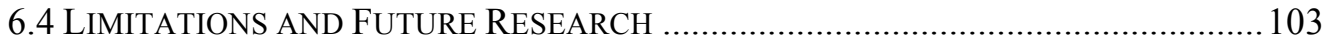

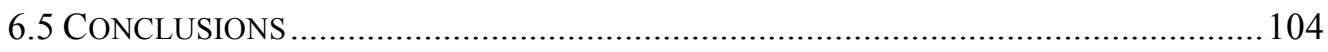

APPENDIX 2: INVITATION, INFORMATION AND ONLINE SURVEY ..................... 107

APPENDIX 3: ONLINE INTRODUCTION, INVITATION AND PARTICIPATION

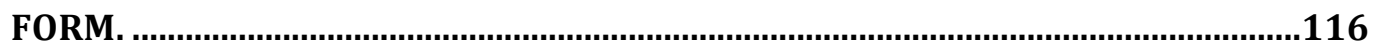

REFERENCES 


\section{List of Tables}

Table 1: Top Producers in the GGOS ............................................ 8

Table 2: Agricultural Value Add.....................................................12

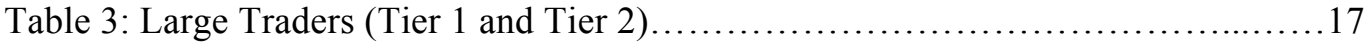

Table 4: An Assessment of Competitive Forces in the GGOS........................29

Table 5: Global Soybean Production 2010/11 (tonnes).................................31

Table 6: Survey Questions by Variable.........................................69

Table 7: EFA Benchmarks........................................................ 74

Table 8: CFA Benchmarks: PLS-SEM Measurement and Structural Model

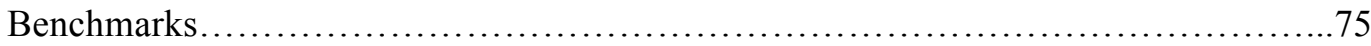

Table 9: Sample Characteristics............................................ 80

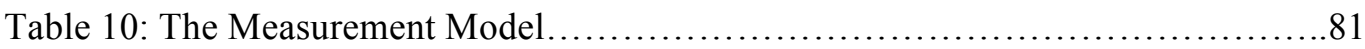

Table 11: Fornell-Larcker Criterion................................................... 84

Table 12: Direct and Indirect Effects of the Mediation Paths...........................89 


\section{List of Figures}

Figure 1: Porter's Five Forces Framework................................... 18

Figure 2: Schematic Overview of Literature .................................36

Figure 3: Basic Dependency............................................49

Figure 4: Intermediate Dependency ........................................ 49

Figure 5: Group Dependency........................................... 50

Figure 6: Network Closure Offset Dependency ............................51

Figure 7: Scientific Structure of Global Mindset.............................55

Figure 8: Conceptual Model...............................................57

Figure 9: The Structural Model Results (Full Path Mediation)....................85 


\section{Abbreviations and Acronyms}

ABCD: ADM, Bunge, Cargill, Louis Dreyfus

CFA: Confirmatory factor analysis

CPO: Crude palm oil

EFA: Exploratory factor analysis

FFF: Five Forces Framework

FOB: Free On Board

GGO: Global grain and oilseed

GGOS: Global grain and oilseed sector

GGOT: Global grain and oilseed trader

GM: Global mindset

IC: Intellectual capital

IGC: International Grains Council

IGCAC: International Grains Council annual conference

MNE: Multinational enterprise

MPOB: Malaysian Palm Oil Board

NW: Network

NWs: Networks

NWL: Network leverage

NWS: Network structure 
Abbreviations and acronyms continued.

PLS-SEM: Partial least squares-structural equation modelling

PC: Psychological capital

SC: Social capital

SME: Small and medium enterprise

TP: Trader performance 


\section{Chapter 1: Introduction}

\subsection{Problem Orientation}

Food production and consumption is a central challenge across the globe. Efficiency, safety and security of supply are central issues to all nations and fundamental drivers within the global grain and oilseed sector (GGOS). With both established and emerging traders manoeuvring to achieve the competitive advantage required to realise high performing organisations (BeVier, 2012). Within this context, the development of networks (NWs) throughout the value chain is dynamic and the importance of global mindset (GM) is high priority.

The networking literature is complex in that it contains various apparent contradictions that require clarification (Javidan \& Bowen, 2013; Levy, Beechler, Taylor, \& Boyacigiller, 2007; Raman, Chadee, Roxas, \& Michailova, 2013). While the constructs and assumptions that different studies have used may have contributed to these contradictory findings, this research primarily looks to unravel the causal influences that GM and NWs have on trader performance (TP), and seeks to explain how the contradictory findings may reconcile through the influence of some intermediary variables (Bengtsson \& Kock, 2000; Gulati \& Gargiulo, 1999; Hamel, Doz, \& Prahalad, 1989; Pett \& Dibrell, 2001; Shah \& Swaminathan, 2008). Combining the GM and NW literature and analysing the relationship between NWs and the GM of the trader provides insights into how TP can be enhanced.

The GM literature is voluminous; however, its grounding in international business research as a fundamental construct is widely debated (Arora, Jaju, Kefalas, \& Perenich, 2004; Cohen, 2010; Javidan \& Bowen, 2013; Levy et al., 2007; Raman et al., 2013; Rhinesmith, 1992; Story \& Barbuto, 2011; Vogelgesang, Clapp-Smith, \& Osland, 2014). Many academics view GM as a prerequisite to performance when applied in an international business context (Nummela, Saarenketo, \& Puumalainen, 2004), whereas others posit that GM does not influence performance directly; rather, it is through other mechanisms that operate within this context that superior performance is delivered (Levy et al., 2007; Raman et al., 2013). 
"It is not the GM per se that enhances performance; it is the mechanism, namely partnership quality, which actually leads to higher performance" (Raman et al., 2013, p. 11).

Raman et al. (2013) concluded that it is the quality of relationships that an actor has, not the actor's mindset itself, which ultimately brings superior benefits to the actor, and it is these benefits that ultimately lead to superior performance. In this regard, the present research extends by introducing a broader representation than partnership quality alone. This study seeks to explore the quality and richness of the trader's entire network, and aims to provide a more complete explanation of how all relationships and actions across the network both contribute and mediate the link between GM and performance.

Within the context of richness of relationships is the notion of embeddedness. The degree of embeddedness can range from strategic partner to casual acquaintance, such as a friend of a friend. Not all network contacts could be described as partners, at times those weaker relationships can be contacts just as valuable to the trader in different ways, offering benefits such as novel information not necessarily known by the traders' closer partners (Burt, 1992; Granovetter, 1973; Michelfelder \& Kratzer, 2013). Through combining the GM and NW literature we will gain a greater understanding of the way that GM works through NWs as a mediator, and unravel some of the inconsistencies in the way that GM, through NWs casually and serially, influences performance.

The intensity of internationalisation has been dramatic in recent years (Gulati \& Gargiulo, 1999; Osarenkhoe, 2010), whereas the link between more intricate and complex constructs, such as GM and NWs, remain in an evolutionary phase. For example, literature linking GM with casual agents of performance, such as partnership quality, NWs or other mediators, is still rather limited, albeit under rapid development (Dyer, Kale, \& Singh, 2001; Gulati \& Gargiulo, 1999; Levy et al., 2007; Osarenkhoe, 2010; Raman et al., 2013).While earlier studies often postulated that rapid internationalisation requires a strong GM of managers (Nummela et al., 2004), it has been the more recent studies that have sought to 
reveal mediating mechanisms at play (Chen, 2013; Dyer et al., 2001; Raman et al., 2013). This study aims to fill an important gap in research by examining the network mechanisms that transform global mindset into superior performance.

The study mainly relies on Social Capital Theory, which is the grounding field of research linking GM literature with NWs literature (Burt, 2000; De Carolis, Eddleston, \& Litzky, 2009; Javidan, Teagarden, \& Bowen, 2010; Maurer \& Ebers, 2006; Musteen, Francis, \& Datta, 2010; Nahapiet \& Ghoshal, 1998; Stam, Arzlanian, \& Elfring, 2014).

\subsection{Research Objectives}

The main research question this study investigates is the mediation effects of network components, such as network structure and network leverage, in the association between global mindset and trader performance in the global grain and oilseed sector. Traders are defined as all traders other than the four Tier 1 large multinationals. In order to answer the main research question, several questions are examined: whether GM influences TP directly and/or indirectly through mediators; whether NWS mediates the relationship between GM and TP; whether NWL mediates the relationship between GM and TP; whether NWL mediates the relationship between NWS and TP; and whether NWS and NWL impose serial mediation between the relationship of GM and TP.

To answer these research questions, the study will review the relevant literature, develop a conceptual model and test the proposed conceptual model using a large-scale questionnaire survey to provide contributions to theory and practice.

\subsection{Value of Research}

This study contributes to both the GM and NW bodies of literature. Firstly, the study reconciles some of the contradictions surrounding the GM and NW literature and, in doing so, provides context and clarification around two network constructs developed in this study that emerge from the NW literature: NWS and NWL. NWS is introduced to the study as representing structural integrity - the arrangement of nodes that make up a network and the ways in which these nodes are connected both directly and indirectly. 
Whereas NWL is action-oriented, NWL measures the degree or ability of the trader to leverage benefits off the NWS and the bonding implications that emerge through the unique NWS and actions of the trader.

This study endorses the critical role that GM plays in enhancing the performance of traders in the GGOS through providing a deeper understanding of how GM, NWS and NWL work through a serial path of mediation to superior TP.

\subsection{Research Methodology}

In order to achieve the objectives of the study, a conceptual model was developed from the extant literature surrounding both GM and NWs. The model was tested and validated using instruments designed to measure GM, NWS, NWL and TP. The study employed a quantitative approach through an online survey instrument. A questionnaire was developed in order to enable the data collection phase of the study. Once the online survey was completed, the study empirically tested the explanatory capabilities of the conceptual model examining traders working within the GGOS.

The data drawn from the results of the online survey were firstly taken into SPSS to be cleaned and, where required, reverse-coded. Following this process, initial EFA testing was performed to identify potential variables that loaded together in constructs that represented the structural model developed in the study. Following this data familiarisation process, the data was analysed with PLS-SEM, using SmartPLS to test the research hypotheses and answer the research questions. The quantitative survey results provided a comprehensive and rigorous analysis of GM, NWs and the impacts that both had singularly, serially and directly or indirectly on TP within the GGOS.

\subsection{Outline of the Research}

The study is organised into six chapters. A brief description of each chapter is provided.

Chapter 2 provides an overview of the GGOS and its place and importance within the global food chain. In addition, an industry analysis of the sector is 
undertaken using Porter's Five Forces Framework to gauge the industry attractiveness, and finally an outlook for the future of the sector is offered.

Chapter 3 provides an extensive review of the literature encompassing GM, NWs and performance, and details the main guiding theories that are embraced within this study and that make up the constructs developed in the conceptual model. From the theoretical framework drawn from these streams of literature, the conceptual model and hypothesis development are explained.

Chapter 4 explains the research design and provides the rationale for employing a quantitative approach. The survey and its development and deployment are also described. Finally, the analysis and statistical techniques employed by the study to test the hypothesis are also explained.

Chapter 5 reports the results of the survey and presents the results of the hypothesis analysis.

Chapter 6 discusses the key findings, and considers them in relation to the conceptual model and the hypothesis. It also specifies the key academic and theoretical contributions of the study, followed by the implications for managerial practices. Additionally, the limitations of the study are acknowledged and areas for future research are suggested. 


\section{Chapter 2: Understanding the Global Grain and Oilseed Sector}

\subsection{Introduction}

The global grain and oilseed sector (GGOS) is the industry and geographic context of the study. This chapter provides an understanding of the sector, including the extent of competition. The next section provides an overview of the sector, including its important position within the global food chain. The role of various stakeholders operating within the industry is also introduced. The sector overview is followed by a more detailed analysis of the broader industry structure through the lens of Porter's Five Forces Framework. Porter's analysis is used to assess the extent of competitive rivalry in the sector, which helps to better understand the implications of the empirical findings of the study for both academics and industry stakeholders. The last section summarises this chapter.

\subsection{Sector Overiew}

\subsubsection{Significance of the sector}

The global food system consists of the activities involved in producing, processing and distributing food to feed the world and links both national and international food systems on a global scale through trade, technology, knowledge sharing, labour and capital exchange (BeVier, 2012). The history of the global food system is characterised by a move from the utilisation of vegetative plants and livestock domestication through to the large-scale sophisticated farming operations of today's industrialised agriculture. Despite the tremendous advances made, the global food system is under threat of being unable to provide sufficient food to cover the exponentially increasing population. By way of an indicative statistic, Godfray et al. (2010) makes the point: "We cannot be said to have a functioning global food system when one in seven people today still do not have access to sufficient food, and an equal number are overfed". BeVier (2012) highlights that the global food system is failing to feed approximately $80 \%$ of the world's poor (those earning less than $\$ 10$ per day), and that more than one billion people worldwide are undernourished. 
In response to this situation, the United Nations' Food and Agricultural Organisation and other groups claim that enough food is produced at a global level to feed everyone, but the failure lies in the access to and distribution of food; furthermore, they argue that a contributing reason is that world trade within the sector is in the hands of a confined group (Sowinski, 2012; UNIDO, 2009).

The GGOS is the most critical component within the global food chain (Sowinski, 2012; USDA, 2014). Grain and oilseed commodities feature directly in both the human food chain through raw and processed foods (e.g. bread, cooking oils, flour), and indirectly as the major staples for animal feed worldwide. Poultry, pork, dairy and beef production, for example, are heavily reliant on these commodities in the formulation of animal diets (e.g. soybean meal, corn, wheat). Adding to these complexities, agriculture is, by its very nature, highly dependent on natural resource endowments, such as arable land, soil type, climatic conditions, and water availability. The world's natural disparities in these agricultural endowments have resulted in some countries through necessity becoming large net importers, while others are net exporters of food (Caiazza \& Volpe, 2012). Population is not an indicator of resource endowment either: some very highly populated countries have very low internal resources and, conversely, some countries with a significant endowment of resources have small populations.

Understanding the resource endowments, and in particular the climatic conditions and soil types required for producing certain key crops, provides insight into why the production of these key commodities is generally centralised within certain geographical areas and the importance of international trade in ensuring food security to a growing world population is also centralised.

A summary of key crops and the major producers in the world is shown in Table 1. In addition to Table 1, the International Grains Council (IGC) provides up-todate information about the sector including FOB (Free On Board) prices of the world grain and oilseed commodities on a daily basis via their web site. On 18 August 2014, IGC posted indicative quotations for FOB prices out of the US Gulf of US\$494 per tonne for US soybeans. 
Table 1: Top Producers in the GGOS

\begin{tabular}{|c|c|c|c|c|c|c|}
\hline & $2007 / 2008$ & $2008 / 2009$ & $2009 / 2010$ & $2010 / 2011$ & $2011 / 2012$ & $2012 / 2013$ \\
\hline \multicolumn{7}{|l|}{ Soybean } \\
\hline USA & 72,859 & 80,749 & 91,417 & 90,605 & 84,192 & 82,561 \\
\hline Brazil & 61,000 & 57,800 & 69,000 & 75,300 & 66,500 & 82,000 \\
\hline Argentina & 46,200 & 32,000 & 54,500 & 49,000 & 40,100 & 49,300 \\
\hline China & 12,725 & 15,540 & 14,980 & 15,080 & 14,485 & 13,050 \\
\hline India & 9,470 & 9,100 & 9,700 & 9,800 & 11,000 & 11,500 \\
\hline \multicolumn{7}{|l|}{ Corn } \\
\hline USA & 331,177 & 307,142 & 332,549 & 316,165 & 313,949 & 273,832 \\
\hline China & 152,300 & 165,914 & 163,974 & 177,245 & 192,780 & 205,614 \\
\hline Brazil & 58,600 & 51,000 & 56,100 & 57,400 & 73,000 & 81,500 \\
\hline $\mathrm{EU}$ & 49,355 & 64,821 & 59,147 & 58,265 & 68,118 & 58,866 \\
\hline Argentina & 22,017 & 15,500 & 25,000 & 25,200 & 21,000 & 27,000 \\
\hline \multicolumn{7}{|l|}{ Rice } \\
\hline China & 130,224 & 134,330 & 136,570 & 137,000 & 140,700 & 143,000 \\
\hline India & 96,690 & 99,180 & 89,090 & 95,980 & 105,310 & 105,240 \\
\hline Indonesia & 37,000 & 38,310 & 36,370 & 35,500 & 36,500 & 36,550 \\
\hline Bangladesh & 28,800 & 31,200 & 31,000 & 31,700 & 33,700 & 33,820 \\
\hline Vietnam & 24,375 & 24,393 & 24,993 & 26,371 & 27,152 & 27,537 \\
\hline \multicolumn{7}{|l|}{ Wheat } \\
\hline EU & 120,833 & 151,922 & 139,720 & 136,667 & 138,182 & 133,850 \\
\hline China & 109,298 & 112,464 & 115,120 & 115,180 & 117,400 & 121,023 \\
\hline India & 75,810 & 78,570 & 80,680 & 80,800 & 86,870 & 94,880 \\
\hline USA & 55,821 & 68,016 & 60,366 & 60,062 & 54,413 & 61,671 \\
\hline Russia & 49,368 & 63,765 & 61,770 & 41,508 & 56,240 & 37,720 \\
\hline \multicolumn{7}{|l|}{ Palm Oil } \\
\hline Indonesia & 18,000 & 20,500 & 22,000 & 23,600 & 26,200 & 28,500 \\
\hline Malaysia & 17,567 & 17,259 & 17,763 & 18,211 & 18,202 & 19,321 \\
\hline Thailand & 1,050 & 1,540 & 1,287 & 1,832 & 1,892 & 2,135 \\
\hline
\end{tabular}

Notes: (000 metric tonnes) (USDA, 2014), starting August 2013 EU reflects addition of Croatia (USDA, 2014). 
Considering this table and the tonnages produced in the 2012/2013 year by the top five world producers, this equates to US\$117.76 billion dollars in soybeans alone. Corn was indicatively quoted at the same time at US\$193 per tonne. This value, reflected against the production figures of the 2012/2013 year for the top six corn producers, equates to US\$129.13 billion (IGC, 204).

The Malaysian Palm Oils Board (MPOB) is a leading provider of information for the palm oil industry. The MPOB website on 21 August 2014 reported a daily crude palm oil (CPO) price of MYR2,087.50. With a Malaysian Ringgit/US dollar cross rate at the time of 3.167 (Bloomberg, 2014), this translates into an FOB value at main ports in Malaysia of US\$659 per metric tonne for CPO (MPOB, 2014).

An FOB value of US\$659 for CPO would translate into a total market value of the 2012/2013 production in the top producers in the world - Indonesia, Malaysia and Thailand - of US\$32.93 billion. The IGC (2014) indicative FOB value ex-US Gulf at the same time for wheat was US\$282; this equates to US $\$ 126.66$ billion produced by the top five wheat producers in the world. The IGC (2014) indicative FOB value ex-Bangkok for Thai 100\% Grade B Rice at the time was US\$463; this equates to US $\$ 218.40$ billion of rice produced by the world, of which the top five producers in the world account for US\$160.27 billion.

Including CPO, soybeans, corn, wheat and rice from the world's leading producers, the magnitude of this industry begins to reveal itself, with these five commodities alone accounting for over US\$600 billion annually from key producers.

Table 1 also highlights that the American continent is the major producer of soybeans and corn and Asia is the major consumer, accounting for a significant amount of international trade in these commodities (USDA, 2014). Using the same-year statistics provided by the USDA web-based statistics service, the US exported 36.87 million tonnes of oilseed grains and Brazil exported 42.02 million tonnes. China alone imported 63.52 million tonnes, and the EU imported 16.89 million tonnes. 
The majority of this trade is soybeans; these soybeans are then processed and soybean oil is produced, as well as the by-product from the oil extraction process, soybean meal, which is then incorporated into animal feed. China produced 71.17 million tonnes of protein meals in the 2012/2013 period, the US 38.68 million, Argentina 27.23 million, Brazil 27.41 million and the EU 27.41 million tonnes. The figures for importers of processed protein meals are significantly different, with the EU importing 23.39 million tonnes and the next closest importer being Indonesia, which imported 3.62 million tonnes. Exporters of protein meals were Argentina (24.04 million tonnes), Brazil (13.24 million tonnes) and the US (10.49 million tonnes) (USDA, 2014).

What is clear from these statistics is that the world cannot escape the concentration element of this sector and the fact that only a few countries have the ability to produce vast quantities of surplus production over domestic requirements. Equally, only a few countries are buying the vast majority of this surplus production. China, being the world's largest buyer, has unprecedented leverage when dealing with sellers and chooses to buy these commodities in their raw, unprocessed form and process the commodities domestically. Smaller nations that do not have the leverage of China must still decipher the markets and manage their own domestic requirements from a much weaker, less-informed position. The ability of China and other key players to influence both world prices and trade terms adds to the difficulties faced by smaller buyers. This vulnerability leads to the opportunity for local experts in host countries that understand the dynamics at play across these international markets to assist key buyers to engage world markets and to buy at the best price they can, and often, more importantly, to ensure ongoing reliable supply (HighQuest, 2011; Hornby, 2014; Murphy, 2012).

\subsubsection{Challenges faced by the sector}

Of all the commodities traded around the globe, food has become the most political. Farm subsidies, varying points of view around genetic modification, and other factors all provide for additional risk that can influence markets (HighQuest, 2011; Sowinski, 2012). 
Notwithstanding the consumer and industry trend to attempt to "buy local", the GGOS is becoming increasingly more globalised for most countries through necessity. Increasing costs of energy commodities and volatile pricing is also having a significant impact on this sector, from not only a pure market supply and demand perspective, but also politically through tax incentives based around renewable energies such as ethanol, which is derived from grain and oilseed commodities.

The changing supply and demand trends and the tax incentives offered to industry will likely underwrite substantial growth within the sector in the future as both food and energy markets compete for the same commodity and supply naturally rises to meet this new demand (HighQuest, 2011).

The tax incentives available to ethanol producers in the EU and biodiesel producers in the US will likely continue to alter production of the underlying commodities, highlighting the intertwined relationships between tax policies, energy prices and agricultural production (Sowinski, 2012).

\subsubsection{The agri-food chain}

The global restructuring taking place through the overlapping of food, feed and fuel complexes provides those involved in commodities with a new set of opportunities and challenges; it is no longer enough for the energy sector to focus solely on oil, natural gas and power. Nor is it enough for food companies to consider using grain futures alone when hedging market price risks. It is impossible for the major food processors to manage the cost of inputs without paying close attention to energy markets today (Meyer, 2013).

The global agri-food chain consists of the different functions and participants involved across the entire value chain, from the initial inputs and production of food through to its delivery to the consumer. Surprisingly, little attention has been paid traditionally to agricultural value chains in developing countries (Caiazza \& Volpe, 2012). In many parts of the world, agriculture continues to play a central role in the social wellbeing and economic development of the people (Caiazza \& Volpe, 2012; Pelupessy \& Van Kempen, 2005). 
Agri-food value chains can be broken into two main categories: agriculturalbased and agricultural-related activities. Agricultural-based activities are those producing agricultural goods, including suppliers of inputs for agricultural production, food processors and manufacturers, traders and retailers. As the sector develops, the value centre is shifting from agricultural-based to agriculture-related activities, such as retailing and upstream activities e.g. biotechnology-enhanced seeds (Caiazza \& Volpe, 2012).

Table 2 highlights the need for developing countries and the actors within these value chains to develop processing locally for both value creation and to minimise wastage. Industrialised countries experience virtually no wastage through processing virtually all their raw commodities. Processing not only creates value, but also increases the shelf life of raw commodities.

Table 2: Agricultural Value Add

\begin{tabular}{c|cc} 
& Industrialised countries & Developing countries \\
\hline $\begin{array}{c}\text { Agricultural products } \\
\text { processed (\%) }\end{array}$ & 98 & 38 \\
$\begin{array}{c}\text { Value add of agricultural } \\
\text { products processed } \\
\text { (US\$ } / \text { TONNE) }\end{array}$ & 185 & 40 \\
Post-harvest losses (\%) & MIN.
\end{tabular}

Source: (UNIDO, 2009)

The agri-food value chains as identified are divided into two main categories: agricultural-based and agricultural-related activities. The agricultural-related activities can be further divided into four key categories:

- Food retailers

- Food processors

- Grain traders

- Input providers

The input providers essentially deliver material inputs to the farming sector inputs such as fertilisers and seed to aid in the production of primary commodities - and the grain traders and food processors subsequently handle, process, transport, market and distribute food and other agri-based products to 
the food retailers, such as supermarkets, which are generally the end sellers to consumers (Caiazza \& Volpe, 2012).

While supermarkets are moving up the value chain through developing international procurement of both raw materials and processed products, large traders are simultaneously moving downstream and becoming more committed to processing, distributing and marketing branded food products themselves. It stands to reason then that the processing sector may indeed be the crossroads at which the entire agri-food chain meets in endeavouring to carve out long-term sustainable value chains and competitive advantage (Caiazza \& Volpe, 2012; HighQuest, 2011; UNIDO, 2009).

As food retailers, specifically large supermarket chains, increasingly expand their global footprints, processed and value-added products are increasingly dominating the agri-food commodities exports and imports trade. Until the early 1980s, trade in bulk commodities accounted for most of the agricultural international trade; by 2012 it accounted for only one-third of the total (Caiazza \& Volpe, 2012; Murphy, 2012; USDA, 2014).

Supermarkets have demonstrated the most profound shift through developing global purchasing platforms around the world. A number of these large companies, such as Walmart, Carrefour and Tesco, are changing the way food is traded globally. Having penetrated every continent and accessing produce directly from where crops are grown - sometimes halfway around the world from where these crops are eventually sold - the implications for the broader sector have not gone unnoticed (Caiazza \& Volpe, 2012; Murphy, 2012).

Traditional grain and oilseed traders, however, have not seen dynamic change as the supermarkets in their position within the global food chain. The only new firm in the top five commodity traders since the mid $-19^{\text {th }}$ century is ADM, which was founded in 1902 but only became a global player in the 1970s. On the other end of the spectrum, Swiss-based André, which was a major player, went bankrupt in 2002 (Caiazza \& Volpe, 2012; HighQuest, 2011; Murphy, 2012). Although the traders shift is not as profound in comparison with the 
supermarkets, these large commodity trading companies have not been standing still, they have been evolving to meet the changing dynamics. They are not just traders of physical agricultural commodities any longer, rather, they operate through all links in the agri-food value chain as input suppliers of fertiliser and seed, landowners, cattle and poultry producers, food processors, financiers, transportation providers, and they own and operate most of the world's grain elevator export terminals. Through these activities they provide much of the physical infrastructure involved in agri-food production and marketing. They are also diversifying increasingly into the production and marketing of industrial products that are derived from agricultural commodities, such as plant-based plastics, paints, and industrial starches (Caiazza \& Volpe, 2012; HighQuest, 2011; Murphy, 2012).

These large commodity trading companies have the capacity to produce, procure, process, and deliver the raw material inputs that are at the heart of the modern agri-food system, and they are uniquely placed to exploit opportunities across a wide range of activities tied both directly and indirectly to the production and trade in agricultural commodities. Because of their unique positions, they continue to exert a great deal of influence over global food systems for farmers, merchants and consumers throughout the world (Caiazza \& Volpe, 2012; HighQuest, 2011; Murphy, 2012).

While they are sometimes competitors, the world's large manufacturers and processors of food, such as Nestlé, are more often important customers of the large traders, and are also closely linked with production and can affect significant influence on agriculture. Like the large traders, the world's food and beverage processors are also very large firms, with the majority being headquartered in the developed world where both the large supermarkets and traders reside, helping to centralise the balance of power on the large host nations of these corporations and providing an increasingly competitive environment for those in the developing world (Caiazza \& Volpe, 2012). 


\subsubsection{Global grain and oilseed traders}

The sector consists of many traders; for the purpose of clarification, this study divides them into two categories ranked by market position, tier 1 and tier 2 respectively.

Four traders make up tier 1; tier 2 is made up of a growing group of more recently emerging MNE traders and filters down to the small traders that operate within the framework of the sector. Tier 1 traders consist of a group of four companies known as the "ABCDs" of the agricultural commodities. These four players are unique, due to their strong positions in both processing and trading environments. By name, the tier 1 companies include (A) Archer Daniels Midland (ADM), (B) Bunge, (C) Cargill and (D) Louis Dreyfus. In the past, these four have had a combined market share of upwards of $90 \%$ of international trade within the sector and each is powerful, unique and private; very little is really understood about the extent of their overall activities (Caiazza \& Volpe, 2012; Murphy, 2012).

Sitting behind the ABCDs is the tier 2 group of emerging MNE traders who, despite their relatively new entrance and comparatively modest trading value of grain and oilseed commodities, are influencing both the market and, in some cases, larger entities overall than the ABCDs themselves. Companies such as Mitsubishi, Marubeni, Glencore Xstrata, Nidera, COFCO, Olam, Sinar Mas and Wilmar are examples of tier 2 traders (Caiazza \& Volpe, 2012; HighQuest, 2011; Hornby, 2014; Murphy, 2012).

The prevalence of these tier 2 traders has been established largely due to the changing global production areas, together with the growth in consumption in the developing world - most noticeably in South America (production), Asia (consumption) and the Eastern European states (production).

The dominance once asserted by the ABCDs is becoming more precarious as the changing dynamics and the impact and positioning ambitions of the new entrants are realised (Hornby, 2014). It is necessary here to mention Glencore Xstrata, Wilmar and COFCO, which are by no means inferior to the ABCD's in their commodity offerings. Glencore Xstrata is heavily involved in other commodity 
sectors and has been successful in making use of the competencies it has gained in other commodity trading activities. These new players understand the working mechanics of international trading and leveraging existing trade volumes and will likely continue to expand their presence in this sector.

These smaller traders, by necessity, often deal with the larger dominant traders, frequently providing the larger firms with particular expertise within the geographical context of where they are based and operate (Caiazza \& Volpe, 2012; HighQuest, 2011; Hornby, 2014).

Table 3 conveys the scale at which the ABCD and second-tier MNE companies are operating, adding further reinforcement to both the significance of these companies and the GGOS as a whole. Furthermore, there are growing combinations of partnership agreements among them and between tiers, as both look to secure superior market positions over competitors, and recognise the competitive advantages of working together.

Table 3: Large Traders (Tier 1 and Tier 2)

\begin{tabular}{|c|c|c|c|c|c|}
\hline Traders & $\begin{array}{c}\text { Revenue in } \\
\text { bn } \\
(2013)\end{array}$ & $\begin{array}{c}\text { Revenue } \\
\text { in bn } \\
\text { (2012) }\end{array}$ & Employees & Countries & Source \\
\hline \multicolumn{6}{|l|}{ Tier 1} \\
\hline ADM & US\$89.8 & US\$89.04 & 31,000 & 140 & $(\mathrm{ADM}, 2014)$ \\
\hline Bunge & US\$61.35 & US\$60.99 & 35,000 & 40 & (Bunge, 2014) \\
\hline Cargill & US\$136.65 & US\$133.9 & 143,000 & 67 & (Cargill, 2014) \\
\hline $\begin{array}{l}\text { Louis } \\
\text { Dreyfus }\end{array}$ & US\$63.6 & US\$57.1 & 22,000 & 100 & $\begin{array}{l}\text { (Louis Dreyfus, } \\
2014 \text { ) }\end{array}$ \\
\hline \multicolumn{6}{|l|}{ Tier 2} \\
\hline Glencore & US\$233 & US\$214 & 200,000 & $50+$ & (Glencore, 2014) \\
\hline Wilmar & US\$44.09 & US\$45.46 & 90,000 & $50+$ & $\begin{array}{l}\text { (Wilmar Intl, } \\
\text { 2014) }\end{array}$ \\
\hline $\mathrm{COFCO}$ & HK $\$ 95.5$ & HK\$91.3 & 30,146 & $\mathrm{n} / \mathrm{a}^{*}$ & $(\mathrm{COFCO}, 2014)$ \\
\hline
\end{tabular}

Note: Data was collected from corporate websites and financial statements. ${ }^{*}$ no exact data detailing number of countries was found. 
Wilmar, for instance, has strategic raw procurement agreements with COFCO and simultaneously competes against COFCO with ADM in China through their jointly owned soybean processing plants (ADM, 2014; COFCO, 2014; WilmarIntl, 2014).

Behind the large, dominant players within the GGOS sits a vast web of smaller traders who are as diverse in size as they are in geographical location, the products they trade and the functions they perform.

These smaller traders, by necessity, often deal with the larger dominant traders, frequently providing the larger firms with particular expertise within the geographical context of where they are based and operate (Caiazza \& Volpe, 2012; HighQuest, 2011; Hornby, 2014).

The strategic approach taken by the small traders is diverse and depends on their capital base, core business and embeddedness in the sectors within which they participate. Many place enormous emphasis on their international NWs; however, due to their numerous and diverse scatterings around the world and the information-sensitive environments in which they operate, the degree to which this is a strategic driver is not well understood in this industry, other than by the traders themselves. Small traders can derive benefits through networking, such as the use of critical infrastructure that is frequently owned by competing large traders.

\subsection{Competitive Assessment of the Sector}

Against the introduction of this multi-tiered sector, it is worth understanding the overall dynamics within the industry, with a specific focus on the implications for tier 2 traders operating within the GGOS. A competitive assessment will be undertaken next, using Porter's Five Force Framework (FFF) as shown in Figure 1. Porter's Five Force Framework is widely recognised as the benchmark for industry analysis and has been central to a vast body of academic research and business practice (Dobbs, 2014; Narayanan \& Fahey, 2005; Porter, 2008; Pringle \& Huisman, 2011). 


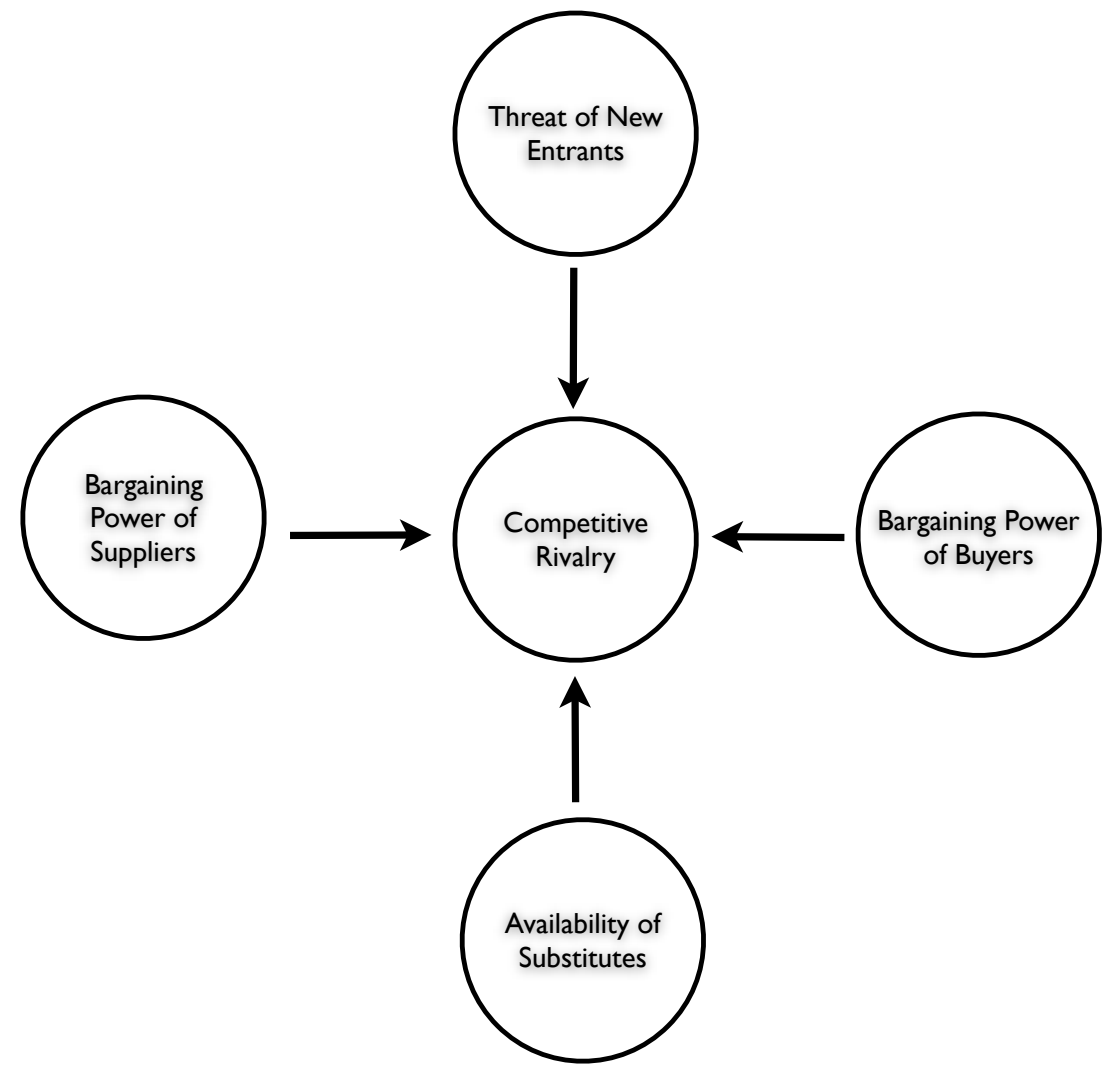

Figure 1: Porter's Five Forces Framework

Source: Porter (1979)

Porter's Five Forces (Porter, 1979; 2008) can be summarised as below:

- The Bargaining Power of Suppliers: Suppliers influence the choice of business strategy through their influence on the pricing, quality and quantity of the goods and services they provide. When suppliers are powerful, they can limit firm profitability whilst increasing their own bottom line. Furthermore, when the cost of switching suppliers is high, it can be difficult for firms to leverage suppliers against one another. Lastly, if suppliers find that an industry is realising high profits, they could be enticed to integrate into that industry.

- The Bargaining Power of Buyers: Buyers also influence a firm's strategic decision-making. When customers are powerful, they can demand increased quality or service levels (incurring higher costs) while also forcing down prices. Buyers can also affect an entire industry's profitability by playing firms against one another. 
Buyers are typically able to exercise greater power when there are few of them, when they purchase in large volumes, or when an industry's products are undifferentiated. Buyers may also threaten to integrate backwards if an industry is too profitable

- Competitive Rivalry: Within an industry, a firm's strategy and profitability are dependent on the rivalry amongst competitors. This rivalry can include discounting prices, advertising, service improvements and product innovations. Industry profitability can be limited when there is high rivalry. In particular, price rivalry between firms drives down individual firm profitability, as well as that of the industry as a whole.

- The Threat of New Entrants: When industry profitability is high, and where entry barriers are low, new entrants may seek to join the market, depleting the market share of incumbent firms and putting pressure on pricing, costs and commitment. The threat of new entrants can be mitigated through having contractual agreements with suppliers (which increases entry barriers) and the expected reactions of the incumbents.

- The Threat of Substitute Products: The last of Porter's Five Forces is the threat of substitutes. When customers are aware of substitute products or services, and where they deem prices to be too high, there is a threat that they will switch to the substitute instead (for example, while a Chinese takeaway may view a Thai restaurant as a competitor, it should not overlook the threat of substitute products being available at a supermarket i.e. grocery stores can be substitutes for restaurants). Industry profitability can suffer if there is a strong threat of substitutes; individual firms must strategically distance themselves from these substitutes through marketing, quality or product performance means.

The consolidation of all five forces defines an industry's structure and shapes the nature of competitive interaction within an industry (Porter, 2008). As different from one another as industries may appear on the surface, Porter (2008) asserts that, fundamentally, the drivers of profitability across all industries are the same. Industry structure drives competition and profitability, regardless of whether the industry produces a product or a service, is emerging or mature, high-tech or low-tech, and regulated or unregulated. 
"If the forces are intense, almost no company earns attractive returns on investment. However, if the forces are considered more benign, many of the participant firms can be profitable" (Porter, 2008, p. 80).

All forces collectively provide insight into the overall competitive rivalry of an industry. Through an analysis of the five forces within the context of the GGOS, both practitioners and academics can better understand areas of opportunity and the profit potential of the industry, assisting individual firms operating within the sector (Dobbs, 2014).

\subsubsection{Rivalry among competitors}

While the $\mathrm{ABCD}$ trading companies have a dominant position in the worldwide trade of grains, oilseeds, sugar, and other related commodities, it is clear that they are now facing a degree of competition from a growing number of new trading companies and market dynamics (Blas, 2013). Countries that are large net importers, particularly in Asia, are increasingly engineering new trading platforms, changing both the rules of engagement and their methods of sourcing food to feed the nation.

Countries such as South Korea and Abu Dhabi are working to establish alternative supply chains away from the ABCDs, in an attempt to ensure their own food security and less reliance on large international traders, through importing the foodstuffs they do not produce themselves.

Such initiatives are providing new geographical opportunities for new entrant traders (Murphy, 2012; UNIDO, 2009). A number of the established Japanese trading companies, such as Mitsui and Marubeni, which have traditionally bought globally but largely sold locally, are also beginning to mobilise the expansion of their grain trading and production operations. It could be argued that the ABCDs' dominance, and the world as they know it, is under threat (Caiazza \& Volpe, 2012; Murphy, 2012; Sowinski, 2012).

Another driver of change has been the development of previously unused or underutilised arable land, leading to greatly enhanced levels of production of grain, soybeans, palm oil and other commodities, which is being handled by both the ABCDs and these newly emerging traders, such as Russia's United Grain 
Company and Wilmar of Singapore (Caiazza \& Volpe, 2012; Fox, 2004; HighQuest, 2011; Sowinski, 2012).

By way of example, Wilmar International states on its website:

"Wilmar International Limited, founded in 1991 and headquartered in Singapore, is today Asia's leading agribusiness group. Wilmar is ranked amongst the largest listed companies by market capitalization on the Singapore Exchange. Wilmar's business activities include oil palm cultivation, oilseed crushing, edible oils refining, sugar milling and refining, specialty fats, oleo chemical, biodiesel and fertilizer manufacturing and grain processing. At the core of Wilmar's strategy is a resilient integrated agribusiness model that encompasses the entire value chain of the agricultural commodity processing business, from origination and processing to branding, merchandising and distribution of a wide range of agricultural products. It has over 450 manufacturing plants and an extensive distribution network covering China, India, Indonesia and some 50 other countries" (Wilmar Intl, 2014).

This highlights that today it is not only the ABCD trading houses who are extending their activities into ingredient or input commodities and new products such as biofuels, industrial products and the like; the new entrant traders are also developing an integrated business model along the same path.

Through networking and resource sharing, they have made dramatic inroads on the traditional supply chains of the ABCDs (Fox, 2004; Hornby, 2014). This new environment has all actors looking vertically upstream, downstream, and horizontally to strengthen and diversify their operations. Furthermore, strategic acquisitions that fuel growth and develop and strengthen global footprints are resulting in a cross- pollination of the ABCDs with the emerging traders (COFCO, 2014; HighQuest, 2011; Hornby, 2014; Murphy, 2012). By way of example, ADM's website displays:

"Collaborations between ADM and Wilmar began in the mid-1990s, when they jointly built a network of soybean processing operations in China. Today, ADM owns a 16 percent equity stake in Wilmar. The companies have significant supplier relationships with each other" (ADM, 2014). 
This highlights the likely intentions of the players and how this sector will continue to evolve. Considering Wilmar was only established in 1991, Appendix 1 visually illustrates the structure of the Wilmar business and a vertical and horizontal expansion strategy that is common to the large players in the sector.

There are many examples of other major mergers and acquisitions in recent decades: ADM's acquisition of A.C. Toepfer, and Cargill's acquisition of Continental Grain and, in 2010, of the newly privatised Australian Wheat Board (Murphy, 2012) all provide confirmation of the consolidation that is taking place among key stakeholders, both new and old, within the GGOS.

\subsubsection{Threat of potential entry}

Profitable industries attract new firms. This often results in many new entrants entering the market, which will, over time decrease profitability for all firms in the industry. Major barriers of entry, such as large capital requirements or economies of scale, are often deterrents that the incumbents like to embrace (Porter, 2008). The size of the players and the nature of the grain trade create high barriers to entry for newcomers, reinforcing the existing players' market power. The capital requirements to engage in the business are substantial: building and maintaining the warehousing, tank, silo and elevator infrastructures to store and move grain requires enormous capital outlay, and the financial instruments that accompany the trade to manage risk, such as futures and options involve large sums of money (HighQuest, 2011; Murphy, 2012).

Transporting bulk commodities around the globe carries a number of critical logistic, storage, transportation and delivery challenges. The timely transportation of a variety of (sometimes perishable) products by land and sea, and the necessity to have cargoes readily positioned at load ports when ships call for loading both require intense planning and expertise.

The ABCD firms are at home in this frame, and in particular have developed significant expertise in this area, which plays a large part in their 'value-add' as traders. The ABCDs own and operate global storage, elevators, transport and delivery systems that are indispensable and often impossible to duplicate within the global grain trade (Caiazza \& Volpe, 2012; HighQuest, 2011; Murphy, 2012). 
Infrastructural requirements are not limited to storage; these grain companies have a significant interest in barges, rail cars and ships and require enormous volumes to ensure that these assets are continually utilised. In many ways, security of volume is as important as competitive (low) pricing and acts as a barrier to entrance, as the big firms' requirements to utilise their fixed-cost regimes are intense. There are several reasons for this. As already mentioned, the companies have significant investments, both vertically and horizontally, in value-added activities in which grain is an input cost.

A loss in one business may carry an offsetting gain in another. For example, livestock companies lost money in 2008, and some of those companies are ABCD subsidiaries. This was offset to some extent by the money they made in other parts of their businesses, such as trading the inputs to such subsidiaries (Murphy, 2012).

The larger the trader, the more significant the advantage they have in access to information (Cargill, 2014). This makes volatility important: they know better than most what supply and demand will look like. All major players within the grain and oilseed trading sector must make big investments every year in financial markets; using this knowledge to full effect can be the difference between absolute success and failure. Volatile prices are good for knowledgeable speculators.

The financial instruments, such as futures and options traded at the Chicago Board of Trade and other exchanges, are a prerequisite when operating within this environment (Murphy, 2012). Considering traders often buy by the shipload and sell by the truckload, it is critical that daily price movements of the underlying commodity are closely monitored and managed to avoid potentially catastrophic losses (HighQuest, 2011).

The ABCDs and the larger new entrant traders have in-house expertise in these areas and are often called upon by processors and other downstream customers to manage these aspects of trading and price risk on their behalf (HighQuest, 2011; Wilmar Intl, 2014). As very large supply or demand requirements can influence prices, often those at disparate ends of the supply chain with influential requirements do not want the other end to be aware of their position. 
This creates opportunities for smaller traders to work confidentially between the parties creating the 'Chinese walls' that each desires (Quadra Commodities, 2014).

\subsubsection{Bargaining power of buyers and suppliers}

The bargaining power of buyers is the ability of customers to dictate terms, in particular when there are many sellers and only a few buyers (Porter, 2008). Conversely, the bargaining power of suppliers is when supplying firms are operating in markets where there are few substitutes or other sellers in their market (Porter, 1979). In the context of this study on grain and oilseed trading, assessing the bargaining power of buyers and sellers can be intricate as it depends on where the actor sits on a particular transaction. The complexity occurs when transactions are between traders themselves (and very slight margins): in this regard, the buyers are suppliers, and the suppliers are buyers.

This scenario is unique to traders (be they grain or other commodity sectors) and should be analysed separately and differentiated from the traditional analysis under the heading of rivalry between competitors (Porter, 1979, 1980, 1990, 2008).

Through the lens of supply chain and core competency, traders are in the business of developing NWs and funding channels that allow for the securing of supply and the meeting of orders of commodities.

The control of critical assets is argued to wage influence on how power is spread across the supply chain (Murphy, 2012; Porter, 2008). Like supermarkets, large traders are often in control of the key infrastructural assets required in a particular region and share the benefit of few buyers but many sellers (Burch, Dixon, and Lawrence, 2013; HighQuest, 2011).

While domestic supply may come from a very large pool of growers, international supply of the majority of grain and oilseed trade is concentrated (i.e. few suppliers). The ABCDs still dominate in this frame, with the previously mentioned new players gaining traction and market share within the sector (Murphy, 2012). 
Given their history in the sector, the ABCDs maintain superior global footprints through the critical infrastructural assets required for global distribution being difficult (and sometimes impossible) to replicate by newcomers. The ABCDs have the capacity to produce, procure, process and deliver the raw materials and processed foods that are at the heart of the modern agri-food system, and this places both those with the assets and those with access to them in strong positions when negotiating with both sellers and end buyers (Fox, 2004; Murphy, 2012).

The dominant position of the ABCDs has been recognised by countries around the world, and there is now growing evidence in the markets that both governments and other sectors within the global food chain, namely supermarkets and food processors, along with the large new entrant traders, are taking further steps to minimise their ongoing reliance on this group of traders, with countries around the world wanting more control of their own food sources (BeVier, 2012).

The power a trader can apply can be viewed within two dimensions: horizontal and vertical. The horizontal power is often depicted as an hourglass: typically, agricultural value chains depend on thousands (if not millions) of producers; hundreds (sometimes thousands) of elevators; a handful of processors and/or exporters; and thousands (if not millions) of buyers (Murphy, 2012). This centralises the power through the concentrated parts of the supply chain in the few hands controlling processing and international trade.

On the other hand, a trader's vertical power is about the various roles they play in more than one part of the value chain. For example, the ABCDs buy grain from the elevators and then process a large share of it. Their subsidiaries then consume much of the processed grain as feed for livestock or as feedstock for biofuels. This vertical integration blurs the margins and provides little room for price discovery, in that the commodities become an internal operating cost and are not sold on the open market (HighQuest, 2011).

As there are relatively few key traders purchasing the majority of bulk agricultural commodities for international trade in any particular market, the 
trading houses have enormous leverage in terms of setting the purchase price with farmers and also with the grain elevators to which farmers in industrialised production systems deliver their grain.

In countries such as Brazil, those elevators are likely to be owned by Bunge and Cargill anyway (Caiazza \& Volpe, 2012; HighQuest, 2011).

Ultimately, the $\mathrm{ABCD}$ firms dominate the domestic and export markets of the major exporting countries, particularly in the Americas (HighQuest, 2011; Murphy, 2012). While emerging markets and the traders from these regions are expanding their operations in countries where state trading companies have previously been dominant, including Australia, Russia and China, so too are the ABCDs expanding their footprint - predominantly through acquisitions of key local entities in these new markets (Caiazza \& Volpe, 2012; Murphy, 2012). A current and pertinent example is ADM's pursuance of Australia's GrainCorp, which owns and operates the majority of Australian elevators and export terminals, having already built a significant shareholding and attempted an outright acquisition (GrainCorp, 2014; ADM, 2014).

“GrainCorp agreed a Aus\$2.8bn (\$2.55bn) takeover by ADM last year, but the deal was scuppered by Australia's government, which objected on grounds that the tie-up, at the time, risked undermining the growth of competition in the country's grain handling industry"..." Patricia Woertz, the ADM chief executive, said two months ago that the group's strategic interest in Australia, as a gateway for crop exports to Asia, "remains the same", and that it would, after GrainCorp fills its vacancy for a chief executive, "have the opportunity to work more closely... to find additional ways to work together and drive value" (Agrimoney, 2014).

Another example of this type of sovereign positioning is the announcement two years ago by China's state-owned grains trader of a $\$ 10 \mathrm{bn}$ war chest for foreign mergers and acquisitions, effectively putting the world on notice that they have the will to develop a global footprint to rival that of the ABCD traders. As reported: 
“China National Cereals, Oil and Foodstuffs Corp last week charged into South American markets with a deal to buy a controlling stake in Nidera, a 94-year-old trading house. The company known as COFCO is now in talks with Hong Kong-based Noble Group, one of Asia's leading commodities traders, to establish a joint venture in sugar, soybeans and wheat. The deals will put China's top grains importer directly in competition with global agricultural trading houses such as Archer Daniels Midland, Bunge, Cargill, Louis Dreyfus Commodities - long known as the "ABCD" companies - and commodities powerhouse Glencore Xstrata” (Hornby, 2014).

Glencore Xstrata, along with Vitol, recently funded a US\$10 billion loan when Rosneft bought TNK-BP, creating the world's largest listed oil producer, and banks were not able to fund the full US\$55 billion required. This is a clear example of how formidable these major trading houses are becoming and how the growing roles they are performing are reaching unparalleled levels of influence (Blas, 2013; Murphy, 2012).

Modern supermarkets are moving increasingly towards a highly concentrated and global structure, whereby they deal directly with international producers and processors of food and are more commonly entering strategic relationships to develop home brands.

The emerging supermarket model, in which most benefits remain with the supermarket or are passed to customers, is perhaps the most threatening potential new entrant for the traders, as most power and leverage typically resides at the retail end of supply chains (Fox, 2004). More than 50\% of growth in global food retail markets is expected to come from emerging markets.

Prior to 1990, supermarkets in China were virtually non-existent. With a population of 1.25 billion, Mainland China has more consumers than Europe and the US combined, and both local and international supermarket chains are moving in (Fox, 2004). Number one on the Forbes Fortune 500 is, ironically, Walmart - the world's largest supermarket franchise has already developed interests in China and could potentially represent a major threat in challenging 
the traders, particularly around the processing of food in the future (Burch et al., 2013; Murphy, 2012; Walmart, 2014; Fortune 500, 2014).

\subsubsection{Threat of substitutes}

The threat of substitute products is something quite different from the threat of new entrants; it could, for instance, come from technology developments, such as plastic products replacing more expensive steel or aluminium products (Porter, 2008). There is no real threat of other food sources providing either the volumes required or the nutritional characteristics of the grain and oilseed commodities (USDA, 2014). That said, the threat of substitutes in the context of the global grain and oilseed trading sector comes in two distinct forms: (1) the threat of processed food manufacturers and supermarket firms; and (2) the threat of competition from other commodity sectors, such as the energy sector (BeVier, 2012; HighQuest, 2011).

While the various geographical regions can look at other regions for supply or demand and play one region off against another, or play import parity off against domestic supply or vice versa, this dynamic is not a threat to traders; rather, it enhances, not detracts, from the role of the trader. Traders are charged with the challenge of identifying the best value available for a particular market and ultimately making a trade that connects the right sellers with the right buyers, resulting in the movement of goods.

The role of distilling all options, and the prices for which each can be purchased, and then defining the logistical costs of getting that product from point $\mathrm{A}$ to point $\mathrm{B}$, is central to trading. The traditional realm of moving bulk commodities is slowly diminishing in proportion to the overall market, relative to consumeroriented or intermediate products in the agri-food sector, which are threatening the traditional role of the trader (BeVier, 2012; HighQuest, 2011).

This is due to the major shifts that are taking place in world production and trade in food - in turn a consequence of the redistribution of power along the agri-food supply chain with the emergence of global retailers such as Walmart, Carrefour, and Tesco, and changing consumer tastes and expectations. 
Table 4: An Assessment of Competitive Forces in the GGOS

\begin{tabular}{|c|c|c|c|}
\hline $\begin{array}{l}\text { Porter's Five } \\
\text { Forces }\end{array}$ & $\begin{array}{l}\text { Tier } 1 \\
\text { ABCD } \\
\text { MNEs }\end{array}$ & $\begin{array}{c}\text { Tier } 2 \\
\text { New Entrant } \\
\text { MNE/SMEs }\end{array}$ & Comments \\
\hline $\begin{array}{l}\text { Threat of New } \\
\text { Entrants }\end{array}$ & M & $\mathrm{S}$ & $\begin{array}{l}\text { The sector is crowded with food processors, } \\
\text { retailers and energy traders all becoming } \\
\text { entrenched in grain and oilseed trading } \\
\text { activities. They manoeuvre both upstream } \\
\text { and downstream to gain further exposure to } \\
\text { the sector and pivot on their existing } \\
\text { competencies. }\end{array}$ \\
\hline $\begin{array}{c}\text { Bargaining } \\
\text { Power of } \\
\text { Suppliers }\end{array}$ & W & S & $\begin{array}{l}\text { Primary production of grain and oilseed } \\
\text { commodities is defined by the ability to } \\
\text { capture supply. Large accumulators, mostly } \\
\text { the tier } 1 \text { ABCD traders, dominate this arena } \\
\text { due to their strong capital position. Tier } 2 \\
\text { traders in some capacity compete at this } \\
\text { level, however are at a disadvantage due to } \\
\text { their newcomer status: their sales proposition } \\
\text { (and position within the supply chain) must } \\
\text { be value-add. Tier } 2 \text { are often required to turn } \\
\text { to tier } 1 \text { traders for supply to align supply } \\
\text { chain economies across their markets. }\end{array}$ \\
\hline $\begin{array}{c}\text { Bargaining } \\
\text { Power of } \\
\text { Buyers }\end{array}$ & M & M & $\begin{array}{l}\text { Both tier } 1 \text { and tier } 2 \text { traders are increasingly } \\
\text { involved in processing businesses. So too are } \\
\text { the traditional buyers of the processing firms; } \\
\text { the supermarket and also external new } \\
\text { entrants are competing for the acquisition of } \\
\text { these processing businesses. Ultimately, } \\
\text { buying power is leveraged by control of } \\
\text { volume and closeness to consumer markets. }\end{array}$ \\
\hline $\begin{array}{l}\text { Threat of } \\
\text { Substitutes }\end{array}$ & W & M & $\begin{array}{l}\text { Conversion through the value chain from } \\
\text { traditional international movement of raw } \\
\text { commodities to a consumer delivery is } \\
\text { widespread and a major threat to the } \\
\text { conventional method of shipping raw } \\
\text { materials over processed consumer products, } \\
\text { as market participants all push for processing } \\
\text { exposure. }\end{array}$ \\
\hline $\begin{array}{l}\text { Competitive } \\
\text { Rivalry }\end{array}$ & W & $\mathrm{S}$ & $\begin{array}{l}\text { Tier } 1 \text { traders have a historic capital } \\
\text { advantage position embedded over all } \\
\text { competitors through ownership of strategic } \\
\text { infrastructure. New entrants are making } \\
\text { ground as host countries promote } \\
\text { homegrown entities. }\end{array}$ \\
\hline
\end{tabular}

Notes: W: Weak, M: Moderate, S: Strong

The retail sector has transformed itself, and with it many aspects of the food system. Although the supermarkets' direct engagement with farmers and production has focused on fresh produce, where the traders are not present, the 
challenges posed by supermarkets to some of their key suppliers, especially food processors, cannot go unnoticed by the traders themselves.

Walmart has established large teams of buyers strategically positioned around the globe for the very purpose of procurement:

"As we continue to grow our Responsible Sourcing program, we are expanding our international responsible sourcing team. Currently, we have more than 140 Responsible Sourcing associates working in our market and sourcing offices around the globe" (Walmart, 2014).

Processing firms are on the move, Nestle has started to move back down the supply chain in its chocolate operations, creating competition for the historically dominant traders (Murphy, 2012). Competitive rivalry within the GGOS differs for the different actors. The small traders face the most competitive and difficult industry forces, as summarised in Table 4.

\subsection{Future Outlook of the Sector}

The ABCD traders today retain strategic assets that are often both geographically unique and required by any party wanting to export out of particular markets. Equally, however, these tier 1 companies are being challenged by both large and new entrant traders such as Glencore Xstrata, Wilmar, and COFCO - with the latter often being strategically supported by host governments and large regional customers looking to reduce the power of, and reliance on, the ABCDs.

The dominant tier 1 actors use these barriers to entry to maintain an oligopolistic trading environment and to keep rivalry and new entry to a minimum. D'Aveni's (1999) work on hypercompetition extends on Porter's Five Forces and provides context on how tier traders large and small may look to break down these barriers to entry and disrupt the status quo. Where the dominant incumbents leverage off their core competencies and enhance them by laying new competencies over them, tier 2 traders could shift the core competencies required and disrupt the incumbents, turning current strengths into weakness (D'Aveni, 1999). Where new entrant traders have made inroads, the ABCD traders will likely look more towards collaboration and acquisition, exampled by the relationship between Wilmar and ADM. 
Further collaboration, strategic partnerships and outright acquisitions are likely to continue in the future as the $\mathrm{ABCDs}$ and regional power bases look for further vertical and horizontal expansion, fusing opposing ends of the supply chain with the intention of securing an element of control and security for the future.

Table 5: Global Soybean Production 2010/11 (metric tonnes)

\begin{tabular}{|c|c|c|c|c|c|c|c|}
\hline & Soybean & \multicolumn{3}{|c|}{ Soybean } & & \multicolumn{2}{|l|}{ Soybean } \\
\hline & Production & $\%$ & Exports & $\%$ & & Imports (2010) & $\%$ \\
\hline United States & $90,610,000$ & $34 \%$ & $41,368,000$ & $45 \%$ & East Asia & $58,935,000$ & $66 \%$ \\
\hline Brazil & $74,500,000$ & $28 \%$ & $30,850,000$ & $33 \%$ & EU & $13,800,000$ & $15 \%$ \\
\hline Argentina & $49,500,000$ & $19 \%$ & $8,500,000$ & $9 \%$ & & & \\
\hline China & $15,200,000$ & $6 \%$ & & & & & \\
\hline India & $9,600,000$ & $4 \%$ & & & & & \\
\hline Rest of & & & & & Rest of & & \\
\hline World & $24,283,000$ & $9 \%$ & $12,072,000$ & $13 \%$ & World & $17,085,000$ & \\
\hline Total & $263,693,000$ & $100 \%$ & $92,792,000$ & $100 \%$ & & $89,820,000$ & $100 \%$ \\
\hline
\end{tabular}

By way of example, soybeans as a vital component within the grain and oilseed sector are heavily concentrated in both production, export and import (Table 5) the Americas representing the major growing and export region and East Asia representing the major import region.

The likelihood that further alliances between key stakeholders at both ends of the value chain, built around soybeans, will continue to develop collaboration and strategic arrangements would appear extremely high.

Such arrangements are not likely to be limited to traders, as we have seen between the likes of ADM and Wilmar. All stakeholders with exposure to the sector will likely continue to identify potential competition and potential collaborative partners, and an element of picking up teams, taking sides and making deals across the entire spectrum to work together with particular parties will become ever more prevalent as stakeholders attempt to create or maintain strategic competitive advantage.

Supermarkets, merchants and processors of both food and fuel, traders and farmer groups will likely network across all environments and establish direct 
channels of both information and business activities. It would not be surprising in the future to see fuel pumps outside all suitable supermarkets, as is already becoming prevalent (PAK'nSAVE, 2014). Supermarkets will likely also continue to have more direct involvement with suppliers that could well extend past fresh produce.

Such hypercompetition and the fusing of multiple different traditional market sectors could see gigantic mergers across the entire spectrum in the future. Consider a 'super firm' that combined the resources, power and activities of a merger between the likes of Cargill, Walmart and Glencore Xstrata. This company would have unprecedented reach across all sectors that have exposure and interest in grain and oilseeds. The only dimension remaining out of their control under such a scenario would appear to be the weather. They would effectively deliver food and fuel to the world with unrivalled strength - so much so that the governments of the world would be unlikely to allow such a momentous collaboration. But the smaller traders and other stakeholders across the supermarket and energy sector could likely do exactly this and go largely unnoticed. The new entrant MNE and SME traders could look to disrupt the incumbent dominant actors on a multitude of fronts limited only to the imagination of the collective group as a whole. This is where the opportunities for small traders sit. Having know-how, contacts and activities within the trading sector, they can be useful in identifying diverse characters across the spectrum that could benefit through collaboration, and bring the parties together. Through doing so, they would create a position within the newly formed alliance and improve their own position.

Often small traders have some advantages over the ABCDs and the large new entrant MNE traders in that they are less committed to any particular infrastructure, origin or market. They can scan the world, identifying opportunities to connect certain parties that provides synergies for all.

Through attempts to develop trade as small traders, when the incumbent is disrupting their attempts to compete, small traders can compete by improving and promoting the traditional offering, turning the large traditional traders past barriers of entry into prison walls. Small traders have the opportunity to create 
more creative, dynamic, flexible and unconventional strategies than the incumbent large traders - through accessing diverse resources through NWs, they are not committed to any particular standard or set of resources. (D'Aveni, 1999).

Small traders can also look to the ABCDs or other large new entrant MNE traders as potential partners; often these small traders are geographically bound and operating in markets that may have been overlooked to date by the large traders for reasons of scale or newly emerging status.

In certain markets the large traders may not consider it worthwhile entering a representative business themselves, rather they may look to have local trading partners and push commodities into these markets through them. Small traders can also broker their knowledge and contacts within the grain and oilseed sector with those outsiders from food or fuel wanting to come into the trading market but who do not have sufficient in-house expertise to do so.

\subsection{Chapter Summary}

This chapter has provided an overview and competitive assessment of the sector in order to provide understanding of the context on which the proposed conceptual model will be tested. The GGOS is significant both in terms of importance and in the way it provides the backbone of the global food chain and is responsible for feeding a growing world population. It also has economic significance in terms of both dollar values of trade in general and of particular companies involved in the sector. The power base of the global food system sits in the hands of those who control critical strategic assets throughout the entire value chain. From a grain and oilseed trading perspective, the most prominent traders are still the ABCD companies that largely control the back end of the value chain through having significant interests in production inputs, such as fertiliser and seed, export elevators and logistical chains, along with processing and merchandising commodities and branded food products.

The front end of the value chain is controlled by the link to the consumer, the supermarket chains and there is no bigger influence in this arena than Walmart, the Fortune 500's number 1 listed company. Between these two powerful and 
concentrated ends of the value chain sit many other stakeholders covering every capacity of the value chain, including the parts the ABCDs and large supermarket chains such as Walmart are engaged in. New entrant companies have emerged and strongly resemble the $\mathrm{ABCD}$ business structures around these agricultural commodities. The extent of competition, though intense, varies between large tier 1 traders and other traders in the sector. The world looks set to develop cross-pollinated strategic alliances between the different stakeholders of the broader sector. If the governments of the world allowed a coming together of superpowers across different areas and parts of the value chain (which they surely wouldn't), competition could be further mutated. 


\section{Chapter 3: Literature Review and Theoretical Framework}

\subsection{Introduction}

This chapter reviews the literature on GM, NWs and firm performance. Firstly, it provides an overview of the network and GM literature to argue for their complementarity. The next section discusses the theoretical underpinnings of the research that include the key theories that guide this research and explanations of the main explanatory variables of the study. The next section develops hypotheses and proposes a conceptual model for empirical investigation. The last section provides a summary of the chapter.

\subsection{Literature Review}

The schematic view of this section is presented in Figure 2, which shows that the main constructs of interest, namely global mindset, network structure and network leverage, are guided by theories such as network theory, resource-based and dependency theory, and transaction costs theory.

The guiding theories of this study are networking and global mindset. Social capital is where the two streams of literature - social capital of the group (network theory) and social capital of the individual (global mindset) - meet. The network structure is influenced by the GM of individuals; those with superior GM build superior network structures. Network structure is the hardware and arrangement of relationships and the position of the actor in the network. The GM of the individual influences the sort of relationships and partnerships the actor is likely to develop (Yu \& Chiu, 2013). However, the GM of the actor is also influential at the action level. Network leverage is the action level - the passing of information or resource benefits and the bridging and positioning functions of the actor fall under NWL (Yu \& Chiu, 2013). 


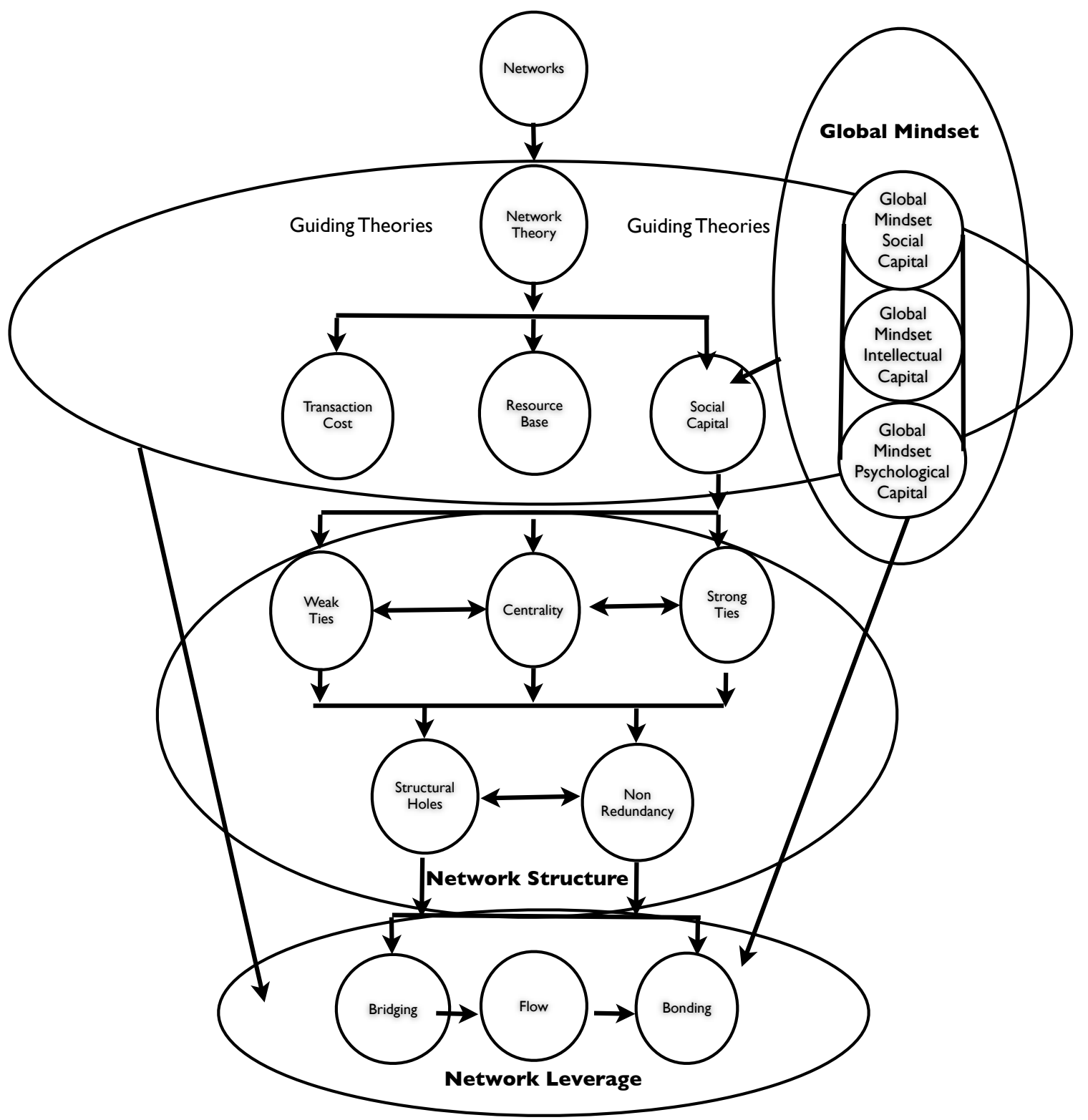

Figure 2: Schematic Overview of Literature 


\subsubsection{Main guiding network theories}

The external relationships that surround an organisation are capable of providing a wide variety of both tangible and intangible benefits. However, NWs and the inter-firm arrangements that evolve through them can result in strong and deeply embedded interdependent relationships. As a result, NWs can be considered a double-edged sword in that whilst they facilitate incremental innovation, they can also hinder radical innovation and go as far as to lock firms into undesirable arrangements that exclude them from potential new opportunities with new partners (Granovetter, 1973; Hansen, 1999).

Chen and Chang (2013) suggest that there are four main theories that guide the literature surrounding NWs and interorganisational relationships: network theory, resource-based theory, transaction cost theory, and social capital theory. The first three of these theories examine the dynamics of the network from the perspective of the actor by considering the position of each separate member (actor) within the network and their role within the relationship or network; the benefits and costs of networking from the actor's perspective are the focus in this regard. The fourth theory, social capital theory, looks at the interaction and various qualities of the relationship between the actors from a holistic perspective: the benefits and costs associated between parties from the group's perspective, as distinct from the actor's perspective, is the focus of social capital Chen and Chang (2013). This social interaction and the implications of outcomes on a contingency basis between actors is a central issue of this study.

\subsubsection{Network theory}

Network theory is built on the premise that different firms have different and varying levels of resources and capabilities, and that by connecting with one another firms can develop a more diverse and integrated set of resources, bringing together strengths that would not otherwise be achievable or affordable (Yu \& Chiu, 2013). This co-specialisation or interfirm specialisation of resources essentially brings all resources of the network partners together for collaborative use. NWs with highly cospecialised and integrated resources can act quickly in taking advantage of new collaborative opportunities, but as these NWs embed themselves deeper the network partners become more interdependent, which may 
limit the actor's access to new partners, novel information and the ability to move on new opportunities that arise from outside the existing members (Burt, 1992; Chen \& Chang, 2004, 2004; Granovetter, 1973).

A firm's network and the resources these NWs open up to them can be both an important source of sustainable competitive advantage, but also have the potential to lock a firm into equally undesirable strategic situations and even alienate them from other potential partners and opportunities (Gulati, Nohria, \& Zaheer, 2000). Network development, therefore, is a very strategic activity, particularly from an international perspective where the actor may rely on network partners to perform activities in other countries on their behalf.

\subsubsection{Resource base and dependency views}

The RBV examines the influence of resource ownership on competitive advantage and performance. Understanding sources of sustained competitive advantage for firms has been and continues to be a major area of research (Barney, 1991; Barney, Wright, \& Ketchen, 2001; Porter, 1980, 1990). A sustained competitive advantage is achieved when a firm is implementing a value creating strategy not simultaneously being implemented by any current or potential competitor, and when these other firms are unable to enjoy any of the same benefits from the strategy being deployed (Barney, 1991).

Barney (1991) identified four attributes that a firms should aim to accumulate that contribute toward sustained competitive advantage: value, rareness, imperfectly imitable, and substitutability. Valuable in the sense they exploit opportunities and/or neutralize threats from other firms in the market place. Rare in that they must be rare among a firm's current and potential competition, and difficult if not impossible to replicate (imperfectly imitable), there can also not be strategically equivalent substitutes for this resource that are valuable, rare and imperfectly imitable (Barney, 1991; Barney et al., 2001).

RBV suggests that superior performance can be achieved through controlling or having proprietary access to superior resources (Street \& Cameron, 2007). Whilst ownership and ultimate control are most favourable, it may be unrealistic for smaller actors to own and control such superior resources. 
Through an alliance or network, presuming they can access such resources in a special way that is not available to the industry as a whole, they may be able to generate some superior market advantage that leads to superior performance over competitors. However, such reliance on others that own these superior resources creates a potential dependency that the stronger actor may exploit over the smaller dependant actor (Esteve-Pérez \& Mañez-Castillejo, 2008).

The transferring and sharing of resources and the relationship between dependence and power is empirically supported and extant in the RBV and RDV literature (Combs, Ketchen, Ireland, \& Webb, 2011; Emerson, 1962; EstevePérez \& Mañez-Castillejo., 2008).

Controlling superior resources and the access of other actors to these resources gives an actor power through the reliance that others have on them to deliver the resources they need. Essentially the power A has over B is strongly correlated to and based upon the dependence of B upon A. When one actor has the dependence of others, they may control behaviour to the extent that others may behave in ways that they would normally resist. This balance and management of one's own power and the power of others is central to the overall dynamics of a network, and the actor's success in it.

For the purpose of establishing NWs, the RBV holds that firms do not have all the resources they need, and are therefore dependent on aligning their external environments for the essential resources required to function. Through an RBV, actors within a business network identify each members core resources and repeatedly encourage collaboration around these resources and, in doing so, build a competitive advantage for all Chen and Chang (2013). Considering that firms cannot generate all the resources they require to operate their businesses internally, they exchange with other firms that have resources they need, and at the same time exchange with others resources that they have others need; this mutual exchange results in benefits to both actors (Yu \& Chiu, 2013).

This appetite to access external resources in the pursuit of competitive advantage over competitors is the essential driving force that has seen expediential growth of business NWs around the world (Chen \& Chang, 2004, 2004; Gulati \& Gargiulo, 1999; Osarenkhoe, 2010). 
In the relationship between network partners, it is important that both perceive they gain value from the relationship if it is to continue and be considered a success (Bohme, Childerhouse, Deakins, \& Corner, 2008). This dimension, and the influence power has over behaviour and performance, will be discussed in greater detail later in this chapter.

\subsubsection{Transaction cost theory}

Widely recognised in the field of transaction cost theory, Williamson (1998) discusses the firm as a governance structure and not a production structure. ('Governance' meaning the process in which order is accomplished in relation to potential conflict that can interfere with potential opportunities and mutual gains between parties).

Transaction cost theory (TCT) highlights how firms can achieve operating cost efficiencies and transparency in the exchange of information, providing a broader and rich flow of information and minimising both costs and the likelihood of opportunism within the network (Yu \& Chiu, 2013; Williamson, 1998; Williamson, 2010). Transaction costs can be described as the governing costs incurred in performing the normal business activities required for an exchange. These include activities such as gathering information and negotiating or writing and enforcing a contract (Chen \& Chang, 2004, 2004; Williamson, 1998). From a TCT perspective, a greater cospecialisation of resources allows each member to both identify and be identified as to what each member specifically contributes to the network. Provided these are positive contributions, it should encourage repeated collaboration Chen and Chang (2013).

Like the RBV, TCT advocates that firms generate power and dependence from other members through superior resource contributions. Those with inferior resource contributions need to make contractual agreements to manage behaviour and regulate power and obligations between members. However, such agreements could never regulate all possible behaviours or opportunistic actions by ambitious partners. Through building strong relationships, over time trust can be developed between network partners, which helps to reduce the likelihood of opportunistic behaviour Chen and Chang (2013). 
Business NWs that develop strong relationships and build up high levels of trust between the members also develop high degrees of embeddedness and enjoy a rich exchange of information and stability. Embeddedness is the degree to which partners are tied to one another.

Those with high levels of embeddedness are likely to share very high levels of cooperation and joint behaviour, whereas those with very low levels of embeddedness find it easier to work with a wide variety of potential partners depending on the situation requirements Chen and Chang (2013). High degrees of embeddedness can limit the ability for member firms to receive and take advantage of novel information and opportunities.

The more embedded they become, the more uniform the information within the network becomes, as deeply embedded network partners often run in the same circles. Business NWs with a low degree of embeddedness find it easier to gain access to novel opportunities and can be more easily reconstructed to meet radical innovation; however, unlike deeply embedded partners that are both motivated and willing to help one another, these network partners with a low degree of embeddedness often lack the motivations or willingness to help each other. (Chen \& Chang, 2004, 2004; Hoang \& Antoncic, 2003; Müller-Seitz, 2012).

The degree of embeddedness that resources are tied to in a particular transaction therefore complicate resources being easily redeployed to another transaction without sacrifice and cost in productivity through the need to adapt the resources to a new transaction (Chen \& Chang, 2004, 2004; Dyer,1996). This examination of the relationship trade-offs at play is covered off and discussed in social capital theory.

\subsubsection{Social capital theory}

Social capital is the term used to define the value of a network when viewed through the lens of the parties collectively, or the network, rather than an actor. Social capital theory postulates that, like all other resources, relationships can be a valuable asset in contributing toward a firm's performance, and should be viewed as a construct in itself (Chen \& Chang, 2004, 2004; Dyer \& Singh, 1998). 
High levels of social capital is strongly associated with developing trust within relationships; through close interaction these relationships develop an understanding of each member's expectations and support becomes strong between members. Trust and the development of understanding and expectations between groups regulate the behaviour of members by each member not wanting to attract negative attention from other members for bad behaviour (Burt, 1992; Tiwana, 2008).

Through the trust that is built up in relationships, it is possible for firms to gain a clear understanding of each member's expectation, together with each other's objectives, and this understanding encourages deep collaboration and minimises opportunism Chen and Chang (2013).

Importantly, the trust and mutual concern between network partners built up through collaboration within business NWs is typically unique, unspoken and therefore not easily imitated by a competitor, which makes relational capital a unique and valuable resource within business NWs Chen and Chang (2013). The relationship strength with network partners will often change over time as circumstances and actor needs change. Stam et al. made the observation that "the optimal configuration of entrepreneurs' social capital changes over time as small firms grow older, and differs for firms operating in different contexts. So, rather than continuing to pit different dimensions of social capital in a 'horse race' to see which one is most beneficial, it appears more productive for future research to further develop a contingency theory of social capital in the small firm context" (Stam et al., 2014, p. 167).

This contingency theory and the changing resource requirements of the member firm is both central to networking and this research. Actors can stand back and observe their own environments, determine what resources they need at any given time to assist them in achieving the firm's goals, and invest in those network relationships that are most likely to help the firm gain access to the right resources at the right time. The changing strengths of relationships, often referred to as the strength of ties, is therefore a central contingency when examining an actor's success or failure in networking efforts. 


\subsubsection{Network structure}

\subsubsection{Relationship strength of ties}

Literature surrounding the importance of relationship strength offers polar opposite views. A collective of researchers, such as Granovetter (1973), found support for strength in weak ties, whereas others, including Nelson (1989) found support for pursuing strong ties in order to achieve optimal performance within a network. Other researchers, in attempting to reconcile these differences when examining the arguments closely, found that both strong and weak ties are important in their own context (Rost, 2011).

Literature supporting maintaining weak ties over strong is most widely known through the work of Granovetter (1973) when he published his work titled "The Strength of Weak Ties". Granovetter defined tie strength by frequency of contact, reciprocity of favours and obligations and friendship (Granovetter, 1973; Nelson, 1989).

Granovetter et al. argue that when the relationship gets too close, the benefit of novel information or advantages is diluted: when we have strong ties knowledge flows freely and therefore partners will be more likely to know who we know, and what we know. Moderating this effect, however, Granovetter et al. acknowledged that those with whom we share strong ties have a greater motivation to be of assistance to partners, and were therefore typically more accessible when asked to do so (Granovetter, 1983). Interestingly, Granovetter et al. asserted that motivation for NWs was critical in that people use strong ties for political mobilisation and solidarity, and weak ties for the transmission of novel information and identification of novel opportunities (Nelson, 1989).

In seeking to reconcile various contradictions in the literature, Nelson (1989) found support for the proposition that strong ties are more in alignment with successful networking over weak through his article titled "The Strength of Strong Ties: Social NWs and Intergroup Conflict in Organizations". Nelson observed that organisations holding high numbers of intergroup strong ties have lower levels of conflict than those that don't. 
However, Nelson noted that excessive intragroup intimacy can create conflict with out-groups through groupthink mentality. Nelson added that if members of a network interact, they should develop positive sentiment toward each other over time, which should help to minimise the risks of conflict. He also suggested that internal cohesiveness can aid in developing negative stereotypes and other perceptual distortions of those outside the group and reduces the group's abilities to gather or process novel information, which can lead to disgruntlement and polarisation, and disruptive conflict can result (Nelson, 1989).

Whilst these propositions are interesting and logical, measurement of the variables has been a challenge. Specifically, the relationship strength literature appears ambiguous about what determines if a relationship is either a strong or weak tie. Nelson (1989) used the number of times two people have direct contact within a specified time frame, in his case one week, as the basis for determining whether a relationship tie is strong or weak.

Granovetter (1973) however used the infrequency two people have contact as the basis. Whilst these measures are supported empirically, they are neither consistent nor complete in determining relationship quality (Granovetter, 1973; Nelson, 1989). The different assumptions researchers have made and the lack of development and cohesion surrounding relationship strength may indeed be a contributor to the inconsistency of findings.

Furthermore, relationship strength may only be correlated with, rather than actually being casual to, organisational performance. Burt advanced this line of thinking by suggesting that it was the bridging of structure holes that drove both network strength and performance (Burt, 1992).

\subsubsection{Structural holes}

Burt advanced the literature in his book titled "Structural Holes" (Burt, 1992) arguing that successful networking is not about strength of ties at all, rather it is about taking advantage of opportunities through standing over structural holes. Underpinning Burt's proposition is that an imbalance of relationships and the strength of ties creates the appearance of structural holes. Burt's theory supports the findings of both Granovetter and Nelson by clarifying that weaker ties are more aligned with developing a greater number of structural holes than strong 
relationships; however, he also supports that it is usually to the strong relationships an actor will turn to mobilise the required resources to bridge the opportunities (Burt, 1992; Krackhardt, 1992; Granovetter, 1973; Nelson, 1989). These key contacts that an actor utilises, both to assist in the mobilisation of the network and to access various sub-groups within the network, can be considered as portals to the larger structural sub-groups of one's network (Burt, 1992; Kalish \& Robins, 2006; Krackhardt, 1995; Shipilov \& Li, 2008; Zaheer \& Bell, 2005).

Burt argues structural holes and bridging these holes leads to superior performance, and acknowledges that both strong and weak ties are relevant and have a place in an actor's networking strategy. We manage strong ties with those close contacts that represent various network clusters of people we wish to access; we maintain weak ties with those actors behind these close contacts or portals we don't know so well (Burt, 1992).

It is, therefore, a matter of balancing the maintenance of strong relationships with key representatives of larger sub-cluster groups or resources to access that group in a meaningful way.

We keep our distance from the group itself, in order to preserve resources for developing other important and potentially beneficial groups and bridging as many structural holes as possible.

It is essentially a case of opportunity costs; one can only manage so many strong ties at once. Burt suggests that if you have two close contacts that lead you to the same cluster, assuming both don't possess any other unique and required resource benefit to the firm, then one of the two strong ties representing that particular cluster group should be weakened but not severed. Having more close ties leading you to the same group of contacts in this situation fattens the network rather than expands it (Burt, 1992). This theory is known as either nonredundancy or redundant network ties. The process and implications of bridging will be discussed in a later section, under NWL.

\subsubsection{Non-redundancy}

Effective networking requires attention to the density of the network to avoid too many overlaps, while still attaining solidarity and cohesiveness with useful 
partners. Overlaps negatively impact network efficiency (Dubini \& Aldrich, 1991; Burt, 1992).

The density of the network is measured by the extent that ties between network contacts exists, specifically the number of actual ties across all partners within the network, as compared with the total number of potential ties if everybody within the network was connected directly (Dubini \& Aldrich, 1991).

Expanding on the previous section and the paragraph above, Burt (1992) argued that managing many relationships can be somewhat relieved through strategically choosing to be closer to a limited number of important contacts, and remaining further away from less important contacts, whilst using this limited number of important key contacts as portals to all the different sub-groups or clusters of weaker network relationships behind them.

Assuming these portals are closer to these weaker contacts than the actor themselves, they should be more motivated to help the actor than the weaker relationships that sit behind them, and will likely have a greater chance in mobilising these other contacts to help the actor than the actor themselves would have (Burt, 1992; Granovetter, 1973; Müller-Seitz, 2012). The actor can therefore sit in a central position, managing important key relationships with a smaller group of key contacts, using this contact as a portal to the cluster groups of people this contact is in touch with and leveraging access to this group through this one key person.

\subsubsection{Central network position}

An actor's network position is also an important aspect to consider when looking at the social structure of the network. An actor's structural position in the network can enhance or reduce the ability to benefit from the network ties, as both resources and information within NWs are not distributed evenly. An actor holding a central position within the network achieves benefits not available in such abundance nor diversity from the peripheral (Granovetter, 1973; Yu \& Chiu, 2013). When an actor holds a central position, they gain access to novel information quickly and efficiently as they have more and better connections than a peripheral actor. 
In addition to superior information, actors with higher network centrality often have greater control and access to superior resources as it can choose from a greater number of alternatives when exchanging beneficial resources ( $\mathrm{Yu} \& \mathrm{Chiu}$, 2013). However, and by way of caveat, holding a central position within a network can be costly. The cost of holding all the network relationships and deciphering the vast volume of information consumes both time and resources that might have been better utilised elsewhere (Yu \& Chiu, 2013).

Therefore, maintaining a central position and managing a limited number of key relationships that are strategic portals to greater diverse clusters of people delivers both the benefits of association with these clusters without requiring a high level of commitment of time or other resources. Structuring one's network to be a central figure, and having the ability to limit the time investment required through the use of portals, the actor can strategically manoeuvre both the information flows and with whom time is invested in accordance with the needs of the day. Through observing the flow of information that channels through the network, the actor can observe and act, turning his attention when and where required. This flow of information, and action that follows, is the subject of the next section and is drawn from the bridging, network flow and bonding literature.

\subsubsection{Network leverage}

\subsubsection{Bridging}

Bridging is essentially the brokering process of spanning structural holes. As argued by Burt (2004, p. 349), “Compensation, positive performance evaluations, promotions, and good ideas are disproportionately in the hands of people whose NWs span structural holes. The between-group brokers are more likely to express ideas, less likely to have ideas dismissed, and more likely to have ideas evaluated as valuable".

Considering the greater homogeneity within, than between, groups, people whose NWs bridge the structural holes between groups have earlier access to a broader diversity of information and have experience in translating information across groups. 
This is the social capital of brokerage (Burt 1992, 2000, 2002). People whose NWs bridge the structural holes between groups have an advantage in detecting and developing rewarding opportunities. Their advantage is information arbitrage. They are able to see early, more broadly, and translate information across groups (Burt, 2004).

Burt argued that an actor could create value through four levels of brokerage: the simplest makes those on the other side of the hole aware of the potential opportunity; the second is a higher level of brokerage, transferring best practice; the third is to draw the attention of two distinct groups of potential alignment benefits between them that they supposedly appear oblivious to. The fourth level of brokerage is to synthesise useful elements between groups for the betterment of all concerned (Burt, 2004).

\subsubsection{Network flow and bonding}

NWS is the framework or the "pipes and channels" of interconnectedness between the actors within the network. The benefits of information, goods or services flow through these pipes. This is known as "flow", with flow taking place along direct or indirect, and long or short paths (Borgatti \& Halgin, 2011; Kalish \& Robins, 2006).

Borgatti \& Halgin submit that different rules apply, depending on what exactly is flowing through the network.

For instance, a dollar bill can be transferred from one actor to another, but can never be in more than one hand at a time. Conversely, a bit of breaking news or information duplicates from actor to actor so that when it passes from $\mathrm{A}$ to $\mathrm{B}, \mathrm{A}$ retains a copy (Borgatti \& Halgin, 2011). Bonding is a term Borgatti \& Halgin applied to the balance of power and the relational structure of the actors. Relational structure could depict the actors in a linear sequence, or an integrated two-dimensional form.

The flow model, along with bonding, is one of the most developed theoretical platforms within network theory.

The function of bonding examines how the actors are connected and who has advantage or power through position. Coleman's (1988) work on network closure 
lays a foundation and explains how actors can combine forces within a closed network structure sanctioning bad behaviour by a third party, whereas in an open structure they cannot. The remainder of this section examines the network closure or openness and relates both to structural configuration of the network relationships and how power is dispersed through the network, an element we refer to in this study following the work of Borgatti \& Halgin as network bonding.

Figure 3 illustrates the fundamental advantage that $\mathrm{B}$ has over both $\mathrm{A}$ and $\mathrm{C}$, in that B enjoys the dependency of the both other actors. A and $\mathrm{C}$ have no alternatives other than B, whereas B can choose either A or C for any given situation. This positional advantage is different from the concept of centrality, which is more in alignment with flow.

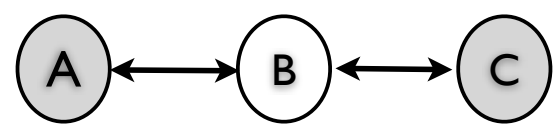

Figure 3: Basic Dependency

Going one step further, in Figure $4 \mathrm{~B}$ and $\mathrm{D}$ emerge in the highest power positions, each having two options where $\mathrm{B}$ can deal with $\mathrm{A}$ and $\mathrm{C}$, and $\mathrm{D}$ can choice from either $\mathrm{C}$ or $\mathrm{E}$. In this same situation $\mathrm{A}, \mathrm{C}$ and $\mathrm{E}$ have low power. A and $\mathrm{E}$ both have only one option, and that option has more power as it has more options than themselves. The same can be said for $\mathrm{C}$, although $\mathrm{C}$ has the opportunity to deal with either B or D, both $\mathrm{B}$ and $\mathrm{D}$ have better options than $\mathrm{C}$ in the dependent options of $\mathrm{A}$ and $\mathrm{E}$.

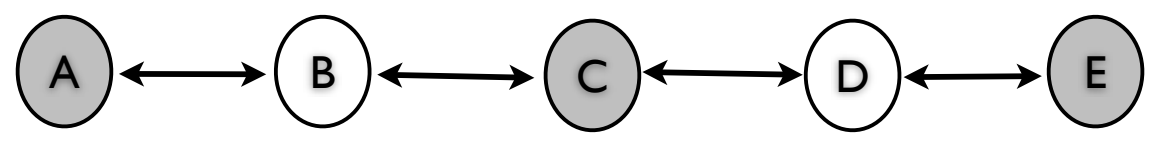

Figure 4: Intermediate Dependency

When considering the perspective of the flow model and network centrality, an actor connected to well-connected others implies greater centrality, which should provide superior flows through the network. Conversely, from an RDT and power or bonding perspective, it is the opposite. Being connected to weak others makes an actor powerful, and being connected to more powerful others makes an actor weaker (Borgatti \& Halgin, 2011; Coleman, 1988; Kalish \& Robins, 2006). 
This can lead less powerful actors to manoeuvre together in an attempt to moderate the more powerful actors' dominant positions and advantage.

This "ganging-up" collaborative approach of weaker actors is a way for the weaker members to neutralise the power when vulnerable. These actors can coordinate and amalgamate their interests to deal with another more powerful actor on the same issue (Coleman, 1988). Below is an example of this situation. As against $\mathrm{E}$ in Figure 5, because there is only one $\mathrm{E}$ and four A's, one might expect that E can choose which of the A's is the most desirable to deal with, meaning that E holds power over the A's (Borgatti \& Halgin, 2011; Coleman, 1988).

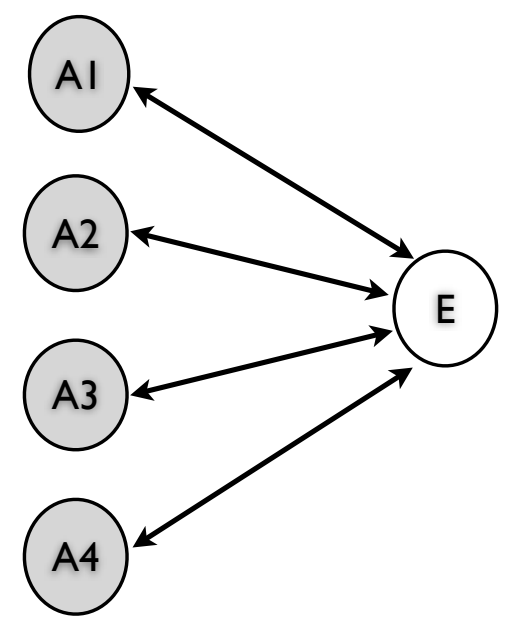

\section{Figure 5: Group Dependency}

However, in such a situation the A's may identify this vulnerability and may also be looking for the same thing from E, so therefore gang up, whereby the A's come together by ties of solidarity. In the extreme, this could be a virtual amalgamation as shown in Figure 6.

This principle is known as unionisation (Borgatti \& Halgin, 2011; Coleman, 1988). 


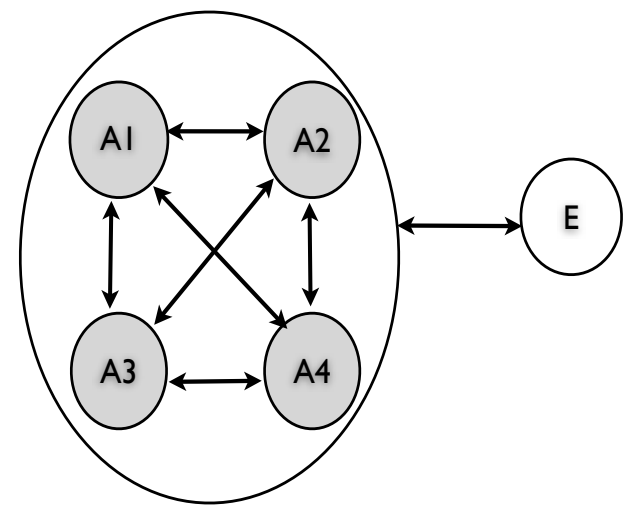

Figure 6: Network Closure Offset Dependency

Figure 5 and Figure 6 highlight two important relationship scenarios, the first being where E can induce competition between the A's and the second where the A's enter ties of solidarity for the purpose of accumulating power to deal with $\mathrm{E}$ (Coleman, 1988).

The latter highlights an important underlying benefit of networking. By working together, the group can accomplish more than it could alone. This phenomenon is a form of social capital, effectively saying that the bonds between the nodes enable those nodes to act as though they are freely transferring the capabilities of each to and from one another without actually doing so (Borgatti \& Halgin, 2011).

This dynamic engagement in managing the abilities of the actor or actors to leverage benefits from the network, where the actor manoeuvres between and within groups for different purposes at different times to either gather information or access resources, or build or deplete a power balance requirement, is operated through the NWS of the actor.

When actors have all the network dimensions discussed poised in a favourable way, their abilities to leverage benefits from their NWs are strongly increased and these increased benefits enjoyed logically lead the trader to superior performance. 


\subsubsection{Global mindset}

There is growing evidence that large scale globalisation is rendering traditional ways of doing business largely irrelevant and requires the attention of firms to ensure the personal attributes of managers incorporate a GM and a holistic global perspective (Kedia \& Mukherji, 1999). In the context of this study, understanding the personal attributes of the trader and their GM assists in unravelling how they leverage benefits through their own abilities, through GM, and through networking strategies NWS and NWL. Through these, understanding of how each singularly and accumulatively influences performance is enhanced.

Perlmutter's (1969) work on geocentrism introduced a stream of research focusing on the cultural dimensions of the actor that has since developed into the stream of literature we today know as GM. Cultural perspective focuses on aspects of cultural diversity and cultural distance that have strong impacts on international operations managing across cultural and international boundaries. The underlying theme of this cultural perspective is best explained by cosmopolitanism, which will be discussed next (Levy et al., 2007).

Whilst various fields and streams of literature have contributed to the building of the GM literature, they provide a degree of conceptual ambiguity and contradiction (Levy et al., 2007). For the purpose of this research, and the context in which we use the GM dimension, it is valuable to trace the underlying themes from the literature, which trace back to two important theoretical constructs inherited from the social sciences - cosmopolitanism and cognitive complexity (Levy et al., 2007).

A cosmopolitan view of the world provides an actor with a broader and deeper understanding of both different cultures and ways of being. Equally, one could say that with a broader and deeper cognitive complexity an actor would inherently have a better understanding of different cultures and places, or at least the propensity to take on and understand these different perspectives more readily (Rhinesmith, 1992). 
Rhinesmith, when describing GM, cosmopolitanism and cognitive complexity in a multidimensional sense suggested that GM was: “... a filter through which we look at the world... a way of being not a set of skills. It is an orientation to the world that allows you to see certain things that others do not see" (Rhinesmith, 1992, p. 63).

GM combines cultural intelligence with a global business orientation (Story \& Barbuto, 2011). In addition, relationships are proposed between GM and individual outcomes such as trust, relationship quality, and organisational commitment (Story \& Barbuto, 2011), cognitive complexity and nonjudgmentalism (Vogelgesang et al., 2014). To spur organisations towards worldclass performance in the global economy, actors must adopt six new mindsets, which include: 1) driving for the bigger, broader picture; 2) balancing paradoxes; 3) trusting process over structure; 4) valuing differences; 5) managing change; and 6) seeking lifelong learning. Each of the six new mindsets is an important component in the development of GM and the total way of thinking (Rhinesmith, 1995).

In more recent times, much work has been developed on GM by Javidan et al. at the Najafi GM Institute, at Thunderbird and describe GM as: "In short, GM is the capability to influence others unlike yourself - and that is the key difference between leadership and global leadership" (Javidan \& Walker, 2012, p. 38). Javidan et al. have divided GM into three major dimensions: intellectual capital (IC), psychological capital (PC) and social capital (SC) (Javidan \& Walker, 2012). An explanation of each will now be discussed. Figure 7 shows the scientific structure of GM developed by Thunderbird and the discussion follows. 


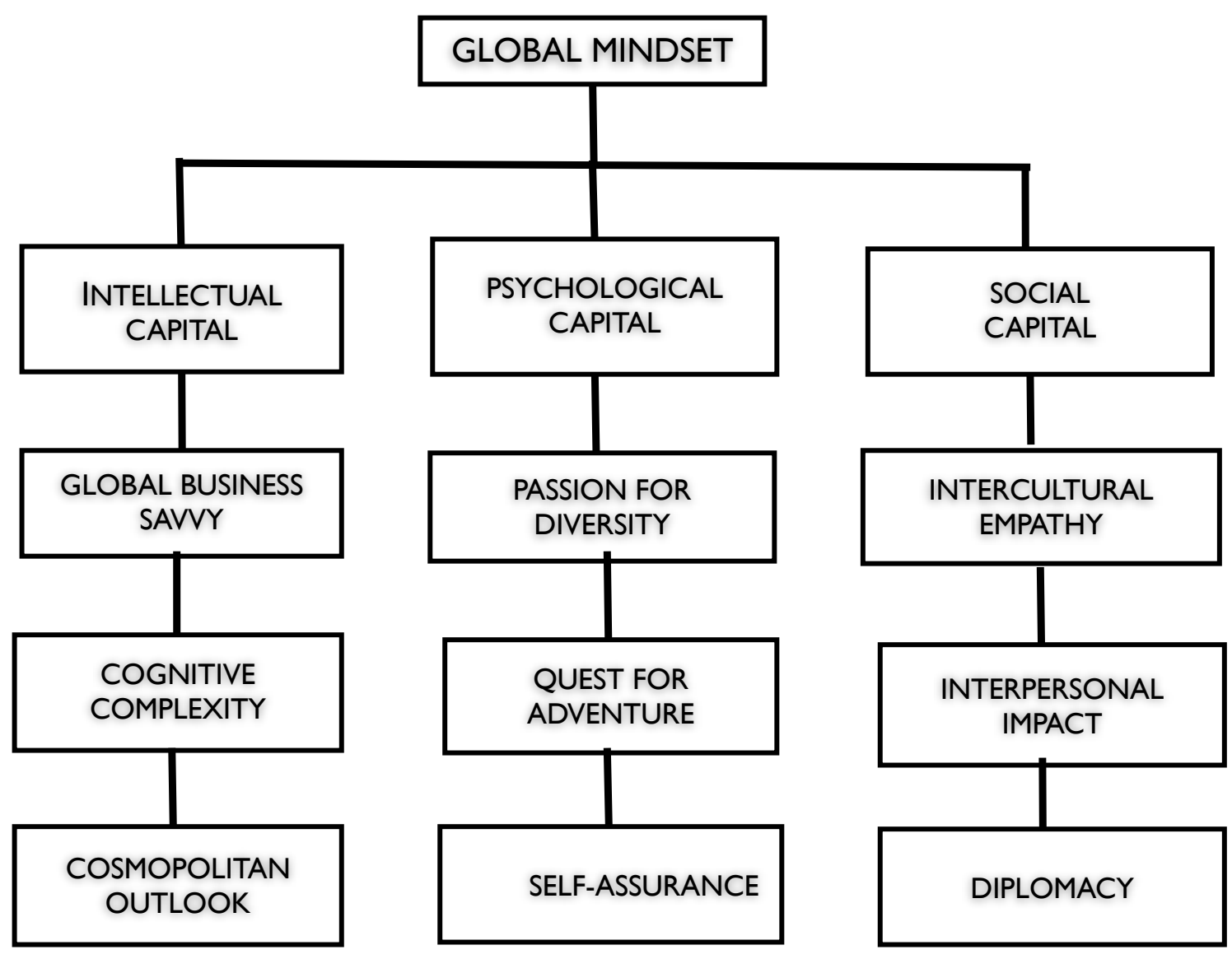

Figure 7: Scientific Structure of Global Mindset

Source: (Javidan \& Walker, 2012, p. 38: EXHIBIT 3).

\subsubsection{Intellectual capital}

IC refers to the actor's knowledge of his global environment, and the ability to digest and leverage benefits through a better understanding of the complexities embedded within global environments. IC consists of three building blocks: global business savvy, cognitive complexity and a cosmopolitan outlook.

An actor with superior global business savvy has knowledge of the way that world business works. They understand how to develop and execute competitive business and marketing strategies across borders and between cultures. They know how to manage risks associated with trading in other countries and have an inherent ability to identify and engage suppliers and other providers across different markets in a positive way. An actor with a superior cosmopolitan outlook appreciates that their home country is not the centre of the universe. 
They know people from other cultures and understand and enjoy these different cultures. They have an appreciation for and knowledge of geography, history and could generally identify who the world's important leaders are.

They are generally up to date with current economic and political hot topics and important world events. An actor with superior levels of cognitive complexity has the ability to see things that others do not see and can grasp complex concepts quickly. They possess strong analytical and problem-solving skills and find abstract ideas offered by others easy to comprehend. These abilities help the actor to articulate the meaning of complex issues and comprehensively explain them to others (Javidan \& Walker, 2012). Nahapiet and Ghoshal (1998) suggested that social capital facilitates the creation of new intellectual capital and that organisations that develop high levels of social capital gain advantages over competitors through creating and sharing intellectual capital.

\subsubsection{Psychological capital}

Through superior psychological capital, an actor can leverage on their intellectual capital. With a strong psychological platform and extensive knowledge of the global industry and environment, an actor is more likely to succeed. Actors with superior levels of PC are passionate about their functions and embrace diversity. They do not just tolerate or appreciate diversity, but thrive on it. Gupta and Govindarajan (2002) suggest that curiosity and openness about how the world works reflects an attitude, an element of the individual's personality, and enhances GM.

They have a genuine interest in exploring or living in other parts of the world and getting to know people from other cultures. They enjoy variety, have a quest for adventure and enjoy the challenge of dealing with delicate situations. Such actors also have a willingness to test their own abilities against unpredictable situations and are prepared to take calculated risks. They are comfortable with uncertainty through higher degrees of self-assurance that aid them to also be comfortable in what others might consider uncomfortable situations. They are self-confident, energetic and witty in tough situations. These people are both observers and doers (Javidan \& Walker, 2012). Linking PC to an outcome perspective, Vogelgesang et al. (2014) found that positive psychological capital mediates the 
relationship between global mindset and performance and also the relationship between cosmopolitanism and inquisitiveness.

\subsubsection{Social capital}

Social capital embraces the networking behaviours that help actors to develop an increasingly cross-cultural, complex, global network of positive relationships (Chen, 2013; Javidan \& Walker, 2012). SC reflects an actor's ability to act in ways that complement building trusting relationships with people from other cultures and parts of the world.

SC also consists of three building blocks: intercultural empathy, interpersonal impact and diplomacy. SC demonstrates the ability to show others empathy and to emotionally connect with people from other parts of the world and build trusting relationships, and an ability to engage others and to have a diverse network of friends and colleagues in many countries (Bowen \& Inkpen, 2009). Those with high levels of SC are seen by their peers as leaders and are considered to be skilled and have credibility in their respective areas. Superior social capital is also linked strongly with diplomacy skills. The actor seeks first to understand, then to be understood. They find it easy to start up conversations with strangers, and have an ability to integrate different perspectives through their ability to listen and willingness to collaborate (Javidan \& Walker, 2012).

\subsection{Conceptual Model and Hypothesis Development}

The proposed conceptual model developed from the extant literature is presented in Figure 8, and the hypotheses are argued in the following sections. On review, four constructs emerged as being potentially relevant in the study, although the dynamics and impact of these was unknown. The framework presents all potential relationships between the variables. In summary, the proposed model argues that GM influences TP both indirectly and serially through two mechanisms: NWS and NWL, respectively. The model also controls for some firm characteristics.

The motivation of the present study was geared around understanding how performance of new entrant and small traders could be improved. Primarily, two potentially related aspects were explored in this regard. 
The first of these aspects was aimed at exploring the individual level, where the personal attributes and capabilities of the trader needed to be understood. The lens of GM was selected for this aspect and the literature was outlined in section 4.6.

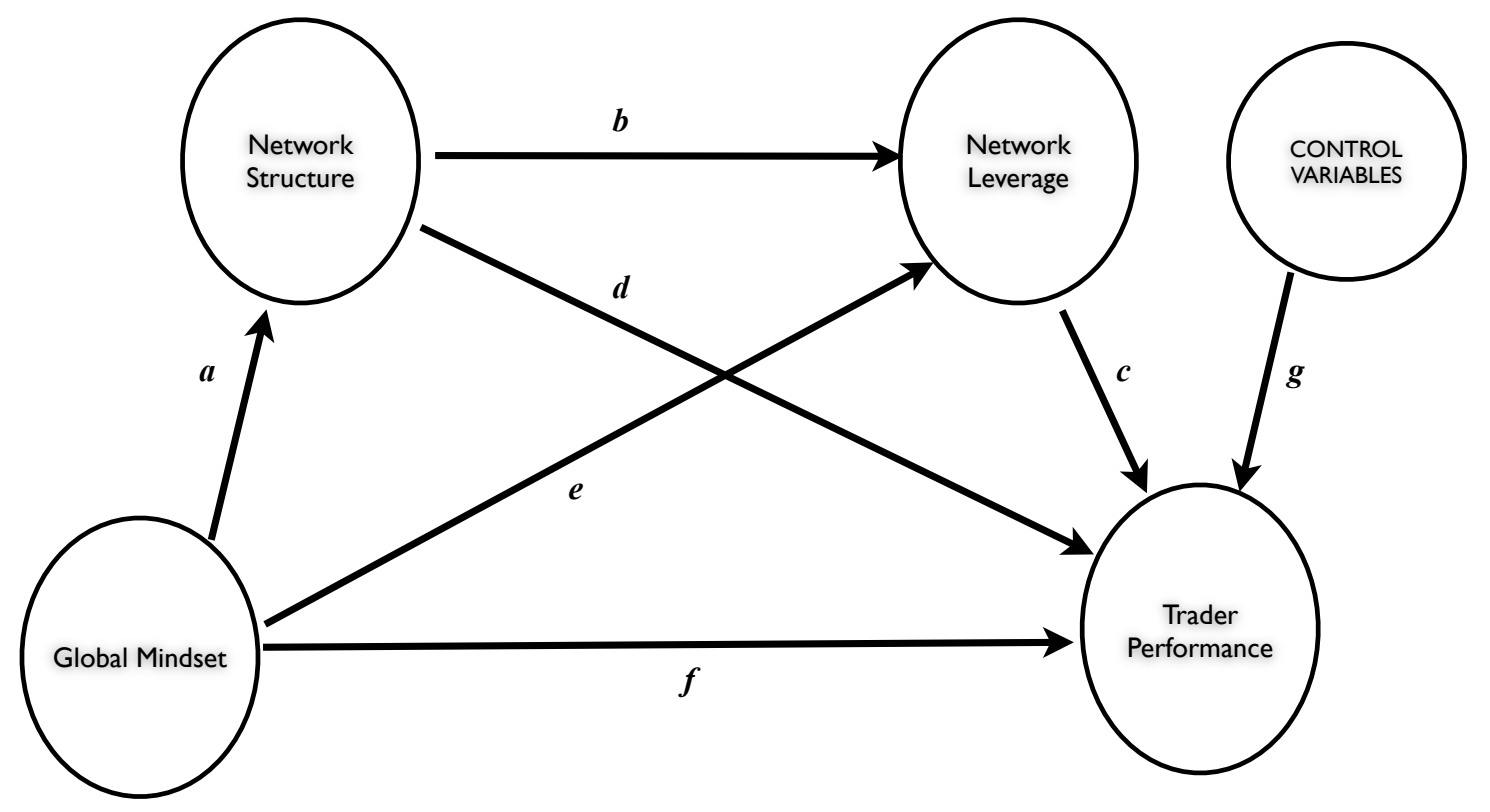

\section{Figure 8: Conceptual Model}

This served two purposes: firstly, it was considered important to understand if the personal attributes of the individual influenced performance directly regardless of the setting; and secondly, it would aid the study in unravelling the indirect impact expected between GM and the second dimension of interest, which was the role of NWs in determining performance.

From a general perspective, the logic was that performance of traders would be influenced by the nature of the network that the traders were operating in, the proposition being that superior networks would result in superior TP.

During the process of exploring the literature in the field of networks, it became apparent that it was prudent to consider two aspects of networks: (1) NWS and (2) NWL, as presented in sections 4.2.2 to 4.2.3. The NWS refers to the hardware of the network, the quality of relationships and how the relationships 
between contacts is configured, and NWL represents the ability to leverage benefits through the network to the betterment of the trader.

The balance of this section argues the logical mechanisms, as derived from the literature, between the variables. Finally, the mechanisms are presented as propositions, following which hypotheses for testing are stated.

\subsubsection{Global mindset, network structure and trader performance}

GM has been described as representing the individual's level of personal competence, expressly the ability to handle the cognitive complexity combined with a certain cosmopolitan view of the world (Felício, Caldeirinha \& Rodrigues, 2012; Levy et al., 2007; Rhinesmith, 1992). Traders with superior GM are likely to be well-connected individuals, so would naturally perform better than those with inferior GM. Having the cognitive abilities to decode complex issues suggests that the person in question is intelligent. Intelligent people can quickly decipher and understand information, have a superior understanding of what things mean and can quickly develop solutions. The GGOS is a highly competitive industry that requires intelligence to distill complex market dynamics with currency, commodity prices and logistical challenges constantly adjusting (HighQuest, 2011). Those with superior GM are also business savvy and know their industries well; they have a broad knowledge and diverse contacts to draw on to take care of any situations that arise. They understand why things work as they do and are able to short circuit problems and take advantage of opportunities before others may even be aware of their existence.

GM is a growing stream of literature and researchers have found support for and against its direct influence on performance. Nummela et al. (2004) found that the financial performance of exporting firms is positively associated with the GM of management. However, the proposition that superior GM of traders can achieve superior performance in the absence of a network would be an intriguing finding for organisations involved in international trade as it would suggest that organisational and industry structure is not relevant. As suggested by Raman et al. (2013): 
"It is not the GM per se that enhances performance; it is the mechanism, namely partnership quality, which actually leads to higher performance".

Following the perspective of Raman, the theoretical expectation of this hypothesis is that there is no direct effect between GM and TP. That is, the importance of mediators, in this case networks, is a necessary element underpinning TP.

Those traders with superior NWS have the right people in the right places. They have a large and diverse mix of both strong and weak ties to assist in whatever challenges or opportunities arise. They are centrally positioned within their respective networks and therefore can quickly reach out to the network when required to do so. The literature is voluminous, although at the same time varying in promoting various aspects of network structure as leading towards enhanced performance (Burt, 1992; Dubini \& Aldrich, 1991; Dyer \& Singh, 1998; Granovetter, 1973; Krackhardt, 1995; Nelson, 1989; Rost, 2011; Yu \& Chiu, 2013; Zaheer \& Bell, 2005).

The proposition that superior NWS can achieve superiority in the absence of efforts to leverage the network would be ambitious, as it suggests that organisations that trade in grain and oilseed commodities only need to ensure that the structural hardware of the network is sufficient for determining TP. However, superior NWS would ultimately place traders in a superior NW position, so based on the arguments provided above - the theoretical expectation is that the null hypothesis will be rejected - the study proposes that:

H1: NWS mediates the association between GM and TP

\subsubsection{Global mindset, network leverage and trader performance}

Those traders with superior NWL make the most out of what they have. They are action-orientated and are constantly monitoring their networks for useful information or resources and always looking to take up opportunities when they see them. Traders that bridge the structural holes between groups often have first-mover advantages over others in detecting and developing rewarding opportunities. Information arbitrage is said to be their advantage. 
They are able to see early, more broadly, and translate information across groups for the betterment of all concerned (Burt, 2004; Borgatti \& Halgin, 2011; Zhou, $\mathrm{Wu}, \&$ Luo, 2007).

The proposition underpinning Hypothesis 2 is that network leverage mediates the relationship between GM and TP. In terms of the structural model developed in this study, network leverage is conceptually different from GM and NWS in that it represents an action rather than a disposition, an effort to drive performance through the network.

Whilst, theoretically, the degree of benefits derived from the leveraging efforts may be determined by both GM and NWS, nonetheless there may still be benefits for any leveraging efforts. Therefore, the theoretical expectation is that the null hypothesis will be rejected. The importance of networks is established in the literature and the ability to leverage networks (as a two-part process of establishing networks and then leveraging them) is logically connected. Hence, it is proposed that:

H2: NWL mediates the association between GM and TP

\subsubsection{Network structure, network leverage and trader performance}

When the trader has superior NWS, they stand on higher ground than others and can see what is happening around them further and more clearly. This advantaged position naturally leads to the opportunities to press for greater leverage from the structure and take up superior opportunities. When traders do the right things, with the right people in the right places, good things happen. The literature supporting such propositions is abundant (Borgatti \& Halgin, 2011; Burt, 1992; Dubini \& Aldrich, 1991; Dyer \& Singh, 1998; Frankenberger, Weiblen, \& Gassmann, 2013; Granovetter, 1973; Hite \& Hesterly, 2001; Krackhardt, 1995; Nelson, 1989; Rost, 2011; Shipilov \& Li, 2008; Sparrowe, Liden, Wayne, \& Kraimer, 2001; Yu \& Chiu, 2013; Tser-Yieth, Hsiang-Hsi, \& Wei-Lan, 2009; Turnbull \& Ford, 1996; Vissa \& Chacar, 2009; Zaheer \& Bell, 2005; Zhou et al., 2007). 
The underlying proposition for Hypothesis 3 is that a superior network structure leads to superior network leverage and, ultimately, superior trader performance. Put another way, a trader's network leverage is optimised in a situation where there is superior NWS. Hypothesis 3, therefore, tests the relationship between network structure and TP mediated through network leverage. The proposition is that superior NWL can be achieved through the construction of a superior NWS. This latter comment is again logically connected and the theoretical expectation is that the null hypothesis will be rejected in favour of the alternative hypothesis. Hence, it is proposed that:

H3: NWL mediates the association between NWS and TP

\subsubsection{Global mindset, network structure, network leverage and trader performance}

Traders operating within the GGOS are international operators - by nature, their trade demands it. Therefore, understanding international markets and having contacts in other strategic locations is essential. Nummela et al. (2004) argue that GM is associated with a commitment and desire to understand both foreign markets and international networks, and an appreciation of the importance that these international contacts or strategic partnerships have.

Therefore, traders with superior GM are more likely to have diverse cultural and social connections, and understand the important role these partners can play in assisting them with their business. They have an ability to get on the level with all those they come into contact with, and will generally have somebody to call on for every occasion (Chen, 2013; Zhou et al., 2007). The cosmopolitan lens through which they see the world means they both enjoy other cultures and have a good understanding of both similarities to and differences from their own. They love to travel and have a quest for adventure, taking them to exciting places, meeting exciting people and gaining a diverse set of skills that can be used in many aspects of their lives (Levy et al., 2007; Perlmutter, 1969; Vogelgesang et al., 2014).

Those traders with superior GM are likely to attract others with the same highlevel thinking, therefore they often know people in important positions who can 
provide both the access to superior information and resources and the motivation to help when called upon.

Furthermore, a trader with superior GM will generally be aware of the scarcity of time and will ensure that the particular needs of the day are meet through making the right contacts at the right time. Javidan (2011) when discussing the IC dimension of GM, refers to actors' knowledge of their global environment and their ability to digest and leverage benefits through a superior understanding of their environments. Javidan \& Bowen (2013) also link GM with having the abilities to influence others unlike yourself, first seeking to understand, then to be understood.

Therefore, it makes sense that a trader with superior GM can survey their network at any time to identify when and where assistance can be called on or may be required, and will have the abilities to influence where influence is demanded.

Traders with superior GM will also have many diverse relationships and superior intuition and perceptions of those relationship dynamics (Javidan \& Walker, 2012; Levy et al., 2007; Perlmutter, 1969; Rhinesmith, 1992). They will instinctively not position themselves to become overly reliant on any one contact in particular, especially when that particular contact holds power over them (Borgatti \& Halgin, 2011; Lozano, Moreno, Adenso-Díaz, \& Algaba, 2013). Rather, they enjoy a rich and diverse interaction with many different contacts who open them up to many diverse information channels and opportunities.

Therefore, the underlying proposition is that superior GM leads to superior construction of NWS, which leads to superior NWL, and this serial path from GM $\rightarrow$ NWS $\rightarrow$ NWL leads to optimal TP. Hypothesis 4 tests the relationship between global mindset, network structure, network leverage and TP.

H4: NWS and NWL have serial mediation effects on the association between GM and TP

Superior network structure can be achieved if constructed by individuals with a superior global mindset. To suggest that superior network structure could be achieved through employing traders with an inferior GM is counter-intuitive. 
Also untenable would be that traders can generate superior NWL through inferior NWS. The literature shows that the connectedness of the network structure and network leverage is very direct (Dyer \& Singh, 1998; Hoang \& Antoncic, 2003; Zaheer \& Bell, 2005). Therefore, the theoretical expectation is that the null hypothesis will be rejected in favour of the alternative hypothesis.

The full path mediation model is that TP is determined by NWL, with NWL being determined by NWS, which itself is determined by GM.

What is critical under the fully mediated pathway is the serial nature of the model. It supports that the sum of the parts, and the organisation of the parts, far outweighs the importance of any of the parts in their own right. From an industry perspective, the model proposes that superior performance can be achieved by employing traders with superior levels of GM and providing them with a setting that complements developing robustly constructed networks and encourages them to optimise the benefits leveraged from the structured network.

From the proposed conceptual model, the potential serial nature is visually apparent. From the initial starting position of the individual, all each has is themselves. From this individual standing, they look across the group and begin interaction with those whom they find attractive.

Attractive can be many things to different people, so there is no specific formula. But nobody is immune to the natural selection of being attracted to those similar to oneself (Javidan \& Walker, 2012; Levy et al., 2007; Rhinesmith, 1992). In summary, those traders with high-level GM are naturally attracted to others with high-level GM, and so as a group they are likely to have access to superior information and resources collectively and can leverage more superior benefits among themselves than those groupings with a lower level of GM.

\subsubsection{Control variables}

Before testing the hypothesis, it is important to ensure that other potential influencing factors that may impact the model are minimised through loading a set of control variables on the dependent variable; in this case, trader performance. Three control variable were included in the conceptual model. The control variables were selected in line with supporting literature where other 
researchers had highlighted their importance in similar studies, as well as for their practical logic in the context of this study (Cavana, 2001; Chadee \& Raman, 2012; Chen, 2013; Jae-Nam \& Young-Gul, 1999; Lambert, 2006; Levy et al.,

2007; Li, 2008). The three control variables selected were: age of the trader; international orientation through trading role (i.e. domestic or international trader); and the location of the trader.

\subsection{Chapter Summary}

This chapter has reviewed the related literature to propose a conceptual model for empirical testing. The proposed conceptual model argues that global mindset itself is not sufficient to enhance trader performance, rather it is the mediation effects of network structure and leverage that transforms GM into superior performance. The next chapter will discuss the methodology applied to test the proposed model. 


\section{Chapter 4: Methodology}

\subsection{Introduction}

This chapter outlines the research methodology applied in the study, including the data collection procedures used and the analytical approach. The chapter begins with a justification of the research philosophy employed (positivism), moving through to the survey design, sample selection and data collection processes. The analytical techniques underpinning the hypothesis testing is explained, beginning with the approach to measuring the explanatory and dependent variables, and how the common methods bias, reliability and validity testing was performed is also explained.

\subsection{Research Design}

Scientific method is critical in research design. The foundations of scientific method are epistemology and ontology (Bono, McNamara, 2011; Cavana, 2001; Seth, 1894). Ontology relates to what we know, or more specifically, the reality of knowledge, whereas epistemology relates to how we know what we know. Two contrasting approaches from the philosophy literature are the hermeneutic and positivist approaches (Babbie, 1998; Bono et al., 2011; Cavana, 2001). The hermeneutic approach defines that there is no true reality, or ability to measure reality, rather that knowledge is "relative" and much of it socially constructed. At the other end of the spectrum is the positivist perspective, the perspective embraced in this study. This study is dealing with traders in the GGOS, where each participant has a clear and insightful perspective of their objective reality and can be easily measured through scales or actual numbers.

A positivist approach to research is based on knowledge gained from "positive" verification of observable experience, rather than intuitive perception. Scientific methods and experimental testing is the best way of achieving this knowledge. The broader context for this approach is the modernist movement (Cavana, 2001; Schrag, 1992). The positivist approach makes the assumption that there is an objective reality and people can know this reality. Also numeric instruments can be used to accurately measure and explain this objective reality. 
There are general patterns of cause and effect that can be used as a basis for predicting and controlling natural phenomena and the goal is to discover these patterns.

We can also rely on our perceptions (observations or measurements) of the world to provide us with accurate data. Provided a strict methodological protocol is followed, research will be objective and replicable across related studies. Positivist approaches rely heavily on experimental methods where variables can be manipulated and measured. These methods ensure that there is a distance between the subjective biases of the researcher and the objective realities that may be held. This generally involves hypothesis generation and testing: proving or refuting. The positivist position is grounded in the theoretical belief that the objective reality can be known and measured by the researcher (Cohen, 2006).

When considering what methodology to employ within a study, the nature of the research questions and objectives of the study are critical. The nature of the research questions will determine whether the research is exploratory or explanatory in nature (Bono et al., 2011; Cavana, 2001). Qualitative research is by definition exploratory and used when we don't know what to expect. Conversely, quantitative research is explanatory and used when we want to measure the size of a construct or relationship. Qualitative research is conceptually subjective and concerned with understanding human behaviour from the informant's perspective and is more complex to analysis than quantitative data. Qualitative research is often specific to a unique setting; replication can be difficult and is open to interpretation from both the respondent and the researcher. Quantitative research, on the other hand, is by definition numerically driven and therefore more replicable across other relevant studies.

This research embraces the positivist quantitative approach in that it best fits with goals to explain and measure the latent constructs developed in the conceptual model, and can later be more readily replicated across other industries by future researchers. The quantitative approach aligns strongly with the positivist approach. Using a quantitative approach allows the causal and outcome relationships that are drawn within the conceptual model to be tested by precise measurements providing statistical support for or against the distinct variables 
and hypothesised relationships (Cavana, 2001; Sparrowe, 2011). The purpose of the study is to understand the causal relationships between latent predictor variables, namely GM, NWS, and NWL, and how each variable influences the performance of global grain and oilseed traders directly and indirectly. Also, through using a quantitative approach, this research can provide standardised empirical measurements representing the complex constructs of GM, NWS, NWL and TP.

\subsection{Survey Design}

The questionnaire designed for this study comprised four sections. All sections were drawn and modelled on other studies within the literature, using established measurements for defining GM, NWS, NWL and TP. Using established measures allows the researcher to utilise previously tested, reliable and accepted measures of constructs. Replicating the constructs removes the requirement to justify the validity of the measures, and also allows for comparison with similar studies (Bono, 2011; Cavana, 2001; Fowler, 1995; Lietz, 2010). In addition to the variables under examination, the questionnaire included 12 control variables aimed at extracting information about the demographic and personal situation of each participant.

When determining the optimal number of response scales, it was necessary to consider whether offering an even or odd number of response scale options was most appropriate. An odd number allows the respondents to choose either a neutral or directional position. Furthermore, the resolution of the scale needs to balance being easy to understand (5-point scale) or fine-grained and potentially complex to answer (9-point scale). Furthermore, 5- and 7-point scales can easily be rescaled in order to facilitate comparisons. The 7-point scale was found to be more reliable as it allows for a greater differentiation of responses than the 5point scale (Cavana, 2001; Cronbach, 1951; Dawes, 2008; Fowler, 1995; Lietz, 2010). Ultimately, the decision to use a 5-point or 7-point scale was made on the basis of what was used in earlier studies: this study employed the same scale as those that had previously been verified.

A small number of questions for each construct category were mixed together on a random basis, with the aim of reducing any potential response bias that may 
exist through the sections and/or over the course of completing the questionnaire (Chang, 2010; Podsakoff, 2003).

Section A also included the marker variable, a theoretically unrelated variable used to assist in demonstrating the validity and reliability of the results. Section B was split into two questions, both of which were measuring the GM dimension. The first category examined the conceptual GM of participants (20 questions), with the second category measuring the contextual GM (20 questions) using 5point Likert scales. Section C and D expanded further the networking dimensions of the study.

Section C consisted of two questions, using 7- and 5-point Likert scales, respectfully. Section D was more open-ended, asking questions about their personal network contacts and how the relationships between and among partners worked. After receiving feedback from the earlier, piloting stages of the questionnaire, it was anticipated that participants may be reluctant to answer such probing questions about their personal relationships, particularly if the conceptual model of this research was correct in that these network contacts and the relationships with each play a significant role in each individual trader's performance. For this reason, each question that was asked in section D had already been asked, albeit in a different form, in the previous sections of A or C.

The questionnaire was designed to establish representative factors of the four constructs of the investigation, GM, NWS and NWL and TP.

\subsection{Explanatory Variables Measurements}

Dimensions that covered the three explanatory variables, GM, NWS and NWL, were included in the questionnaire to provide empirical measurements across the sample to represent respective scores for each for individual participants. For each of the explanatory variables, participants were asked a number of questions drawn from the literature of other similar studies, where the wording was modified where appropriate to make them more meaningful to the participants in the trading context of this study. The explanatory variables are defined in Chapter 3, the questionnaire items for each is grouped and listed in Table 6. 
Table 6: Survey Questions by Variable

\begin{tabular}{|l|l|l|}
\hline \multicolumn{2}{|l|}{ Global Mindset: (Arora et al.,2004; Kefalas \& Neuland, 1997). } & $\begin{array}{l}\text { Likert } \\
\text { Scale }\end{array}$ \\
\hline Q1 & I prefer to act in my local environment (reverse scored) & 5-point \\
\hline Q2 & Most of my social affiliations are local (reverse scored) & 5-point \\
\hline Q3 & Most of my professional affiliations are international & 5-point \\
\hline Q4 & $\begin{array}{l}\text { In trying to accomplish my objectives, I find diversity and multicultural teams } \\
\text { play valuable roles }\end{array}$ & 5-point \\
\hline Network Structure: (Koka \& Prescott, 2008) and Burt (1992; 2000; 2002; 2004) & \\
\hline Q1 & The number of network contacts & 7-point \\
\hline Q2 & The diversity of your network & 7-point \\
\hline Q3 & Your position as a central figure and link between your network contacts & 7-point \\
\hline Q4 & We have generated a lot of profits together & 5-point \\
\hline Q5 & The number of strong relationships & 7-point \\
\hline Q6 & We have secured different partners based on different business requirements & 5-point \\
\hline Network Leverage: Kim et al. (2013), McEvily and Zaheer (1999). & \\
\hline Q1 & We have achieved a high level of joint profits between us & 5-point \\
\hline Q2 & We have increased joint profits shared between us & 5-point \\
\hline Q3 & We have gained strategic advantages over our competitors & 5-point \\
\hline Q4 & Our relationship has resulted in in strategic advantages & 5-point \\
\hline Q5 & Retention of Client base & 7-point \\
\hline Q6 & $\begin{array}{l}\text { We have gained benefits that enable us to compete more effectively in the } \\
\text { market place }\end{array}$ & 5-point \\
\hline Dependent Variables: Chen (2013); Mauer (2006); Chen and Chang (2013). & \\
\hline Q1 & Growth in sales/turnover & 7-point \\
\hline Q2 & Growth in profits & 7-point \\
\hline Q3 & Growth in market share & Expansion of client base \\
\hline
\end{tabular}

Note: 5-point Likert Scale (1) Strongly disagree, (5) Strongly agree. 7-point Likert Scale (1) Substantially below industry average, (7) Substantially above industry average

Table 6 also lists the studies from which these construct items are borrowed. GM questions were replicated from Arora et al. (2004), having been developed originally by Kefalas et al. in 1997. NWS questions were modelled on (Koka \& Prescott, 2008) and aligns with the work of Burt (1992, 2000, 2002, 2004). 
Network leverage questions were borrowed from (Kim, Kim, Pae, \& Yip, 2013) and (McEvily \& Zaheer,1999).

The dependent variable was developed from performance measures used in relevant literature and based on financial performance measures. Only measures that had been empirically tested in numerous studies throughout the literature were used (Cavana, 2001; Chen, 2013; Mauer, 2006; Yu \& Chiu, 2013).

\subsection{Common Methods Variance}

Common methods variance (CMV) is variance that is attributed to the measurement method rather than to the constructs themselves being measured (Chang, 2010). Research findings can be seriously affected by common methods bias.

When self-report surveys are used to collect data and used at the same time by the same participants, CMV may be a concern. CMV has the potential to create a false correlation through internal consistency generated from a common source (Chang, 2010; Podsakoff, 2003).

There are four general methods often referred to in the literature that researchers should use to avoid or correct potential CMV that this research considered at the time the questionnaire was developed (Chang, 2010; Podsakoff, 2003). Firstly, the obvious step is to avoid any potential CMV in the research at the design stage. Using different sources in the construction of key measures helps. In particular, the independent and dependent variables should be constructed from different sources. Secondly, procedural remedies such as mixing the order of the questions and using different scales in designing and administering the questionnaire can help reduce the likelihood of CMV; thirdly, studies that included complex interactions and non-linear effects common with complicated regression models also reduce the likelihood of CMV, as participants are unlikely to intuitively map such difficult interactions. Lastly, there are statistical remedies to detect any CMV. A post hoc Harman one-factor analysis is often used to check if the variance in the data can be largely attributed to a single factor. 
All four methods were employed in this study. Questions for each construct were developed from similar but different previous studies ranging from 1997 through to 2013 .

Several questions were also mixed and a range of both 5- and 7-point Likert scales was used. The study can also be considered a complex model and required PLS-SEM analysis. Further, a post hoc Harman one-factor test was performed. Likert scales contributed to reducing CMV in two ways, firstly by using different scales for different questions, and secondly, by grounding participants against the industry by asking participants to consider their position against industry average. The majority of this survey's questions were asked in either 5- or 7-point Likert scales, which were also easy to rescale when the participants were asked if they strongly disagreed (1) or strongly agreed (5) or substantially below industry average (1) or substantially above industry average (7), respectively. CMV will always be a concern in a study that pursues a serial or casual nature, where one construct influences and leads to another. When the inter-construct correlations are high, a common concern is that it is CMV that has influenced such relationships. But this is not always the case, and this study is one such occasion where we not only accept strong correlations but anticipated that they would exist.

When one construct is casually influential against another it follows that they may in some way be measuring the same, or at least a similar, dimension (Bono, 2011; Cavana, 2001; Chang, 2010; Podsakoff, 2003; Zhang, 2012). In this study, the conceptual model is hypothesising that there is a serial path of mediation and that high correlations are further reinforcement of the underlying importance of the relationships that exist between constructs in the model.

\subsection{Data Collection Procedure}

\subsubsection{Sample selection}

As the purpose of this study is to examine the impact that both GM and networking (NWS and NWL) has on TP within the GGOS, traders from around the world were identified and targeted to participate in the survey. The International Grains Council Annual Conference (IGCAC) database was selected 
for this study due to its recognition as one of the industry's preeminent conferences (HighQuest, 2011; IGC, 2014).

All attendee's listed as "traders" on the IGCAC database that had provided email addresses were included in the potential participant list to undertake the survey. From this process, 900 potential participants were identified and a series of emails were sent. The survey itself was circulated via Qualtrics (online survey provider) by invitation to potential participants and follow-up emails to prompt them to respond.

The first emailing of the surveys included a personalised and confidential response connection so that any reminder emails could be managed on a mass scale, with those who had answered being removed from the list.

The software also allowed for other features. These were:

1. An anonymous connection to be emailed out.

2. The ability for respondents to invite additional participants. Whilst being mindful of snowballing issues, it was decided that this feature should be employed. Given the nature and underlying themes of the study, included networking, participants' network partners were considered to contribute to the study rather than take away from it. Furthermore, the ability to consolidate the strength of these relationship between variables, and/or test for reliability offset the concerns of snowballing.

3. In addition to personal reminders, the Australian Grain Industry body Grain Trade Australia assisted by emailing out to their database an endorsement to support the study.

The data collection period was a total of eight weeks, starting on 23 April 2014 through to 24 June 2014.

\subsubsection{Data collection}

All data was collected using the automated reporting function in the software. Response rates were monitored, with reminders being sent through the Qualtrics server bi-weekly. Once the data collection period closed, data was then downloaded in a CSV format to be coded for uploading into SPSS, for data 
cleaning and initial construct development through exploratory analysis techniques.

During the initial process, reverse score questions were also transformed in SPSS and a new variable was added with the initial coding, plus an " $R$ " indicating the reverse coding.

\subsection{Analytical Techniques}

\subsubsection{Exploratory and confirmatory factor analysis}

Preliminary coding and exploratory factor analysis was completed in SPSS with data transferred into SmartPLS for SEM structural model analysis to test the conceptual model developed in Chapter 3. Exploratory and confirmatory factor analyses are powerful statistical techniques. The techniques have both similarities and differences.

Exploratory factor analysis (EFA) and confirmatory factor analysis (CFA) are employed to understand shared variance of measured variables attributed to a factor or latent construct.

Despite their similarities, they are both conceptually and statistically distinct analyses. With EFA, the researcher has no need for preconceived ideas or hypotheses about which factors may emerge or which variables will load these factors, rather the goal is to maximise the amount of variance explained. By contrast, CFA evaluates a priori hypothesis and is largely driven by theory. A CFA analysis requires that the researcher has established hypothesis, the number of factors and whether or not these factors are correlated, and which variables load onto and reflect which factors. Various EFA and CFA benchmarks are shown in Tables 7 and 8. 
Table 7: EFA Benchmarks

\begin{tabular}{|c|c|c|}
\hline Criterion & Measures & Assessment \\
\hline $\begin{array}{l}\text { Central Limit } \\
\text { Theorem }\end{array}$ & $\begin{array}{l}\text { You can assume the } \\
\text { distribution is normal with a } \\
\text { large enough sample size. }\end{array}$ & If $n>30$, normality can be assumed. \\
\hline R-matrix & $\begin{array}{l}\text { Shows the correlation } \\
\text { between variables and helps } \\
\text { to visually identify which } \\
\text { ones may fit together as } \\
\text { factors. Also used to ensure } \\
\text { multicollinearity while } \\
\text { avoiding singularities. }\end{array}$ & $\begin{array}{l}\text { Multicollinearity has variables } \\
\text { correlating with } r>0.3 \text { with some } \\
r>0.8 \text {, but without singularities } \\
\text { where } \\
r=1 .\end{array}$ \\
\hline $\begin{array}{l}\text { Bartlett's Test of } \\
\text { Sphericity }\end{array}$ & $\begin{array}{l}\text { Indicates if } \begin{array}{l}\text { there is } \\
\text { correlation }\end{array} \\
\text { sufficient } \\
\text { between variables to proceed } \\
\text { with EFA. }\end{array}$ & $\begin{array}{l}\text { Significance should be } p<0.05 \text {. If } \\
\text { not, delete variable(s) with low } \\
\text { correlations. }\end{array}$ \\
\hline $\begin{array}{l}\text { Kaiser-Meyer- } \\
\text { Olkin Measure of } \\
\text { Sampling } \\
\text { Adequacy }\end{array}$ & $\begin{array}{l}\text { A ratio on a scale from } 0 \text { to } \\
\text { 1. Compares the sum of } \\
\text { partial correlations with the } \\
\text { sum of correlations and } \\
\text { provides an indication if the } \\
\text { dataset contains an adequate } \\
\text { sample for factor analysis. }\end{array}$ & $\begin{array}{l}<0.5 \text { inadequate } \\
0.5-0.6 \text { miserable } \\
0.6-0.7 \text { mediocre } \\
0.7-0.8 \text { middling } \\
>0.8 \text { meritorious }\end{array}$ \\
\hline Eigenvalues & $\begin{array}{l}\text { Measures how evenly the } \\
\text { variances in the sample is } \\
\text { distributed. Used in scree } \\
\text { plots to help identify factors. }\end{array}$ & $\begin{array}{l}\text { Values tending toward } 0 \text { are a } \\
\text { concern. They indicate the potential } \\
\text { presence of a singularity. }\end{array}$ \\
\hline Scree plots & $\begin{array}{l}\text { A graphical representation } \\
\text { of eigenvalues against the } \\
\text { variables. Used to help } \\
\text { identify factors. Can also } \\
\text { provide an indication of } \\
\text { severe outliers in the data. } \\
\text { Ideally used with } n>200 \text {. }\end{array}$ & $\begin{array}{l}\text { The inflexion point(s) indicate the } \\
\text { borderlines between factors. }\end{array}$ \\
\hline Kaiser's criterion & $\begin{array}{l}\text { Used with scree plots and } \\
\text { recommends the number of } \\
\text { factors present in the } \\
\text { analysis. }\end{array}$ & $\begin{array}{l}\text { Factors should only be considered } \\
\text { for retention with eigenvalues }>1 \text {. }\end{array}$ \\
\hline Factor rotation & $\begin{array}{l}\text { Helps to differentiate how } \\
\text { much the variables load onto } \\
\text { each factor by rotating the } \\
\text { axes so that each variable } \\
\text { loads primarily onto one } \\
\text { factor. }\end{array}$ & $\begin{array}{l}\text { Use an orthogonal rotation to show } \\
\text { uncorrelated factors, and an oblique } \\
\text { rotation if you wish to allow the } \\
\text { factors to correlate. Oblique } \\
\text { rotations should only be used if } \\
\text { there is a theoretical reason why the } \\
\text { factors may be correlated. }\end{array}$ \\
\hline
\end{tabular}

Source: Discovering statistics using SPSS: And sex and drugs and rock 'n' roll Field (2009). 
Table 8: CFA Benchmarks: PLS-SEM Measurement and Structural Model

\section{Benchmarks}

\begin{tabular}{|c|c|}
\hline \multicolumn{2}{|c|}{ Evaluation of the Measurement Model: Reflective Measurement Models } \\
\hline $\begin{array}{l}\text { Internal } \\
\text { consistency } \\
\text { (composite } \\
\text { reliability) }\end{array}$ & $\begin{array}{l}\text { Composite reliability should be higher than } 0.708 \text { (in exploratory } \\
\text { research, } 0.60 \text { to } 0.70 \text { is acceptable). Cronbach's alpha is a } \\
\text { conservative measure of internal reliability. }\end{array}$ \\
\hline $\begin{array}{l}\text { Indicator } \\
\text { reliability }\end{array}$ & $\begin{array}{l}\text { Indicators with outer loadings greater than } 0.40 \text { should be } \\
\text { considered. Indicators with outer loadings between } .40 \text { and } 0.708 \\
\text { should be removed if their removal increases the composite } \\
\text { reliability and AVE above the suggested threshold value. Indicators } \\
\text { with outer loadings higher than } 0.708 \text { should not be removed. }\end{array}$ \\
\hline $\begin{array}{l}\text { Convergent } \\
\text { validity (average } \\
\text { variance } \\
\text { extracted) }\end{array}$ & The AVE should be higher than 0.50 . \\
\hline $\begin{array}{l}\text { Discriminant } \\
\text { validity } \\
\text { (Fornell-Larcker } \\
\text { criterion and cross } \\
\text { loadings) }\end{array}$ & $\begin{array}{l}\text { An indicator's outer loadings on a construct should be higher than } \\
\text { all its cross loadings with other constructs. As per the Fornell- } \\
\text { Larcker criterion, the square root of the AVE of each construct } \\
\text { should be higher than its highest correlation with any other } \\
\text { construct. }\end{array}$ \\
\hline \multicolumn{2}{|c|}{ Evaluation of the Structural Model: Inner Model } \\
\hline $\begin{array}{l}\text { (Coefficients of } \\
\text { determination } R^{2} \text { ) }\end{array}$ & $\begin{array}{l}\text { PLS-SEM aims at maximising the } R^{2} \text { values of endogenous latent } \\
\text { variables in the path model. Thus, the objective is high } R^{2} \text { values. } \\
\text { In general, } R^{2} \text { values of } 0.75,0.50 \text { or } 0.25 \text { for the endogenous } \\
\text { constructs can be described as respectively substantial, moderate } \\
\text { and weak measure of fitness of the proposed model. }\end{array}$ \\
\hline $\begin{array}{l}\text { Predictive } \\
\text { relevance }\left(Q^{2}\right)\end{array}$ & $\begin{array}{l}Q^{2} \text { values larger than } 0 \text { indicate that the exogenous construct has } \\
\text { predictive relevance. }\end{array}$ \\
\hline $\begin{array}{l}\text { Size and } \\
\text { significance of } \\
\text { path coefficients }\end{array}$ & $\begin{array}{l}\text { In SmartPLS, bootstrapping can be used to assess the significance } \\
\text { of path coefficients. Path coefficients with a } \rho=.05 \text { or less can be } \\
\text { used to access path model mediation. If one of the indirect paths is } \\
\text { non-significant at the } \rho=.05 \text { or less, then do not test mediation. }\end{array}$ \\
\hline$f^{2}$ effect sizes & $\begin{array}{l}\text { The effect size } f^{2} \text { allows assessing an exogenous constructs } \\
\text { contribution to an endogenous latent variable's } \mathrm{R}^{2} \text { value. The } f^{2} \\
\text { values of } 0.02,0.15 \text { and } 0.35 \text { indicate an exogenous construct's } \\
\text { small, medium or large effect on the endogenous construct. }\end{array}$ \\
\hline Mediation & $\begin{array}{l}\text { In SmartPLS, direct, indirect and total effects within the inner } \\
\text { structural model are measured between factors and along paths. } \\
\text { The p-value tests the level of significance ( }<<.01 \text { or } p<.05 \text { ). The } \\
\text { variance accounted for (VAF) determines the size of the indirect } \\
\text { effect in relation to the total effect. The benchmark measurement } \\
\text { for the VAF are as follows; VAF }>80 \% \text { (Full mediation), } 20 \% \leq \\
\text { VAF } \leq 80 \% \text { (Partial mediation), VAF }<20 \% \text { (No mediation). }\end{array}$ \\
\hline
\end{tabular}

Source: A primer on partial least squares structural equation modelling (PLS-SEM) Hair, Ringle $\&$ Sarstedt (2014). 


\subsubsection{Path modelling and analysis using PLS-SEM}

SmartPLS was selected for running the Partial Least Squares Structural Equation Modelling (PLS-SEM) procedure. SmartPLS is a linear path modelling tool. SmartPLS was provided free over the internet and is a complete and comprehensive software application for estimating and reporting both the measurement model and inner structural model. In particular, in this research for PLS-SEM path models, for submission of results for mainstream academic purposes (Hair et al., 2014; Hansmann, 2004).

Structural equation modelling (SEM) is a second-generation multivariate data analysis method that effectively tests linear and additive causal models, providing confidence levels for structural relationships (Al-Gahtani, Hubona, \& Wang, 2007; Hair \& Sarstedt, 2011). SEM has provided a powerful analytical tool in marketing and management research, particularly for quantifying the causal-effect relationships between latent constructs (Hair \& Sarstedt, 2011). SEM emerged in marketing literature during the 1980s. The requirement to develop procedures to test theories and concepts has led to the development of the SEM approach (Hair \& Sarstedt, 2011). In terms of the robustness of estimations and statistical power, PLS-SEM is advantageous when working with small sample sizes (Hair, Ringle, \& Sarstedt, 2013).

While many researchers view PLS-SEM as equivalent to carrying out covariance-based SEM (CB-SEM) analyses, it also includes other unique and very useful functionality. PLS-SEM is a causal modelling approach aimed at maximising the explained variance of the dependent latent constructs. This is contrary to CB-SEM's objective of reproducing the theoretical covariance matrix, without focusing on explained variance. When properly applied, the method has many benefits not offered by CB-SEM (Hair \& Sarstedt, 2011).

The philosophical distinction between CB-SEM and PLS-SEM has been highlighted by Hair \& Sarstedt (2011). If the research objective is theory testing and confirmation, then the appropriate method is CB-SEM. In contrast, if the research objective is prediction and theory development, then the appropriate method is PLS-SEM. 
Conceptually and practically, PLS-SEM is similar to using multiple regression analysis. The primary objective is to maximise explained variance in the dependent constructs, but additionally to evaluate the data quality on the basis of measurement model characteristics.

Given PLS-SEM's ability to work efficiently with a much wider range of sample sizes and increased model complexity, and its less restrictive assumptions about the data, it can address a broader range of problems than CB-SEM.

Before the structural model estimates are examined, the reliability and validity of the measurement model should first be established (Hair \& Sarstedt, 2014). The next chapter provides an account of the procedures and benchmarks used in this study for both the outer measurement model and the reflective inner structural model.

\subsection{Chapter Summary}

This chapter has described research methodology to test the proposed conceptual model. The research design fits well with the research question. The design allows for the generation of data that can be analysed through very robust and powerful statistical procedures. A positivist quantitative approach is undertaken to test the proposed hypotheses. The details as to the survey design and analysis techniques are discussed, which help in analysing data in the next section. The completion rate of the questionnaire, as highlighted in the next chapter, was consistent with the piloting of the survey, and accommodated in the overarching design of this research. 


\section{Chapter 5: Data Analysis and Results}

\subsection{Introduction}

This chapter presents the findings from the analysis conducted on the proposed conceptual model, from the data collected from the online survey. The conceptual model was presented, together with hypotheses, in Chapter 3. This conceptual model proposes that NWs (NWS and NWL) mediate the association between GM and TP. This chapter analyses the data to examine the relationships proposed in Chapter 3. The following section then highlights response rate, followed by the sample characteristics section. Section 4 presents the measurement model and then the structural model results are presented in Section 5 .

\subsection{Response Rate}

Of the 900 potential participants to whom invitations were sent, 245 surveys were opened. Of these 245, 148 (60.4\%) did not answer any questions at all. Due to this perceived high rate of non-engagement, a follow-up telephone call was made to a number of those participants who had opened the survey but not answered any questions. The enquiries found that: (1) $42 \%$ said it just looked too long and they did not have the time, and did not complete the survey, with (2) $58 \%$ saying they intended to complete the survey (with $25 \%$ following though). Ultimately, the data comprising 78 respondents (those who completed all of part B) was used in the final analysis. The study meets the minimum sample size criteria of 75, having a maximum of six arrows pointing at any construct required for $80 \%$ power (Hair et al., 2014).

Earlier feedback during pilot testing confirmed that the questionnaire was considered long and would take approximately 15-20 minutes to complete. A compromise between shortening the questionnaire or a lower response rate was considered and the decision in favour of the latter was made. Given the potential serial nature the conceptual model proposes, a broader response of dimensions was given priority over sample size. During the piloting phase, feedback raised some concerns about Section D: participants were originally asked to list the initials of the five most important contacts (see Appendix 2) and to answer a 
series of questions relating to the relationships that existed among the partners, with both the candidates and each other.

Unfortunately, the concerns raised in the pilot study materialised and the base findings from Sections A to $\mathrm{C}$ were relied upon as the base data.

Specifically, the results from the survey showed that approximately $40 \%$ of participants that completed sections B and C still considered section D either too complicated or too sensitive to answer, the latter being thought to be the reason. Taking the lowest response rate for each section, Sections B, C and D had responses of 78 , dropping to 74 , dropping to 42 respectively. This is considered to be an interesting finding in itself, in that nearly $40 \%$ of our final sample did not complete this section. The conclusion drawn was based on feedback from the pilot period where those that piloted shared that they felt Section D was considered sensitive and doubted the sample would share this information. Our pilot participants were correct. It is not uncommon for sensitive information to reduce response rates (Cavana, 2001); however, adequate numbers for the purpose of this study were collected from other sections of the survey for the purposes of developing constructs to test the conceptual model.

\subsection{Respondent and Demographic Profiles}

The demographics of sample are presented in Table 9. Respondents predominantly identified themselves as grain traders (76\%), with oil traders and by-product traders making up the balance. Not surprisingly, given the international nature of the study context, $67 \%$ of participants considered themselves international rather than domestic traders. Nearly half of all participants were Australasian-based, with the balance made up from the rest of the world. Traders from Asia, the Middle East, Africa and Eastern and Western Europe were all represented, as were traders from both North and South America. Almost all respondents worked for companies at their head office, suggesting that perhaps trading may be something that is monitored closely by senior management of trading companies and not something generally performed from the outpost offices. 
Head office and trader location data mapped with a $\beta=.95$ and significant to the $p<.01$, so were considered to be measuring the same dynamic - the trader and the firm's head office location. These two are represented in Table 9 under the description location.

Table 9: Sample Characteristics

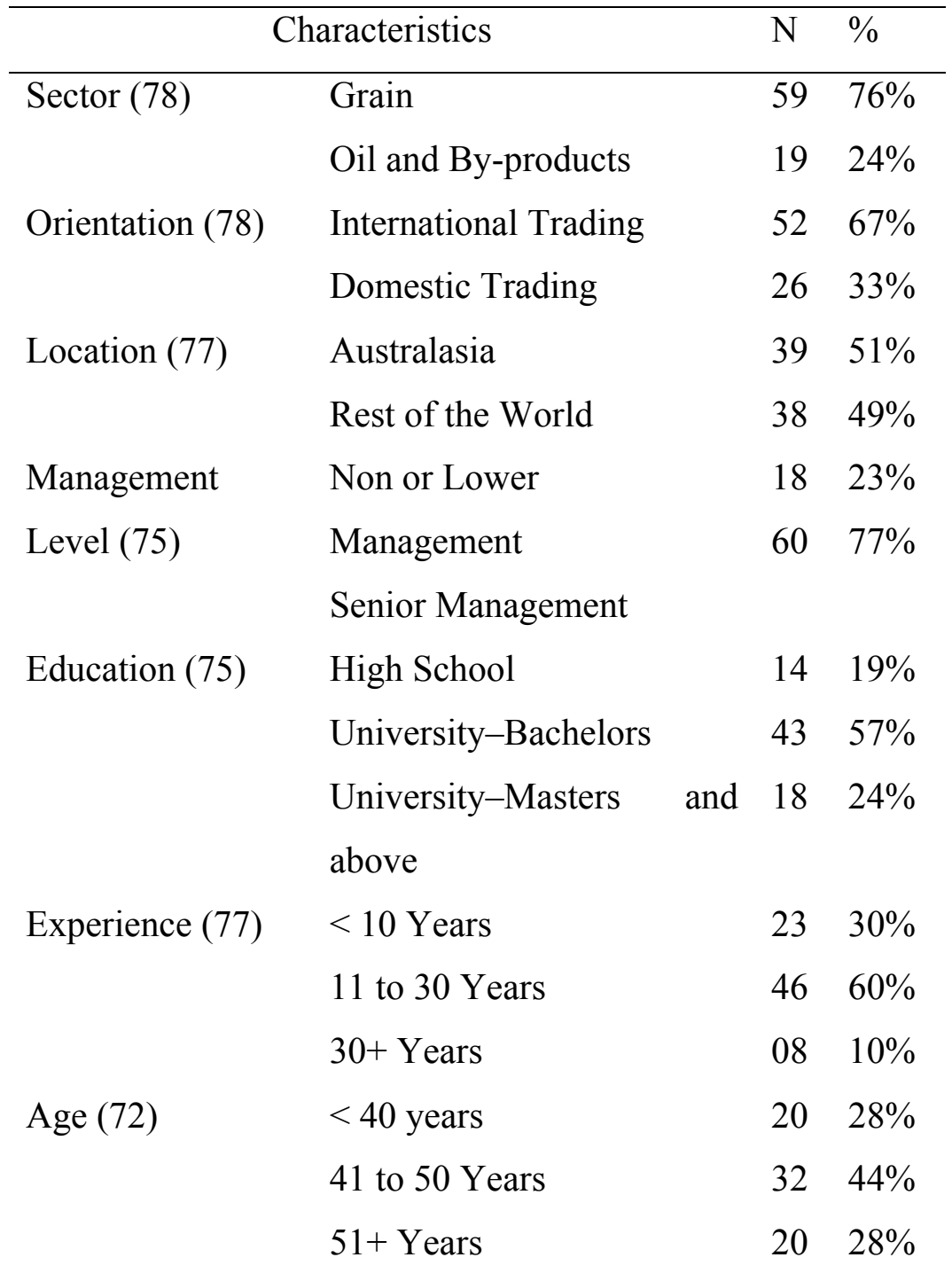

Note: Figures in parentheses denote the number of respondents $(\mathrm{N})$ for each characteristic 


\subsection{Evaluation of the Measurement Model}

The logic of using multiple variables to measure a concept is that the variance is more accurately accounted for. The improved accuracy stems from the assumption that using several indicators (variables) to measure a single concept (factor) is more likely to represent all the different aspects of the concept more completely than using fewer indicators (Hair et al., 2014). Table 10 details the results of the reliability and validity tests. These tests were performed through running a PLS algorithm; the settings were set to the default settings recommended by Hair; a maximum of 300 interactions and a stop criterion of 7 was used, with missing values being handled by casewise deletion (Hair et al., 2013).

Table 10: The Measurement Model

\begin{tabular}{ll}
\hline \multicolumn{1}{c}{ Constructs } & Loadings \\
\hline Global mindset $(\mathrm{GM}) \alpha=.73, \mathrm{CR}=.82, \mathrm{AVE}=.54$ & .72 \\
1. Enjoys international interaction & .75 \\
2. Friend of the world & .88 \\
3. International team player & .56 \\
4. Thrives and relies on diversity and multi-cultural relationships & \\
& \\
Network structure (NWS) $\alpha=.80, \mathrm{CR}=.86, \mathrm{AVE}=.51$ & .74 \\
1. NW size & .79 \\
2. NW diversity & .83 \\
3. NW closure and embeddedness & .52 \\
4. Framework 'pipes' interconnected-efficiency & .84 \\
5. Strong ties & .50 \\
6. Framework 'pipes' interconnected-diversity & \\
& .75 \\
Network leverage (NWL) $\alpha=.80, \mathrm{CR}=.86$, AVE $=.50$ & .72 \\
1. Positive flow via the NW & .67 \\
2. Growth of positive flow via the NW & .78 \\
3. Embedded strategic advantages over competitors via the NW & .65 \\
4. Efficient bridging resulting in strategic advantages via the NW & .64 \\
5. Superior bonding via the NW & \\
6. Superior market efficiency via the NW & \\
Trader performance (TP) $\alpha=.86, \mathrm{CR}=.90$, AVE $=.70$ & .83 \\
1. Growth in sales/turnover & .83 \\
2. Growth in profits & .88 \\
3. Growth in market share & \\
4. Expansion of client base & \\
&
\end{tabular}

Note: AVE $=$ Average Variance Explained, $\alpha=$ Cronbach's alpha, $\mathrm{CR}=$ Composite Reliability 


\subsubsection{Internal consistency (composite reliability)}

As highlighted by Hair et al. (2014), the first criterion to be evaluated is typically internal consistency. The traditional criterion and perhaps most widely accepted measure for internal consistency has been Cronbach's alpha. Cronbach's alpha provides an estimate of the reliability based on the inter-correlations between the model's predictor variables.

Cronbach's alpha has been criticised as a measurement when performing PLSSEM analysis as it assumes that all indicators are equally reliable (i.e. all the indicators have equal outer loadings on the construct) (Hair et al., 2014). However, PLS-SEM modelling prioritises the indicators according to their individual reliability. Moreover, Cronbach's alpha is sensitive to the number of items in the scale and generally tends to underestimate the internal consistency. As such, it can be used, and provides a conservative measure of internal consistency. Another method of measuring the internal consistency reliability better suited to PLS-SEM modelling is the composite reliability test. The composite reliability scores are considered acceptable when all scores are inside the recommended band of .70 to .90 , certainly $>.95$. (Hair et al., 2014). Both Cronbach's alpha and consistency reliability scores were acceptable; Cronbach's alpha scores ranged from $\alpha=.73$ for GM to $\alpha=.83$ for TP. The consistency reliability scores ranged from $\mathrm{CR}=.82$ for $\mathrm{GM}$ to $\mathrm{CR}=.90$ for $\mathrm{TP}$.

\subsubsection{Indicator reliability and convergent validity (average variance extracted)}

There are many potential sources of measurement error in social sciences research. Hair et al. (2014) argued that all measurements used in multivariate analysis are likely to contain some degree of measurement error; the objective, therefore, is to minimise this error as much as possible. Measurement error can be described as the difference between the true value of the variable and the value obtained by a measurement (Hair et al., 2014). Indicator reliability measures the factor loadings of the construct to determine the extent to which they are measuring the same phenomenon. Higher outer loadings on a construct indicate that the associated indicators have much in common. 
Ideally, the standardised outer loadings should be $>.70$. Communality (which is the square of standardised factor loadings should be $>.50$. However, Hair et al. (2014) argue that researchers should proceed with caution when rejecting indicators on the basis of loadings being $<.70$, arguing that often a strong case can be made for retaining weaker loadings; if they make theoretical sense and add to the overall discovery of the construct under investigation.

If loadings do make theoretical sense and add to the discovery being sorted, then loadings between .40 and .70 should be kept in the model unless their removal results in an increase in convergent validity measures above the required benchmark. Researchers frequently observe weaker outer loadings, especially when new scales are being developed. In this study, considering we were developing constructs that included multiple dimensions, factor loadings between .04 and .70 were considered on their own merits, with particular focus on how each theoretically contributed towards the overall theory of the construct it aimed to measure. Particular care was taken to ensure that all benchmarks were met and that the measurement model was robust. A total of 21 variables were loaded onto the factors developed in the conceptual model: GM (4), NWS (6), NWL (6) and TP (4). The average loading was .73, with the lowest being .50 and the highest being .88. All AVE values met the benchmark criteria of AVE $\geq .50$.

Convergent validity is the extent to which a measure correlates positively with alternative measures of the same construct. An AVE value of $\geq .50$ indicates, on average, that the construct explains more than half of the variance of its indicators (Hair et al., 2014). Furthermore, when testing a narrowly defined construct AVE can be measured with and without the variables that are below the desired .70 factor loading threshold. In such situations, if the AVE reduces or stays the same through deletion, then the lower factor loadings should be retained (Hair et al., 2014). This study is looking at multiple aspects of NWs in each of the two NW constructs, therefore meeting the benchmark AVE $\geq .50$ was the primary concern. The loadings $<.70$ that were retained fitted with theory and were considered to add to the measurement goals of the constructs within the conceptual model and were therefore retained. 
Furthermore, each construct satisfied the discriminant validity tests and so were empirically supported to be measuring unique phenomena (Hair et al., 2014).

\subsubsection{Discriminant validity}

Discriminant validity looks to explain the extent to which a construct is truly distinct from other constructs and is capturing unique phenomena not represented by other constructs in the model. One method for testing discriminant validity is an examination of the cross loadings of the indicators. An indicator's outer loading should be stronger against the construct it is representing than any other construct within the model (Hair et al., 2014).

Fornell-Larker Criterion is another method and a more conservative approach to assessing discriminant validity. The Fornell-Larcker Criterion compares the square root of AVE values against the latent variable correlations. Specifically, the square root of each AVE should be greater than the highest correlation with any other construct (Hair et al., 2014). Table 11 details that all four constructs from the conceptual model satisfy the Fornell-Larcker Criterion where the square roots of the AVEs for each is greater than the highest correlation with any other construct (Hair et al. , 2014).

Table 11: Fornell-Larcker Criterion

\begin{tabular}{|c|c|c|c|c|c|c|c|}
\hline & GM & MGT & NWL & NWS & $\mathrm{TP}$ & EXP & $\mathrm{LOC}$ \\
\hline GM & .74 & & & & & & \\
\hline MGT & .03 & $\mathrm{n} / \mathrm{a}$ & & & & & \\
\hline NWL & .26 & -.12 & .71 & & & & \\
\hline NWS & .31 & -.09 & .51 & .72 & & & \\
\hline TP & .22 & -.04 & .61 & .43 & .84 & & \\
\hline EXP & .15 & .27 & .18 & .19 & .07 & $\mathrm{n} / \mathrm{a}$ & \\
\hline LOC & .65 & .02 & .18 & .19 & .07 & .09 & $\mathrm{n} / \mathrm{a}$ \\
\hline
\end{tabular}

As a final test, a post hoc Harman one-factor test was run in SPSS to check whether the variance in the data can be largely attributed to a single factor. Common methods variance should not be an issue in this study, as the total variance explained was below the threshold of .50, measured at $34.4 \%$ (Chang, 2010). From the test performed in both SmartPLS and SPSS, we can confirm that 
all benchmarks for both reliability and validity of the outer measurement model were met and an evaluation of the inner structural model will be explained next.

\subsection{Evaluation of Structural Model}

Further to the PLS algorithm run to measure the outer model, bootstrapping and blindfolding methods were used to evaluate the hypothesised relationships within the inner structural model. The bootstrap was then performed. Subsamples were set at 5000 and sign changes were set to individual changes and bias-corrected and accelerated (BCa), as recommended by Hair (2013). Figure 9 and Table 12 details the results drawn from the PLS-SEM analysis.

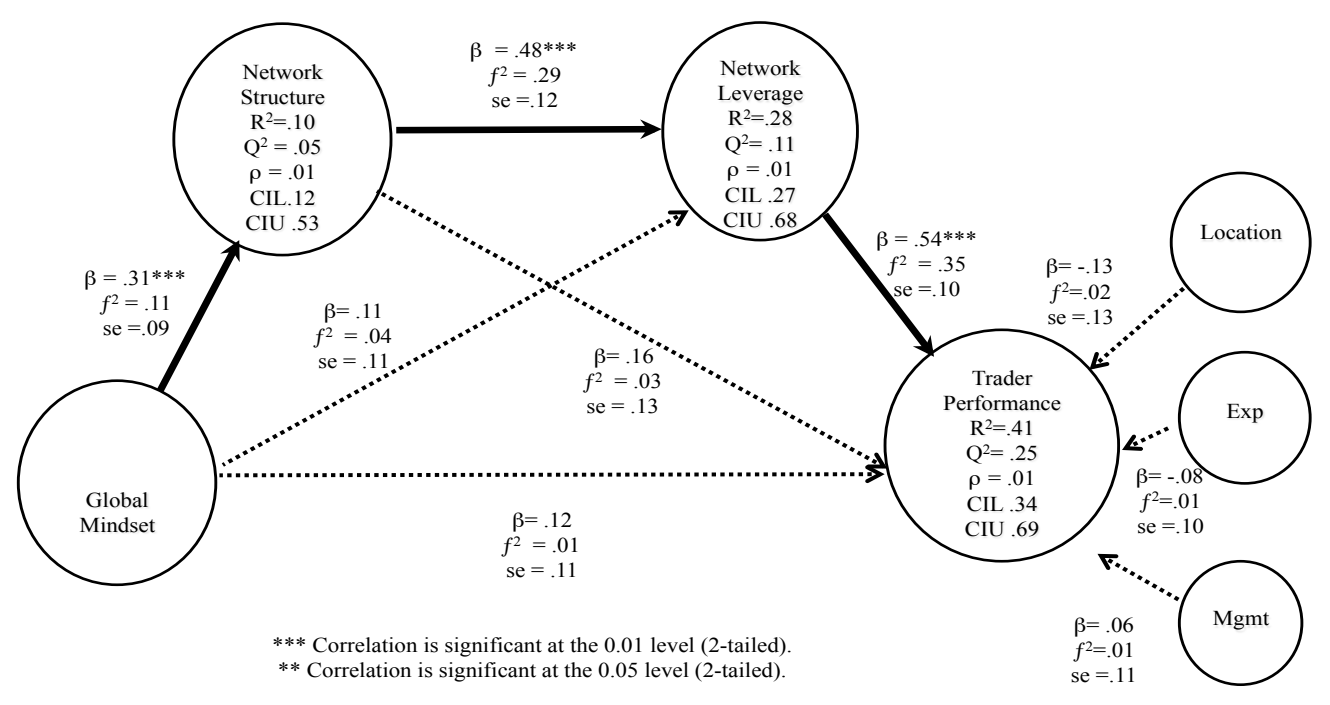

Figure 9: The Structural Model Results (Full Path Mediation)

The structured model results can be accessed using various benchmarks presented in Table 8. Measurements such as $\mathrm{R}^{2}, \mathrm{Q}^{2}, f^{2}$, path coefficients and standard errors. The results from the analysis confirmed full path mediation of a serial nature from $\mathrm{GM} \rightarrow \mathrm{NWS} \rightarrow \mathrm{NWL} \rightarrow \mathrm{TP}$, significant at the $\rho=.01$ level. 
The direct path coefficients are significant at the $\rho=.01$ level around the entire path of mediation and are expressed by a solid lines, whereby the remaining direct paths are neither significant nor expressing strong correlations and are represented by the broken lines. The non-significant direct paths shown by broken lines and significant direct and indirect paths (solid lines) indicate the full serial mediation detailed in Table 12.

As PLS-SEM aims to maximise the explained variance of the dependent variables. $\mathrm{R}^{2}$, also known as the coefficient of determination mesures the explained varience of the dependent variable. The $\mathrm{R}^{2}$ is a measure of the model's predictive accuracy (Hair et al., 2014). The TP $\mathrm{R}^{2}$ value of .41 implies that the model represents $41 \%$ of the explained variance in TP. In addition, the $\mathrm{R}^{2}$ has consistently improved throughout the path. The value was .10 as far as NWS, .28 continuing to NWL and .41 for TP confirming that the power of explained variance improved as each explanatory variable was serially included in the path. In addition, a blindfolding procedure was performed to obtain cross-validated redundancy $\left(\mathrm{Q}^{2}\right)$ measures for each endogenous construct. The $\mathrm{Q}^{2}$ measures how well the path model can predict the originally observed values (Hair et al., 2014). The settings were as follows: omission distance was 5, with maximum iterations set at 300 , and stop criterion set at 7 . The missing data algorithm to manage missing data was by casewise deletion. All $\mathrm{Q}^{2}$ values were greater than 0 , with $.05, .11$ and .25 for NWS, NWL and TP respectively. $\mathrm{Q}^{2}$ above 0 support that the exogenous constructs have predictive relevance for the endogenous construct TP in the structural model.

The effect size $\left(f^{2}\right)$ shows the practical relevance of path coefficients (Ellis, 2010). While path coefficients represent statistical significance, effect sizes provide the practical significance of the findings. The effect size $f^{2}$ assesses an exogenous construct's contribution to an endogenous latent variable's $\mathrm{R}^{2}$. The $f^{2}$ values of $.02, .15$ and .35 indicate an exogenous construct's small, medium, or large effect, respectively, on an endogenous construct.

The $f^{2}$ values are supported in this model with growing effect through the mediation, with findings of .11, .29 and .35, respectively (Hair et al., 2014). Interpreting these values obsrved in this study, the effect sizes starts the path at 
the smaller scale, but builds to medium effect and reaching large effect for the full path mediation, further endorsing the requirement of the full path for GM to have an optimum impact on TP.

However, the $\mathrm{R}^{2}$ values and $f^{2}$ values on balance could be described as having a medium serial path mediation effect, indicating that there are still other factors outside the model that also contribute toward the mediation between GM and TP.

Following testing the structural model's fitness criteria, and finding the full path mediation, the next task was to develop a more detail empirical understanding of two questions that arose: 1) whether the mediation is full or partial; and 2) whether mediation is significant. This can be established by testing the variance accounted for (VAF) in order to ascertain whether mediation is full or partial, as described in Exhibit 7.18 by Hair et al. (2014). The VAF determines the size of the indirect effect in relation to the total effect. This helps to explain the degree to which the variance of the dependent variable is directly explained by the independent variable and how much the construct's variance is explained by the indirect relationship through the mediator. The benchmark measurements for the VAF presented in Hair et al. (2014) are as follows: VAF $>80 \%$ (full mediation), $20 \% \leq \mathrm{VAF} \leq 80 \%$ (partial mediation), $\mathrm{VAF}<20 \%$ (no mediation). Direct, indirect and total effect results were collected from the bootstrapping output, along with path $\rho$ values explaining the level of significance for each path and presented in Table 12.

\subsection{Evaluation of hypothesis}

The results presented in Table 12 confirms the full path mediation proposed in the concpetual model. However, paths hypothesised in H1 and H2 $\mathrm{GM} \rightarrow \mathrm{NWS} \rightarrow \mathrm{TP}$ and $\mathrm{GM} \rightarrow \mathrm{NWL} \rightarrow \mathrm{TP}$, neither of these paths were stateistically significent so no mediation conclusions can be drawn (Hair et al., 2014). These results provide further support the full path is required for mediation between GM and TP. In that the paths predicted in $\mathbf{H 1}$ and $\mathbf{H} 2$ non-significence suggests there is likely the existence of other mediators in these paths; for instance, NWL being the additional mediator required in the first path and NWS being the other mediator required in the second path. 
Furthermore, the direct paths between GM pointing to NWL and TP both have relatively modest non-significent betas of $\beta=.11$ and $\beta=.12$, respectively.

H1: NWS mediates the association between GM and TP

The path was non-significent, therefore the null hypothesis is accepted, NWS alone does not mediate the relationship between GM and TP.

H2: NWL mediates the association between GM and TP

The path was non-siginificent, therefore the null hypothesis is accepted, NWL alone does not mediate the relationship between GM and TP.

NWS is significantly mediating the association between GM and NWL and is significant to the $\rho=.01$ level. NWL is significantly mediating the association between NWS and TP and is also significant to the $\rho=.01$ level. The power of the conceptual model is therefore explained through the serial path $\mathrm{GM} \rightarrow \mathrm{NWS} \rightarrow \mathrm{NWL} \rightarrow \mathrm{TP}$, showing full serial path mediation that is significant at the $\rho=.01$ level.

The visual structural model detailed in Figure 9 illustrates the significent path at the $\rho=.01$ level and provides the $\beta$ 's, firstly, GM to NWS, and then NWS to NWL, and NWL to TP. Furthermore, the $\mathrm{R}^{2}$ increases collectively as the path's move from start to finish. The indirect effects between GM and TP are .19 and significent to the $\rho=.01$ level. The VAF scores supported partial mediation along the path. Full mediation according to Hair et al. (2014) requires a VAF $>.80$, this study reported on the full path a $\mathrm{VAF}=.62$, and scores of $\mathrm{VAF}=.58$ and $\mathrm{VAF}=.62$ for the split paths $\mathrm{GM} \rightarrow \mathrm{NWS} \rightarrow \mathrm{NWL}$ and $\mathrm{NWS} \rightarrow \mathrm{NWL} \rightarrow \mathrm{TP}$, respectively. Therefore mediation is partial, indicating that there are other variables outside of the model mediating the relationship between GM and TP in addition to NWS and NWL.

Table 12 confirms all indirect and total effects are significent to the $\rho=.01$ level, with the exception of the indirect effect between $\mathrm{GM} \rightarrow \mathrm{NWS} \rightarrow \mathrm{NWL}$ which is significent to the $\rho=.05$ level. This path also had the lowest VAF score, VAF $=.58$. In addition the lowest $\beta=.31$ significant to the $\rho=.01$ level and $\mathrm{R}^{2}$ around the mediation path occurred between GM and NWS. 
Therefore, the relationship between GM $\rightarrow$ NWS would be a logical place to start to look for further explained varience.

H3: NWL mediates the association between NWS and TP

The indirect and total effect results presented in Tabe 12 confirm partial mediation significent to the $\rho=.01$ level. Therefore the null hypothesis is rejected in favor of the alternative hypothesis. NWL does mediate the relationship between NWS and TP.

H4: NWS and NWL have serial mediation effects on the association between GM and TP.

The indirect and total effect results presented in Tabe 12 confirm partial mediation significent to the $\rho=.01$ and $\rho=.01$ level, respectively. Therefore the null hypothesis is rejected in favor of the alternative hypothesis and it is empirically confirmed that there is full path mediation present between GM and TP serially through NWS and NWL, respectively.

Table 12: Direct and Indirect Effects of the Mediation Paths

\begin{tabular}{|l|c|c|c|c|}
\hline \multicolumn{1}{|c|}{ Mediation Paths } & Direct Effects & $\begin{array}{c}\text { Indirect } \\
\text { Effects }\end{array}$ & $\begin{array}{c}\text { Total } \\
\text { Effects }\end{array}$ & $\begin{array}{c}\text { Variance Accounted } \\
\text { For (VAF) }\end{array}$ \\
\hline $\mathrm{GM} \rightarrow \mathrm{NWS} \rightarrow \mathrm{NWL}$ & .11 & $.15^{* *}$ & $.26^{* * *}$ & .58 Partial mediation \\
\hline $\mathrm{NWS} \rightarrow \mathrm{NWL} \rightarrow \mathrm{TP}$ & .16 & $.26^{* * *}$ & $0.42^{* * *}$ & .62 Partial mediation \\
\hline $\mathrm{GM} \rightarrow \mathrm{NWS} \rightarrow \mathrm{NWL} \rightarrow \mathrm{TP}$ & .12 & $0.19^{* * *}$ & $0.31^{* * *}$ & .61 Partial mediation \\
\hline $\mathrm{GM} \rightarrow \mathrm{NWS} \rightarrow \mathrm{TP}$ & No mediation, one of the indirect paths non-significant \\
\hline $\mathrm{GM} \rightarrow \mathrm{NWL} \rightarrow \mathrm{TP}$ & No mediation, one of the indirect paths non-significant \\
\hline \multicolumn{4}{|l}{} \\
\hline
\end{tabular}

With the VAF scores detailed, the model supports partial mediation, indicating that there are other potential mediators that are also mediating the relationship between GM and TP. The inclusion of influential control variables allow the researcher to draw more meaningful conclusions about the relationships that exist within the model and also identify other mediating influences to add to the overall predictive power of the inner model. For such inclusion, control variables should meet three conditions. Firstly, the researcher should expect that the 
control variable will be correlated with the dependent variable through theory or past empirical results. Secondly, the researcher should expect that the control variables will be correlated with the hypothesised independent variable(s). Thirdly, there is a logical reason that the control variable is not a more central variable in the study, either a hypothesised one or a mediator (Bono et al., 2011). Accordingly, three control variables, namely experience, management level and location were included in the model. No control variables were statistically significant, location had the strongest $\beta=-13$ indicating that that the power generated from the model came from the explanatory varibales GM, NWS and NWL and the serial nature through which they work in explaining varience in TP.

\subsection{Chapter Summary}

The most compelling academic finding of the section, which also has profound practical implications, was the serial mediation effects explaining the relationships developed in the conceptual model. This relationship defines that GM influences NWS, and that superior NWS increases the ability to leverage benefits from networks, and these culminatively lead to superior TP. From a trader's perspective, this research provides the statistical rigour and empirical support for the connections between the constructs and strategic options available to traders in the GGOS. The next chapter discusses the findings in light of the relevant literature. 


\section{Chapter 6: Discussion and Conclusions}

\subsection{Introduction}

This chapter brings the study to its conclusion. A discussion of the findings of the study will be conducted first, with reference to the connections between both GM and TP, and the mediating role that networks play in determining the outcome GM has on TP. The findings are discussed in light of the related literature. Research contributions and implications are discussed next, followed by a concluding section.

\subsection{Discussion of the Findings}

The most notable finding of this study is that superior GM does not lead directly to superior performance; rather, these findings support the position of Raman et al. that GM is mediated through other mechanisms - in this case, NWS and $\mathrm{NWL}$ - and it is this complete serial path that is required to transform a trader's superior GM into superior performance.

\subsubsection{GM and Performance}

Raman et al. (2013) highlighted the need for researchers to develop a better understanding of how GM influences performance and in the same article suggested that this underdeveloped area would be well served by specifically looking at network and partner selection against performance. This study has picked up on this direction, with the results building on Raman's and others work in the field (Chen, 2013; Javidan \& Walker, 2012; Kedia et al., 1999; Levy et al., 2007; Nummela et al., 2004) contributing to both GM and NW theory, particularly the impact of these on performance.

\subsubsection{GM and NWS}

Social capital theory is the grounding field of research that links the GM literature with NWs literature (Burt, 2000; De Carolis et al., 2009; Javidan et al., 2010; Maurer \& Ebers, 2006; Musteen et al., 2010; Nahapiet \& Ghoshal, 1998; Raman et al., 2013; Stam et al., 2014). NWS was introduced in the literature 
review as equivalent to being the "hardware" behind the network: the structural arrangement comprising of the nodes that make up a network and the ways in which these nodes are connected both directly and indirectly.

The conceptual model developed in this study consequently focused on four previously identified elements from the literature to represent NWS, namely (1) the strength of relationship ties, (2) structural holes, (3) non-redundancy, and (4) central network position.

The findings presented in this research are consistent in that strong ties, structural holes, non-redundancy and central position are all components that lead to a strong NWS with high efficiency (Burt, 1992; Coleman, 1988; Granovetter, 1973; Krackhardt, 1992; Nelson, 1989; Rost, 2011). That is, traders in the GGOS who characterised their NWS in this way achieved superior performance. An analysis below of the findings from this study for each of the four elements is compared independently with previous studies.

\subsubsection{Relationship tie strength and GM}

This study found that superior GM leads to the construction of superior network structure. Central within this link is that superior GM assists the trader to develop strong relationship ties with useful network partners. Literature supports that through superior GM the trader has a cosmopolitan view and is more likely to attract both a more diverse and useful group of people, and possess the personal attributes and cognitive complexities that assist in developing strong relationships and incorporating trust and understanding with useful network contacts. In doing so, those partners become increasingly motivated to assist the trader when called upon for assistance (Burt, 1992; Burt, 2000; Granovetter, 1973; Javidan \& Walker, 2012; Nelson, 1989; Raman et al., 2013; Rhinesmith, 1992; Rost, 2011; Story \& Barbuto, 2011; Vogelgesang et al., 2014).

Studies that have been completed in the area of relationship ties notably often referred to Granovetter (1973) for his work on "The Strength of Weak Ties" and Nelson (1989) for his titled "The Strength of Strong Ties", at first appearance fundamentally support opposing views on the importance of relationship strengths. 
On closer examination, our findings support the views surrounding strong ties of both authors, insofar as both acknowledge that those we hold strong ties with are more useful and motivated to assist their partners, providing both information and use of external resources when assistance is asked for. As it applies to the importance of strength in weak ties, this study found no support for the proposition of advantage through weak ties, and appears to refute the findings of Granovetter et al. concerning their importance.

The argument for strength of weak ties lies in their potential for delivering novel information that is unlikely to be sourced through an actor's strong ties for reasons of homogeneity between strong relationship ties (Granovetter, 1983). This noted, and reflecting the findings of this study, it is conceivable that traders are still able to access novel information from those lesser known or unknown indirect connections within the greater network through the strong ties. This point will be further clarified when discussing the remaining components of networking.

\subsubsection{Central network position and GM}

The structural position within the network can both enhance and detract from the ability of traders to extract benefits from their networks. This study found support for the premise that those with superior GM are more likely to stand in central positions within their networks. Both the GM and NW literature supports that holding a central position within the network provides the trader with more control and benefits not available in either abundance or diversity from the periphery. From a resource-base theory perspective, neither information nor resources are distributed evenly within a network and those more centrally placed individuals have access to a greater number of alternatives (Barney et al., 2001; Yu \& Chiu, 2013). A downside of holding a central position (and highlighted in relevant networking literature) is that it is time-consuming and costly (Yu \& Chiu, 2013). This may be a legitimate concern for those traders who have a propensity to focus on quantity rather than quality when managing relationships; however, that does not appear to be the case with traders within the GGOS who possess superior GM. 


\subsubsection{Structural holes and GM}

On the dimension of quality of relationships, Burt (1992) questioned whether relationship strength had any relevance to successful networking, instead suggesting that those standing over structural holes are at a higher risk of receiving both good ideas and potential opportunities across the network.

The GM literature holds that traders with superior GM have larger and more diverse networks. It would also then be logical that those traders with superior GM would have larger, more diverse networks, and therefore more opportunity to identify structural holes across their networks.

The findings support that; indeed, superior GM is strongly correlated with network diversity, which is the essential precursor to the development of structural holes (Javidan \& Walker, 2012; Rhinesmith, 1992; Story \& Barbuto, 2011). The GM literature is abundant in that it links with the actor's interest and also ability to attract a diverse set of network partners. Rhinesmith highlighted that those with superior GM look at the bigger, broader picture, value diversity and multicultural exchange, and are open to new ideas. Story and Barbuto (2011) connected GM with outcomes such as trust and member relationship quality. This study's findings align with those supporting the premise that traders with superior GM would have superior access and diversity within potential network partners, which would naturally lead to more potential structural holes and the superior cognitive attributes to know what to do with such information and opportunities when presented.

\subsubsection{Non-redundant network contacts and GM}

Picking up on another dimension of relationship qualities of networks, Dubini and Aldrich (1991) acknowledge that while it is important to maintain solidarity and cohesiveness with useful network partners, it is equally important to pay attention so that the network does not have too many overlaps. Burt (1992), building on non-redundancy theory, added that when two contacts lead you to the same network cluster of contacts - assuming neither has another unique offering in other ways - the result is that the network is fattened rather than strengthened. 
This study included questions within the survey that are aimed at aligning with non-redundancy, and although the dimension is not distinctly isolated it can be argued that the findings support that high non-redundancy within the network leads to superior NWS. What is definitive within the study's findings is that those traders with superior GM developed superior NWS, which in network theory includes high non-redundancy of their respective networks. Consequently, the theories of both Dubini \& Aldrich (1991) and Burt (1992) on nonredundancy, although written over 20 years ago, have largely been unchallenged and from the perspective of this study appear to hold today.

The central finding in this study linking to the proposition associated with nonredundancy is that traders who possess superior GM will develop a larger diverse group of network partners and will be better able to identify structural holes than those with inferior GM.

\subsubsection{GM, NWS and NWL}

With GM and NWS explained in the previous section, this section builds on the serial nature of this networking process, continuing to explain how superior NWS lays an optimal foundation from which the trader can leverage superior benefits from the network, and how superior GM further intensifies this leverage potential.

\subsubsection{GM, NWS and flow}

If the NWS is the configuration of pipes that connect actors within a network, flow is what runs through those pipes (Borgatti \& Halgin, 2011). To the GGO trader, flow is the benefits exchanged between network partners or the information or external resources made available to the trader through the network. The GGOS is a high-value, knowledge-intensive industry, and traders within this sector extract benefits both of information and access to external resources from the network. In alignment with Chen (2013), who found that GM, social networks and alliances were significantly related to performance, this study found that traders with superior GM developed superior NWS and, in compounding these two superior attributes, intensified the ability for traders to extract a superior flow of benefits from the network. 
Further extending Chen's work, who found that international alliances were required to link superior GM and social networks with performance, this study detailed that it was the action taken i.e. the process of leveraging benefits from the network, that lead to superior performance rather than the NWS itself. In this context, GM has the opportunity to make further contributions along the serial path observed in this study toward TP post the development of superior NWS.

\subsubsection{GM, NWS and bridging}

NWL, and in particular bridging, defines action within the network: without leverage the network would be a static, structural form that would not yield benefits. In theory, bridging is the process of brokering influence that results in the superior flow of both information and resources, primarily through identifying and spanning structural holes (Burt, 1992; Kalish \& Robins, 2006; Krackhardt, 1995; Shipilov \& Li, 2008; Zaheer \& Bell, 2005). As stated by Burt (2004, p. 349), “Compensation, positive performance evaluations, promotions, and good ideas are disproportionately in the hands of people whose NWs span structural holes". Those who bridge structural holes will gain earlier access to a broader diversity of information and have an advantage in detecting and developing rewarding opportunities. Burt (2004) argued that through bridging, their advantage is information arbitrage.

\subsubsection{GM, NWS and bonding}

The function of bonding examines how different actors within the network are connected and the dynamics of power between partners. Explained by Borgatti \& Halgin as the relational structure of the actors. Coleman's (1988) work on network closure provided insight into how two weaker actors can unify forces to restrain a powerful self-serving partner. The flow of resources through the network and the relationship between dependence and power is well supported in the RBV and RDV literature (Barney et al., 2001; Combs et al., 2011; Emerson, 1962; Esteve-Pérez \& Mañez-Castillejo, 2008). The concentration of power in the GGOS means smaller traders will likely be reliant on both large buyers and suppliers that control superior resources, and this reliance on those resources creates a potential dependency that could be exploited by those stronger actors 
(Esteve-Pérez \& Mañez-Castillejo, 2008). As a component of the NWL construct from the conceptual model and tested through the results of the survey, this study supports that those traders with superior GM and NWS will better manage these dynamics than those with inferior GM and NWS. The group dependency explanation detailed in Figure 5, and offset dependency gained through network closure as illustrated and Figure 6 provide those traders in the GGOS with potential options to rally support among their ranks to dilute the power of the $\mathrm{ABCD}$ and other large MNEs as a strategy to competitive advantage. It may indeed be critical that they work together in this manner, providing at least the illusion that they have a degree of unification and that opportunistic behaviour towards one member would likely result in consequences from others.

\subsubsection{GM, NWS, NWL and TP}

With the serial nature proposed in the conceptual model, moving through the constructs from GM, leading to NWS, leading to NWL already explained, this section concludes the final step, the central research question, which is how GM and networks influence TP. Essentially, it can be described as a compounding effect, which reinforces the strong relationship between NWL and TP. Although GM and NWs do not explain all the statistical variance of TP outright, the serial path completing through the intersection of NWL and TP provides insight into the accumulative power of GM and NWs, although it would be difficult to debate that superior GM versus inferior GM in almost all settings would provide a superior outcome.

This study provides empirical evidence that GM and NWS alone will not lead to superior performance; superior performance is obtained by turning potential into reality through leveraging access to superior resources. In the context of this study, a trader's NWS determines the scope of the external resources available and the degree and efficiency to which the trader has access to them. It is the final step, however, the actions of the trader to leverage benefits from the network, which connects the GM and NWS of the trader to superior TP. The mediating role that the two dimensions of networking plays between GM and TP will be discussed next. 


\subsubsection{Full path mediation}

GM and NW literature overlap in social capital theory (Bowen \& Inkpen, 2009). It is therefore logical that superior GM, a form of social capital, would positively influence networks, another form of social capital. What at first appearance may not appear to follow logic so explicitly is that traders with superior GM do not directly enjoy superior TP when compared with those with inferior GM. Therefore, traders in the GGOS cannot depend on their GM alone to improve their performance. Rather, traders need to consider a broader, holistic approach that encompasses mediating dynamics as a path toward superior performance. This study found that GM and TP are indirectly linked through a full path of mediation via NWS and NWL. Furthermore, this path is serial in nature, and requires all four constructs from the conceptual model to translate superior GM into superior performance.

Those traders with superior GM would be expected to build more useful relationships with greater diversity than those with inferior GM. Bowen and Inkpen (2009), by way of example, argue that those with superior GM have abilities to show others empathy and are better able to emotionally connect with others from all parts of the world and build trusting relationships. Embracing supporting literature and the findings of this study, it is argued then that those traders with superior GM have, by default, superior NWS to those with inferior GM. It is also argued that they would then have the ability to leverage superior benefits from superior their NWS than those that have inferior GM.

Therefore, the path linking GM and TP is explained: those traders with superior GM develop superior NWS, which collectively assists the traders to leverage superior benefits from the network, which ultimately translates into superior TP. Not only does this argument have theoretical support, but it also has also gained empirical support in this study.

Full path mediation is confirmed statistically significant to the $p=.01$ level through the serial path proposed in the conceptual model: GM $\Rightarrow$ NWS $\Rightarrow$ NWL $\Rightarrow \mathrm{TP}$. 


\subsubsection{Control variables}

Three control variables were employed by the study. These were: (1) location; (2) management level; and (3) trader experience. No control variables were statistically significant at the desired $p<.05$ level with TP. It was therefore decided to choose control variables that might logically impact TP and the conceptual model. Considering the concentration of the industry from both the perspective of origin of commodities available for export and the concentration of importers detailed in Chapter 2, location was thought to potentially influence the outcome of traders; equally their market experience and level of management could logically be influential. Although location had a $\beta=-.21$ and management level had a $\beta=.11$, as mentioned neither were statistically significant, so no inferences were made about the impact they might have.

\subsection{Research Contributions and Implications}

\subsubsection{Contribution to theory}

A central purpose of the present study was to draw the various components of network theory - consisting of resource-based view (RBV), transaction cost theory, and of particular importance in this study, social capital theory - together and align with GM theory. Through the conceptual model developed, the study could test how each singularly and accumulatively influences performance, where conclusions could be drawn from the empirical analysis.

The study makes two main contributions. Firstly, the study endorses the critical role of GM in enhancing performance of both MNE and SME traders in the GGOS.

Most of the current studies have focused on GM and large firms; this study focused more on the smaller firms. Secondly, the study provides a deeper understanding of how GM enhances performance, and the mediating role of NWS and NWL in explaining the relationship with performance.

Current research has mainly suggested single mediation of partnership quality (Raman et al., 2013). This study goes a step further and includes NWL into the argument adding further clarification to the dynamics at play and helping to 
further reconcile some of the inconsistencies that exist within the extant GM and NW literature.

Within NWS, all four components, namely (1) the strength of relationship ties, (2) structural holes, (3) non-redundancy and (4) central network position, appear to hold importance. The finding that strong ties was supported parallels the extant literature arguing the importance of strong ties (Krackhardt, 1992; Nelson, 1989; Raman et al., 2013; Rost, 2011; Zhou et al., 2007). Running against the strength of ties literature, one inconsistency was found. The strength in weak ties appears to have been overstated in the literature. This stream developed originally by Granovetter (1973) was built on the premise that weak ties were the primary source of novel information, as those with whom we hold strong ties generally know what we know and who we know. The findings of this study argue that traders can still access novel information through strong ties, provided they stand in a central position between non-redundant partners and exploit structural holes across the network.

Granovetter (1973) in arguing his support for weak ties acknowledged that those with whom we have strong ties have a higher motivation to help when asked. The findings of this study go further and suggest that rather than it being the strength of ties that dictates the speed and volume in which the trader gains access to novel information, it is actually the more centrally positioned the trader is within the network that provides them with both more options and faster access to information or other external resources (Granovetter, 1973; Yu \& Chiu, 2013).

Network size and diversity are the precursors to both non-redundancy and structural holes, both of which work together by virtue of the fact that the more non-redundant cluster groups the trader has access to, the greater the number of structural holes between clusters.

This theory argues that provided the trader selects an important central figure from each cluster to act as a portal to that cluster and develops a strong trusting relationship with that partner, that partner can provide them with access to that group in a more meaningful way than the trader themselves could likely achieve 
directly. Our findings align with theory and endorse the work of Burt and the extant literature surrounding the theories of structural holes and the benefits of non-redundant relationships (Burt, 2004; Burt, 1992; Dubini \& Aldrich, 1991; Granovetter, 1973; Krackhardt, 1995; Müller-Seitz, 2012).

NWL is the fluid link between NWS and TP: the NWS itself is a static, structural form through which resources in all forms flow. The failure of past studies to consider networks in this complete multidimensional process, or to only consider one aspect of networking, such as the strength of relationship ties (Granovetter, 1983; Granovetter, 1973; Nelson, 1989), accounts for inconsistencies found within the networking literature. This study contributes to the networking literature by reconciling some of these inconsistencies.

While Burt (1992) acknowledges the literature supporting weak ties in that they are more likely to present structural holes than closely held strong ties, we found no link supporting weak ties in our findings in any capacity. Conversely, GM, NWS and NWL in this study aligned with strong ties. GM literature is rich in attributing superior cognitive complexities to those with superior GM, as opposed to those with inferior GM, meaning these individuals are more intelligent and can decipher information quickly and understand what is going on around them. Firstly seeking to understand, even when they don't speak the same language, they are empathic and intuitive towards body language and, having a cosmopolitan view of the world, relate to many cultures. With such outwardfacing characteristics, they develop strong trusting relationships easily, compared with those with inferior GM (Bowen \& Inkpen, 2009; Javidan et al., 2010; Levy et al., 2007).

Having already established that those with superior GM develop more superior NWS than those with inferior GM, it makes theoretical sense that these traders with superior GM would also have more superior bridging and bonding skills than those with inferior GM. Bonding, for example, is often a function of the power of alternatives - those with more options, by way of network partners to choose from, have power when other partners have limited options (Borgatti \& Halgin, 2011; Coleman, 1988). 
Considering that those with superior GM have more network partners from diverse backgrounds, where many are likely to be also trusted allies, it also makes theoretical sense that these people would also have a higher chance of having more options to choose from than those with inferior GM when turning to the network for assistance.

\subsubsection{Managerial implications}

In addition to the theoretical contributions already explained, the managerial implications offer new insights for managers and traders in the GGOS. The study provides a number of important contributions to understanding the conceptual and empirical relationships that exist between GM, NWS and NWL and how these serially lead a trader to superior performance. Specifically, besides working to develop a superior GM, which should be a given for any industry professional, traders can benefit from applying the rules of engagement based around networking developed in this study. How do traders construct a superior network structure? Following that, how can traders leverage superior benefits from that structure?

The answer lies in ensuring efficient use of time by selecting partners that are non-redundant so that they provide benefits of a unique kind, either by way of the network cluster they are associated with or by way of other benefits they provide the trader. Traders also need to ensure that they are centrally positioned between these key contacts that act as portals to the defined cluster groups identified in the network and build strong supporting relationships within these portals.

Once attention to the NWS is understood and optimised, the trader can look to broker opportunities through bridging. The flows that are generated through the network come from the NWS and bridging opportunities develop new and additional pipes through which new and beneficial resources can flow to the trader. Being aware of power balance and opportunistic nature of certain partners from the bonding perspective when positioned between strong partners, traders should not encourage network closure between the parties, as standing between two more powerful contacts directly connected creates weakness, not strength. 
Creating other options with equally powerful alternatives neutralises the power of the considered threat.

\subsection{Limitations and Future Research}

As with all empirical research, this study carries certain limitations. These limitations should be considered when interpreting and applying the study's findings. While the findings may have practical relevance to many industries, this study's results are limited to GGO traders.

Furthermore, the GGOS consists of more than just traders and the sector is experiencing a shift of both incumbent and new entrant stakeholders up and down the value chain; outside commodity sectors, such as energy traders, supermarkets and large food processors, are wading in on trading environments within the GGOS. This study is limited to traders within the GGOS, but cannot exclude the relevance across the entire value chain; that is, a limitation and generalisation across the broader sector must be made carefully and a concern held for external validity (Cavana, 2001). This broader perspective that includes all potential stakeholders is an area that invites future research to gain a deeper understanding of this industry transformation underway. To test whether the findings of this study hold across this broader population involved in the sector would provide further insight into both the industry itself, but equally to theory, in particular GM and NW theories.

A potential source of common methods bias was that the online survey instrument used for data collection was completed by the same participants for both the independent and dependent variables. However, every precaution was taken to minimise this risk and, based on the common methods variance tests, it can be argued that the findings are not at risk of common methods bias (Cavana, 2001). The questionnaire was also considered long by many, in that it took 15 to 20 minutes to complete. This reduced the response rate and overall sample size.

Whilst the sample size is relatively small in comparison with the total market, the snowball efforts applied helped bolster the numbers to an acceptable response for the purposes of the study; although, the snowballing approach itself is a limitation in that it may create sampling bias (Cavana, 2001). 
However, given the nature of this study, and that the networks of the traders were themselves of central focus of the study, the snowballing could be argued to contribute more than it could take away from the study.

A final aspect that is seen as a potential limitation is the longitudinal aspect that could be considered when studying networks. This study invites a longitudinal study to extend on the findings and networking instruments introduced in the study against the sector.

This would be interesting, given the changes taking place within the sector, along with the business life cycle where traders' requirements from the network change over time. Other potential areas of interest that this study raises are the other influencing variables that contribute to superior performance - GM and networking provides some explanation, but statistical variance remains unexplained.

This study invites future research to replicate this study, where appropriate, across other industries to explore whether they hold in the broader sense.

\subsection{Conclusions}

This study makes two main contributions to theory. The first contribution is that the study adds empirical support that superior GM does not directly lead to superior performance. Rather, superior GM works through networks, and it is the mediating role that NWs play that ultimately translates superior GM into superior performance. The second contribution is that the study builds on the mediating connection between partnership quality and its mediating role between GM and performance. Although partnership quality plays an important function, this study has drawn on the broader overall network function from the literature and classified it into two distinct parts: the static structural configuration (NWS), followed by brokering NW function, whereby benefits are leveraged from this structure (NWL).

This two-dimensional approach to networking provides a fresh perspective and offers future researchers fresh insights that may encourage them to replicate the study across other settings, extending this work and enriching relevant academic literature. 
From a trader perspective, this knowledge can be used in its entirety by practitioners to enhance competitive positioning and performance within the market place. Traders need to be aware that opportunistic behaviour is not lost on either the $\mathrm{ABCD}$ or the large new entrant MNE traders, and they may willingly step over others, particularly SME traders, who may be perceived as powerless and deal directly with the end user commercial interest if given the opportunity. The incumbent traders, though already heavily involved across most of the value chain, including the processing sector, are likely to continue to become increasingly involved.

It is predicted that a foot race will ensue between the traders and the supermarkets, and other outside stakeholders from other commodity sectors, such as energy, will compete for acquisitions within GGOS processing sector.

In essence, small traders have fewer resources and less power than either the $\mathrm{ABCD}$ or other MNE traders. Therefore, it is absolutely imperative that they develop NWs with parties that have power and influence - the closer to the consumer the better.

Gaining access to these partners and buying power in a unique way not available to the market in general allows them to leverage power through such collective interests as though it were their own. By assisting those powerful retailers and food processors that have scale but are not yet au fait with GGOS trading competencies, SME traders can broker their knowledge in the field and assist those wanting to stake a claim in the sector with the expertise to do so. This is the way forward for the SME grain and oilseed traders. 


\section{Appendix 1. Integrated Business Model}

Source: Wilmar International (2014)

\section{Integrated Business Model}

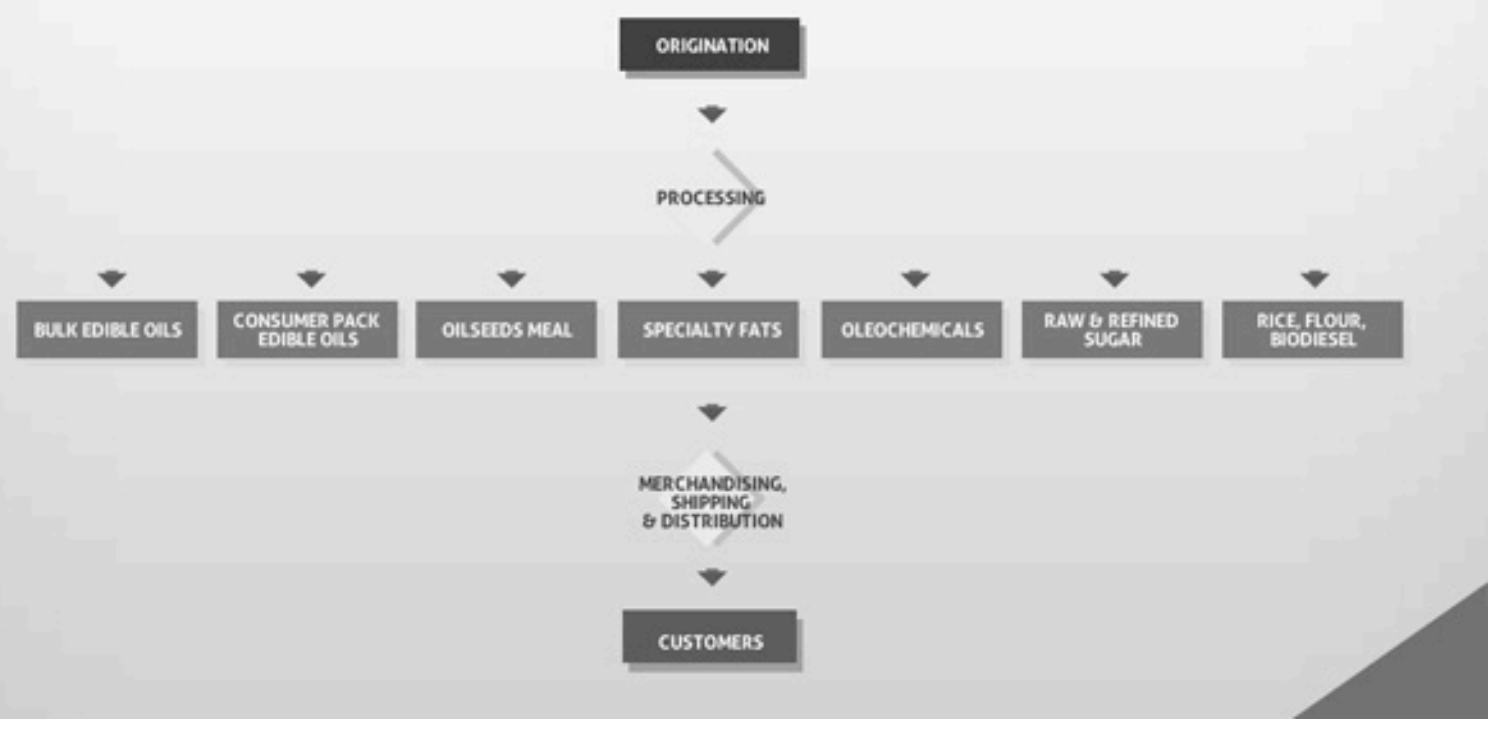




\section{Appendix 2: Invitation, Information and Online Survey}

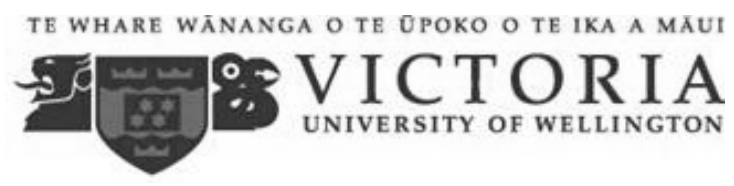

This survey is a part of my Masters thesis. The survey is about understanding the impact of global mindset and networks on the performance of small traders in the global grain and oilseed sector. You and all the other traders from your firm are invited to complete the questionnaire. The Pipitea Human Ethics Committee at Victoria University of Wellington has approved the questionnaire. The information obtained from the survey will be kept in locked files and destroyed after 3 years. It should take approximately 15 minutes to complete the survey. Please note that your responses are completely confidential and there are no right or wrong answers. Your objective and accurate answers are critical to the success of the study and highly appreciated. Should you have any queries, please contact Richard Price on cell +64274721851 or by email pricerich@myvuw.ac.nz.

\section{SECTION A}

This section helps us understand you and your business as a trader

A1. Please choose the commodity sector you are involved in (where your majority of revenue comes)
a) Vegetable Oils
b) Grains
c) Oilseed Bi-products
d) Grain Bi-products

A2. Please choose the type of trading that best describes your business activities
A. Commodity Importer
B. Commodity Exporter
C. Domestic Trader
D. Other, please specify

A3. What year was your firm established?

A4. What city is your firm's Head Office situated in? 
A5. How many years have you been trading grain and oilseed commodities?

A6. What city are you based in?

A7. What year were you born?

A8. Please state your highest education

A9. Have you ever lived abroad?

If "Yes", for how many years in total?

A10. How would you describe your position with your company?
a) Non-management
b) Lower management
c) Middle management
d) Senior management

A11. How would you rate your performance as a trader relative to the industry average over the last two years on the following?

$(1=$ substantially below industry average, $2=$ Moderately below industry average $3=$ Slightly below industry average, $4=$ About the same as industry average, $5=$ Slightly above industry average, $6=$ Moderately above industry average, $7=$ Substantially above industry average)

1. Growth in Sales/turnover

2. Growth in Profits

3. Retention of Client Base

4. Expansion of Client Base

5. Growth in Market Share

$\begin{array}{lllllll}1 & 2 & 3 & 4 & 5 & 6 & 7 \\ 1 & 2 & 3 & 4 & 5 & 6 & 7 \\ 1 & 2 & 3 & 4 & 5 & 6 & 7 \\ 1 & 2 & 3 & 4 & 5 & 6 & 7 \\ 1 & 2 & 3 & 4 & 5 & 6 & 7\end{array}$


A12. How would you rate the following considering the last two years with respect to your networks performance

$(1=$ strongly disagree, 2 = Disagree, $3=$ Neutral, $4=$ Agree, $5=$ Strongly Agree $)$

1. We have achieved a high level of joint profits between us

2. We have generated a lot of profits together.

3. We have increased joint profits shared between us

4. We have gained strategic advantages over our competitors.

5. Our relationship has resulted in strategic advantages

6 . We have gained benefits that enable us to compete more effectively in the marketplace.

7. We have secured different partners based on different business requirements

8. We can select the best partner from a large pool of candidates for each situation that arises

9. We have only a few partners for all our business requirements.

$\begin{array}{lllll}1 & 2 & 3 & 4 & 5\end{array}$

$\begin{array}{lllll}1 & 2 & 3 & 4 & 5\end{array}$

$\begin{array}{lllll}1 & 2 & 3 & 4 & 5\end{array}$

10. The business relationships with our network partners could be better

$\begin{array}{lllll}1 & 2 & 3 & 4 & 5\end{array}$

$\begin{array}{lllll}1 & 2 & 3 & 4 & 5\end{array}$

described as a "cooperative effort".

A13. Please indicate your firm's average annual financial turnover for the past 2 years (USD equivalent)
A. Zero to USD 10 million
B. USD 10 million to USD50 million
C. USD 50 million to USD100 million
D. USD 100 million to USD500 million
E. More than USD 500 million 
A14. When considering the events that surrounded the Global Financial Crisis back in 2008 , and the factors that lead to this collapse. Please respond below to the following statements considering your perceptions of the reasons ( $1=$ Strongly Disagree, $2=$ Disagree, $3=$ Neutral, 4= Agree, 5= Strongly Agree)

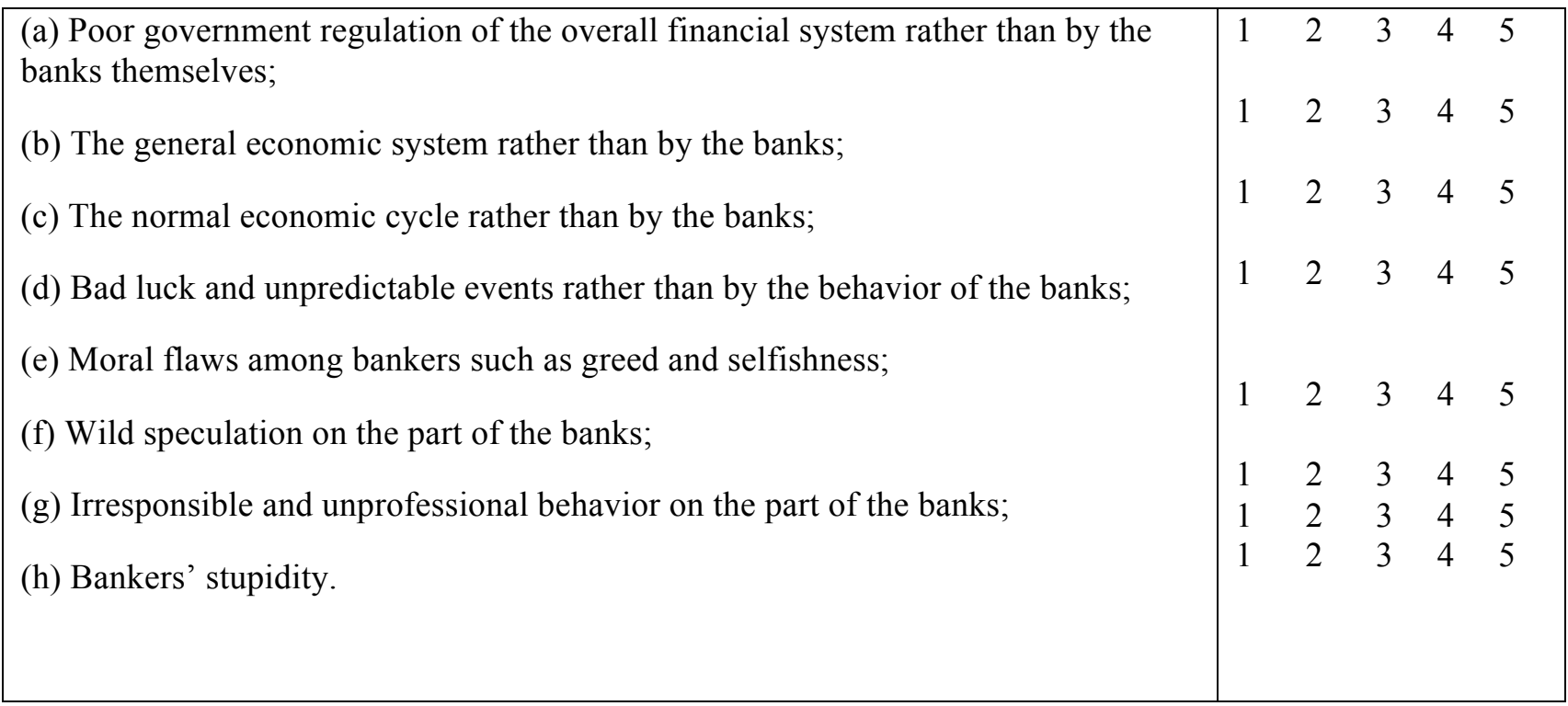




\section{Section B}

This Sections deals with various aspects of global mindset as a trader

B1. In terms of your own thinking, please indicate the extent to which you agree or disagree with the following

$(1=$ strongly disagree, $2=$ Disagree, $3=$ Neutral, $4=$ Agree, $5=$ Strongly Agree $)$

1. In my job, the best one can do is to plan ahead for at the most one year.

2. Doing business with former enemies is not patriotic

3. I think it is necessary today to develop strategic alliances with organizations around the globe.

4. Projects that involve international dealings are long term.

5. I take pride in belonging to an international organization.

6. I believe that in the next 10 years the world will be the same as it is today.

7. In this interlinked world of ours, national boundaries are meaningless.

8. Almost everybody agrees that international projects must have a shorter payback period than domestic ones.

9. We really live in a global village.

10. In discussions, I always drive for the bigger, broader picture.

11. I believe life is a balance of contradictory forces that are to be appreciated.

12. I consider it to be a disgrace when foreigners buy our land and buildings.

13. I really believe that $5-10$ years is the best planning horizon in our line of business.

14. I find it easy to rethink boundaries, and change direction and behavior.

15. I feel comfortable with change, surprise, and ambiguity.

16. I get frustrated when someone is constantly looking for context.

17. Contradictors are time wasters that must be eliminated.

$\begin{array}{lllll}1 & 2 & 3 & 4 & 5\end{array}$

$\begin{array}{lllll}1 & 2 & 3 & 4 & 5\end{array}$

$\begin{array}{lllll}1 & 2 & 3 & 4 & 5\end{array}$

$\begin{array}{lllll}1 & 2 & 3 & 4 & 5\end{array}$

$\begin{array}{lllll}1 & 2 & 3 & 4 & 5\end{array}$

$\begin{array}{lllll}1 & 2 & 3 & 4 & 5\end{array}$

$\begin{array}{lllll}1 & 2 & 3 & 4 & 5\end{array}$

$\begin{array}{lllll}1 & 2 & 3 & 4 & 5\end{array}$

$\begin{array}{lllll}1 & 2 & 3 & 4 & 5\end{array}$

$\begin{array}{lllll}1 & 2 & 3 & 4 & 5\end{array}$

$\begin{array}{llll}2 & 3 & 4 & 5\end{array}$

$\begin{array}{lllll}1 & 2 & 3 & 4 & 5\end{array}$

18. I have no time for somebody trying to paint a broader, bigger picture.

19. I believe I can live a fulfilling life in another culture.

20. Five years is too long a planning horizon. 
B2. In terms of your own actions, please indicate the extent to which you agree or disagree with the following

$(1=$ strongly disagree, 2 = Disagree, $3=$ Neutral, $4=$ Agree, $5=$ Strongly Agree $)$

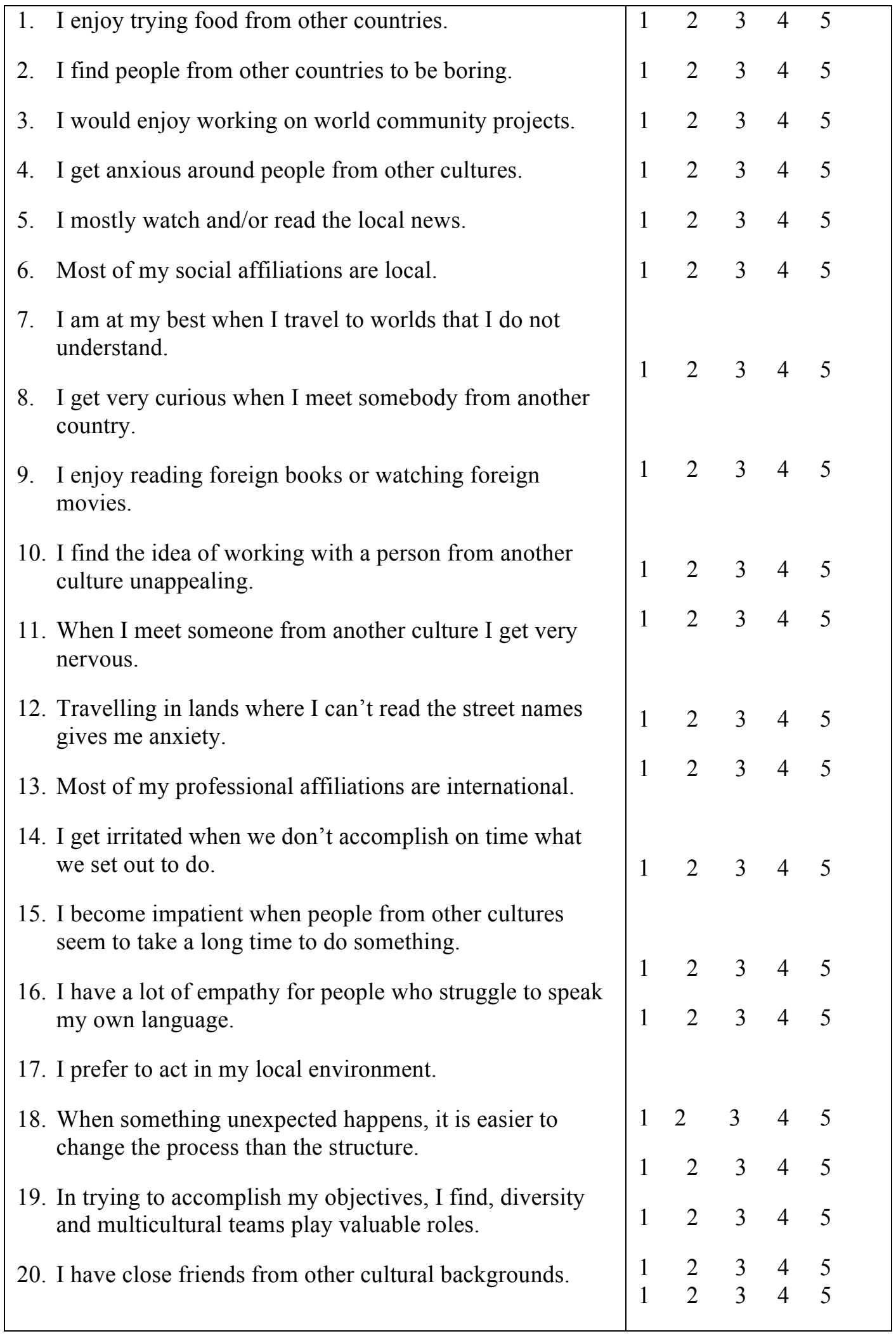




\section{Section C}

This section deals with various aspects of networking you employ as a trader

\section{Networks}

A business network is a type of social network that exists for the purpose of conducting some sort of business activities amongst the members. It consists of those you know well and those you do not know well but maintain a business relationship with. Considering networks in this way please answer the following questions:

C1. In comparison to other trader's networks, how would you rate your network when considering the following statements?

( $1=$ Substantially below industry average, $2=$ Moderately below industry average, $3=$ Slightly below industry average, $4=$ About the same as industry average, $5=$ Slightly above industry average, $6=$ Moderately above industry average, $7=$ Substantially above industry average)

\begin{tabular}{|c|c|c|c|c|c|c|c|}
\hline $\begin{array}{l}\text { 1. The number of network contacts you have in comparison to } \\
\text { other traders }\end{array}$ & 1 & 2 & 3 & 4 & 5 & 6 & 7 \\
\hline $\begin{array}{l}\text { 2. The diversity of your network contacts backgrounds and } \\
\text { demographics }\end{array}$ & 1 & 2 & 3 & 4 & 5 & 6 & 7 \\
\hline $\begin{array}{l}\text { 3. Your position as a central figure and link between your other } \\
\text { network contacts }\end{array}$ & 1 & 2 & 3 & 4 & 5 & 6 & 7 \\
\hline 4. The number of strong relationships you have & 1 & 2 & 3 & 4 & 5 & 6 & I \\
\hline 5. The number of weak relationships you have & 1 & 2 & 3 & 4 & 5 & 6 & 7 \\
\hline
\end{tabular}

$\mathrm{C} 2$. When considering your network contacts, and their own contacts. How would respond to the following?

$(1=$ Strongly Disagree, $2=$ Disagree, $3=$ Neither Agree nor Disagree, $4=$ Agree, $5=$ Strongly Agree)

\begin{tabular}{|c|c|c|c|c|c|}
\hline 6. Most of my network contacts know each other & 1 & 2 & 3 & 4 & \\
\hline 7. Most of my network contacts don't know each other & 1 & 2 & 3 & 4 & \\
\hline $\begin{array}{l}\text { 8. Most of my network contacts know only me and not my other } \\
\text { contacts }\end{array}$ & 1 & 2 & 3 & 4 & \\
\hline 9. Most of my important network contacts also know each other & 1 & 2 & 3 & 2 & \\
\hline $\begin{array}{l}\text { 10. Most of my important network partners own contacts are also } \\
\text { known to me }\end{array}$ & 1 & 2 & 3 & 2 & \\
\hline $\begin{array}{l}\text { 11. I always look to bring my network partners together when I see } \\
\text { potential }\end{array}$ & 1 & 2 & 3 & 2 & \\
\hline
\end{tabular}




\section{Section D}

This section deals with your more important network partners, and how you relate as a network

D1. Please identify up to 5 network partners not employed by your firm that you consider significant in managing your business. List these important network partners on a piece of paper, allocating them identifiable individual characters of either $\mathrm{A}$ to $\mathrm{E}$ or their initials. Then use either the allocated letter (or initials) in the contacts space provided below so you can identify each contact for the purpose of answering the remaining questions in section D.

\begin{tabular}{|l|l|l|l|l|l|}
\hline Network Partners (example) & A & B & C & D & E \\
\hline $\begin{array}{l}\text { Network Partners A to E } \\
\text { (actual) }\end{array}$ & & & & & \\
\hline
\end{tabular}

D2. Considering the network partners identified above. On the scales provided below please indicate the relationship status between the various network partners.

Scale of (1 to 3 ) where $1=$ The contacts do not know each other, $2=$ The contacts relationship is weak, $3=$ The contacts relationship is Strong). For example if network partner A has a very strong relationship with network partner D, then you put 3 in the box which intersects A \& D.

\begin{tabular}{|l|l|l|l|l|l|}
\hline & A & B & C & D & E \\
\hline A & & & & & \\
\hline B & & & & & \\
\hline C & & & & & \\
\hline D & & & & & \\
\hline E & & & & & \\
\hline
\end{tabular}

D3. Please tell us approximately how many conversations per month (on average) you have with each network partner identified above. By conversation we simply mean any communication directly either in person, or over the telephone or internet, text messaging or emails or any other form of communication you consider significant with this partner.

\begin{tabular}{|l|l|l|l|l|l|}
\hline Network Partner & A & B & C & D & E \\
\hline Conversations (Per month) & & & & & \\
\hline
\end{tabular}


D4. Considering the network partners identified above, please rate the strength of your relationship with each of the contacts.

\begin{tabular}{|l|ccccc|}
\hline Network Partner & Relationship Strength & & & \\
\hline 1 & Very weak & Weak & Average & Strong & Very strong \\
\hline 2 & Very weak & Weak & Average & Strong & Very strong \\
\hline 3 & Very weak & Weak & Average & Strong & Very strong \\
\hline 4 & Very weak & Weak & Average & Strong & Very strong \\
\hline 5 & Very weak & Weak & Average & Strong & Very strong \\
\hline
\end{tabular}

Thank you very much for your cooperation. If you would like a copy of the executive summary of the research, please fill in the contact details below.

Company name:

E-mail address: 


\section{Appendix 3: Online Introduction, Invitation and Participation}

\section{form.}

\section{Greetings,}

I would like to invite you to participate in research I am doing at Victoria University of Wellington, as part of my Masters degree in International Business. This research investigates how the interplay between global mindset and networks influence small traders performance in the global grain and oilseed sector. The potential implications for traders like you include discovering how the dimensions of global mindset and networks can enhance performance.

This research will involve completing a 15 minute web-based survey which will be available from the xx April 2013. All responses to this survey are confidential. Your name will not be used in the study and any information attributable to you will not be included in any analysis.

I have attached an information sheet which further details the research I am undertaking. If you have any questions about this research, please feel free to contact me. I will also be grateful if you can forward my survey link to other fellow traders who you think would be interested in the survey and its findings. In case you would not like to participate in the survey please email me at the address above. Else, please expect my survey invitation in the next week.

Kind Regards,

Richard Price (Principal Investigator)

International Business Master Student

School of Marketing and International Business

Victoria University of Wellington

Richard Price (pricerich@myvuw.ac.nz),

Masters Student, School of Marketing and International Business, Victoria University of Wellington, New Zealand, Mobile phone: +64 274 721851; Home: +64 75741346 


\section{PARTICIPANT INFORMATION SHEET}

\section{Global Mindset, Networks and SMall Trader Performance: A STUdy OF THE GLOBAL GRAIN AND OILSEED SECTOR}

Welcome,

I would like to invite you to participate in the research I am undertaking at Victoria University of Wellington, as part of my Masters degree in International Business. This research investigates the impact of global mindset and networking on small trader performance in the context of the grain and oilseed sector. The potential implications for traders like you include discovering how the various dimensions of global mindset and networks contribute toward enhancing performance.

All responses to this survey are confidential. Your name will not be used in the study and any information attributable to you will not be included in any analysis. The data will be reviewed by the researcher and supervisor only, and will be securely stored in a locked cabinet and password protected computer. The data from this survey will be destroyed 3 years after the conclusion of this research.

Summary results of this survey may be published in academic or professional journals and presented at academic or professional conferences. If you would like a written summary of the project at the end of the study, please provide your contact details on the questionnaire. You can be reassured that the written summary would not contain any information that is traceable to you or any of the other participants.

The survey will take approximately 15 minutes to complete. I would be grateful if you can forward my survey link to other fellow traders who you think would be interested in the survey and its findings.

If you have any questions about this research, please feel free to contact me.

Kind regards,

Richard Price (pricerich@myvuw.ac.nz),

Masters Student, School of Marketing and International Business, Victoria University of Wellington, New Zealand, Mobile phone: +64 274 721851; Home: +64 75741346

Dr. Revti Raman (revti.raman@,vuw.ac.nz)

Senior Lecturer in International Business, School of Marketing and International Business, Victoria

University of Wellington, New Zealand, Telephone: +64 04 463-7452 


\section{Email including the Survey Link}

Greetings,

I would like to invite you to participate in research I am doing at Victoria University of Wellington, as part of my Masters degree in International Business. This research investigates how the interplay between global mindset and networks influence small traders performance in the global grain and oilseed sector. The potential implications for traders like you include finding out how the various dimensions such as global mindset and networks enable enhanced performance.

All responses to this survey are confidential. Your name will not be used in the study and any information attributable to you will not be included in any analysis. The data will be reviewed by the researcher and supervisor only, and will be securely stored in a locked cabinet and password protected computer. The data from this survey will be destroyed 3 years after the conclusion of this research. Summary results of this survey may be published in academic or professional journals and presented at academic or professional conferences.

If you would like a written summary of the project at the end of the study, please provide your contact details on the questionnaire. You can be reassured that the written summary would not contain any information that is traceable to you or any of the other participants.

This research will involve completing a 15-minute web-based survey. Your participation in this survey will be considered as your consent to participate you're your willingness to contribute to data collection. A final reminder also, I would be most grateful if you can forward my survey link to other fellow traders who you think would be interested in the survey and its findings. Please email me if you would not like to receive reminders to undertake the survey. $\quad$ Click here to begin ...

Kind Regards,

Richard Price (Principal Investigator)

Master Student - International Business

School of Marketing and International Business

Victoria University of Wellington

Richard Price (pricerich@myvuw.ac.nz),

Masters Student, School of Marketing and International Business, Victoria University of Wellington, New Zealand, Mobile phone: +64 274 721851; Home: +64 75741346 


\section{References}

ADM (2014), Corporate website. URL http://www.adm.com Retrieved 23 August, 2014

Al-Gahtani, S. S., Hubona, G. S., \& Wang, J. (2007). Information technology (IT) in Saudi Arabia: Culture and the acceptance and use of IT. Information \& Management, 44(8), 681-691. doi: http://dx.doi.org/10.1016/j.im.2007.09.002

Agrimoney, (2014) Corporate website URL: http://www.agrimoney.com. (2014). http:/www.agrimoney.com/news/wild-flavors-deal-hasnt-emptied-admswarchest--7240.html. Retrieved 23 August 2014.

Arora, A., Jaju, A., Kefalas, A. G., \& Perenich, T. (2004). An exploratory analysis of global managerial mindsets: a case of U.S. textile and apparel industry. Journal of International Management, 10(3), 393-411. doi: http://dx.doi.org/10.1016/j.intman.2004.05.001

Arrow Commodities (2014) Corporate website URL: http://www.arrowcom.com.au Retrieved 23 August 2014.

Babbie, E. M., J. (1998). The Practise of Social Reseach: Wadsworth Publishing Company, 1998.

Barney, J. (1991). Firm Resources and Sustained Competitive Advantage. Journal of Management, 17(1), 99-120.

Barney, J., Wright, M., \& Ketchen, D. J. (2001). The resource-based view of the firm: Ten years after 1991. Journal of Management, 27(6), 625-641.

Bengtsson, M., \& Kock, S. (2000). "Coopetition" in Business Networks--to Cooperate and Compete Simultaneously. Industrial Marketing Management, 29(5), 411-427.

BeVier, G. (2012). Global Food Systems: Feeding the World. Reproduction in Domestic Animals, 47, 77-79. doi: 10.1111/j.1439-0531.2012.02058.x

Blas, J. (2013). Apr 14 Commodities: Tougher times for trading titans. FT.com. Retrieved from internet.

Bloomberg. (2014). Market App. iphone: live data feed.

Bohme, T., Childerhouse, P., Deakins, E., \& Corner, J. (2008). Balancing power and dependency in buyer-supplier relationships. International Journal of Electronic Customer Relationship Management, 2(2), 120-139.

Bono, J., McNamara, G. (2011). FROM THE EDITORS: PUBLISHING IN AMJ-PART 2: RESEARCH DESIGN. Academy of Managament Journal, 54(4), 657-660.

Borgatti, S. P., \& Halgin, D. S. (2011). On Network Theory. Organization Science, 22(5), 1168-1181. doi: 10.1287/orsc.1100.0641

Bowen, D. E., \& Inkpen, A. C. (2009). Exploring the Role of "Global Mindset" in Leading Change in International Contexts. The Journal of Applied Behavioral Science, 45(2), 239-260.

Burch, D., Dixon, J., \& Lawrence, G. (2013). Introduction to symposium on the changing role of supermarkets in global supply chains: from seedling to supermarket: agri-food supply chains in transition. Agriculture and Human Values, 30(2), 215-224. doi: 10.1007/s10460-012-9410-x 
Burt, R. S. (1992). Structural Holes:the Social Structure of Competition. Harvard University Press, Cambridge.

Burt, R. S. (2000). The network structure of social capital. Research in Organizational Behavior, 22(0), 345-423. doi: http://dx.doi.org/10.1016/S0191-3085(00)22009-1

Burt, R. S. (2004). Structural Holes and Good Ideas. American Journal of Sociology, 110(2), 349-399. doi: 10.1086/421787

Bunge (2014), Corporate website. URL http://www.cargill.com Retrieved 23 August, 2014

Caiazza, R., \& Volpe, T. (2012). The Global Agro-food System From Past to Future. China - USA Business Review, 11(7).

Cargill (2014), Corporate website. URL http://www.cargill.com Retrieved 23 August, 2014

Cavana, R. D., B.; Sekaran, U. (2001). Qualitative and Quantitative Methods: John Wiley \& Sons Aust Ltd.

Chadee, D., \& Raman, R. (2012). External knowledge and performance of offshore IT service providers in India: the mediating role of talent management. Asia Pacific Journal of Human Resources, 50(4), 459-482. doi: 10.1111/j.1744-7941.2012.00039.x

Chen, Chung-Jen., \& Chang, Lien-Sheng. (2004). Dynamics of Business Network Embeddedness. Journal of American Academy of Business, Cambridge, 5(1/2), 237-241.

Chang, S.-J. v. W., Arjen; Eden, Lorraine. (2010). From the Editors: Common method varience in international business research. Journal of International Business Studies, 41, 178-184.

Chen, S.-J. (2013). The effects of social networks and a global mindset on Taiwanese manufacturing SMEs' ability to form alliances to increase international and financial performance. (3560967 D.B.A.), Alliant International University, Ann Arbor.

COFCO (2014). Corporate website. URL: http://www.chinaagri.com/ Retrieved 23 August, 2014

Cohen, D. C., B. (2006). Qualitative Research Guidelines Project. http://www.qualres.org/.

Cohen, S. L. (2010). Effective global leadership requires a global mindset. Industrial and Commerical Training, 42(1), 3-10.

Coleman, J. S. (1988). Social Capital in the Creation of Human Capital. American Journal of Sociology, 94, S95-S120. doi: 10.2307/2780243

Combs, J. G., Ketchen, J. D. J., Ireland, R. D., \& Webb, J. W. (2011). The Role of Resource Flexibility in Leveraging Strategic Resources. Journal of Management Studies, 48(5), 1098-1125. doi: 10.1111/j.14676486.2009.00912.x

Cronbach, L. J. (1951). Coefficient alpha and the internal structure of tests. Psychometrica, 16(93-96).

D'Aveni, R. A. (1999). Strategic supremacy through disruption and dominance. Sloan Management Review, 40(3), 127-135.

Dawes, J. (2008). Do data characteristics change according to the number of scale points used? An experiment using -point, 7-point and 10-point scales. International Journal of Marketing Research, 50(1), 61-77. 
De Carolis, D. M., Eddleston, K. A., \& Litzky, B. E. (2009, 2009/03//). Why networks enhance the progress of new venture creation: the influence of social capital and cognition. Entrepreneurship: Theory and Practice, 33, $527+$.

Dobbs, M. E. (2014). Guidelines for applying Porter's five forces farmework: a set of industry analysis templates. Competitiveness Review, 24(1), 32-45.

Dubini, P., \& Aldrich, H. (1991). Personal and extended networks are central to the entrepreneurial process. Journal of Business Venturing, 6(5), 305-313. doi: http://dx.doi.org/10.1016/0883-9026(91)90021-5

Dyer, J. H., Kale, P., \& Singh, H. (2001). How to Make Strategic Alliances Work. MIT Sloan Management Review, 42(4), 37-43.

Dyer, J. H., \& Singh, H. (1998). The relational view: Cooperative strategy and sources of interorganizational competitive advantage. Academy of Management. The Academy of Management Review, 23(4), 660-679.

Ellis, P. D. (2010). Effect sizes and the interpretation of research results in international business. Journal of International Business Studies, 41, 1581-1588.

Emerson, R. M. (1962). POWER-DEPENDENCE RELATIONS. American Sociological Review, 27(1), 31-41.

Esteve-Pérez, S., \& Mañez-Castillejo, J. A. (2008). The Resource-Based Theory of the Firm and Firm Survival. Small Business Economics, 30(3), 231249. doi: $10.1007 / \mathrm{s} 11187-006-9011-4$

Felício, J. A., Caldeirinha, V. R., \& Rodrigues, R. (2012). Global mindset and the internationalization of small firms: The importance of the characteristics of entrepreneurs. International Entrepreneurship and Management Journal, 8(4), 467-485. doi: http://dx.doi.org/10.1007/s11365-012-0232-5

Field, A. (2009). Discovering Statistics Using SPSS (Vol. Third Edition): SAGE Publications Ltd.

Fortune 500, (2014). URL: http://www.fortune.com/fortune500/. (2014). Retrieved 28 August, 2014

Fowler, F. J. (1995). Improving Survey Questions. Design and Evaluation. London: Sage.

Fox, B. V. a. T. (2004). Global Food Chains-Constraints and Opportunities for Smallholders. OECD.

Frankenberger, K., Weiblen, T., \& Gassmann, O. (2013). Network configuration, customer centricity, and performance of open business models: A solution provider perspective. Industrial Marketing Management, 42(5), 671-682. doi: http://dx.doi.org/10.1016/j.indmarman.2013.05.004

Glencore Xstrata (2014), Corporate website. URL http://www.glencore.com Retrieved 23 August, 2014

Godfray, H. C. J., Crute, I. R., Haddad, L., Lawrence, D., Muir, J. F., Nisbett, N., . . . Whiteley, R. (2010). The future of the global food system. Philosophical Transactions of the Royal Society B: Biological Sciences, 365(1554), 2769-2777.

GrainCorp (2014), Corporate website. URL http://www.GrainCorp.com.au Retrieved 23 August, 2014

Granovetter, M. (1983). The Strength of Weak Ties: A Network Theory Revisited. Sociological Theory, 1, 201-233. doi: 10.2307/202051 
Granovetter, M. S. (1973). The Strength of Weak Ties. American Journal of Sociology, 78(6), 1360-1380. doi: 10.2307/2776392

Gulati, R., \& Gargiulo, M. (1999). Where do Interorganizational Networks Come From? American Journal of Sociology, 104(5), 1439-1493.

Gulati, R., Nohria, N., \& Zaheer, A. (2000). Strategic networks. Strategic Management Journal, 21(3), 203-215. doi: 10.1002/(SICI)10970266(200003)21:3<203::AID-SMJ102>3.0.CO;2-K

Gupta, A. K., \& Govindarajan, V. (2002). Cultivating a Global Mindset. The Academy of Management Executive (1993-2005), 16(1), 116-126. doi: $10.2307 / 4165818$

Hair, J. F. R., C.M.; Sarstedt, M. (2011). PLS-SEM: INDEED A SILVER BULLET. Journal of Marketing Theory and Practice, 19(2), 139-151.

Hair, J. H., G;Ringle,C;Sarstedt,M. (2014). A PRIMER ON PARTIAL LEAST SQUARES STRUCTURAL EQUATION MODELING (PLS-SEM): SAGE.

Hair Jr, J. F., Ringle, C. M., \& Sarstedt, M. (2013). Partial Least Squares Structural Equation Modeling: Rigorous Applications, Better Results and Higher Acceptance. Long Range Planning, 46(1-2), 1-12. doi: http://dx.doi.org/10.1016/j.lrp.2013.01.001

Hamel, G., Doz, Y. L., \& Prahalad, C. K. (1989). Collaborate with Your Competitors--and Win. Harvard Business Review, 67(1), 133-139.

Hansen, M. T. (1999). The Search-Transfer Problem: The Role of Weak Ties in Sharing Knowledge across Organization Subunits. Administrative Science Quarterly, 44:82.

Hansmann, K.-W. R., Christian, M. (2004). SmartPLS Manual. University of Hamburg. Retrieved from http://ibl-unihh.de

HighQuest. (2011). How the Global Oilseed and Grain trade Works. US SOybean Export Council.

Hite, J. M., \& Hesterly, W. S. (2001). The evolution of firm networks: From emergence to early growth of the firm. Strategic Management Journal, 22(3), 275-286.

Hoang, H., \& Antoncic, B. (2003). Network-based research in entrepreneurship: A critical review. Journal of Business Venturing, 18(2), 165-187. doi: http://dx.doi.org/10.1016/S0883-9026(02)00081-2

Hornby, L. (2014). Cofco challenges 'ABCDs' as it bolsters China's global supply chain. FT.com.

IGC. (2014). Latest export prices. Retrieved 21 August 2014

Jae-Nam, L., \& Young-Gul, K. (1999). Effect of Partnership Quality on IS Outsourcing Success: Conceptual Framework and Empirical Validation. Journal of Management Information Systems, 15(4), 29-61.

Javidan, M., \& Bowen, D. (2013). The 'Global Mindset' of managers: What it is, why it matters, and how to develop it. Organizational Dynamics, 42(2), 145-155. doi: http://dx.doi.org/10.1016/j.orgdyn.2013.03.008

Javidan, M., Teagarden, M., \& Bowen, D. (2010). Making It Overseas. Harvard Business Review, 88(4), 109-113.

Javidan, M., \& Walker, J. L. (2012). A Whole New Global Mindset for Leadership. People \& Strategy, 35(2), 36-41.

Javidan, M. T., M.B. (2011). Conceptualising and measuring global mindset. Advances in Global Leadership, 6, 13-39.

Kalish, Y., \& Robins, G. (2006). Psychological predispositions and network structure: The relationship between individual predispositions, structural 
holes and network closure. Social Networks, 28(1), 56-84. doi: http://dx.doi.org/10.1016/j.socnet.2005.04.004

Kedia, B. L., \& Mukherji, A. (1999). Global Managers: Developing A Mindset For Global Competitiveness. Journal of world business, 34(3), 230-251.

Kefalas, A.G., Neuland, E.W., (1997). Global mindsets: an exploratory study. Paper presented at the Annual Conference of the Academy of International Business, Moneterrey, Mexico, 4-7 October, pp 5-9.

Kim, S., Kim, N., Pae, J. H., \& Yip, L. (2013). Cooperate "and" compete: coopetition strategy in retailer-supplier relationships. Journal of Business \& Industrial Marketing, 28(4), 263-275. doi: 10.1108/08858621311313875

Koka, B. R., \& Prescott, J. E. (2008). Designing alliance networks: the influence of network position, environmental change, and strategy on firm performance. Strategic Management Journal, 29(6), 639-661. doi: 10.1002/smj.6

Krackhardt, D. (1992). The Stregth of Strong Ties: The importance of philos in organizations. Networks and organizations: Structure, form, and action. 216, 239.

Krackhardt, D. (1995). Structural Holes: The Social Structure of Competition. Administrative Science Quarterly, 40(2), 350-354.

Lambert, T. A. E., Lillian. T.; Reeves, Melissa. P (2006). Predictors of Networking Intensity and Network Quality Among White-Collar Job Seekers. Journal of Career Development, 32(4), 351-365.

Levy, O., Beechler, S., Taylor, S., \& Boyacigiller, N. A. (2007). What we talk about when we talk about 'global mindset': Managerial cognition in multinational corporations. Journal of International Business Studies, 38(2), 231-258.

Li, H. Y. (2008). The entrepreneurial process between social networks and firm performance. (3341114 Ph.D.), Hong Kong Polytechnic University (Hong Kong), Ann Arbor.

Lietz, P. (2010). Research into questionnaire design. A summary of the literature. International Journal of Marketing Research, 52(2), 249-272.

Louis Dreyfus (2014), Corporate website. URL http://www.ldcom.com Retrieved 23 August, 2014

Lozano, S., Moreno, P., Adenso-Díaz, B., \& Algaba, E. (2013). Cooperative game theory approach to allocating benefits of horizontal cooperation. European Journal of Operational Research, 229(2), 444-452. doi: 10.1016/j.ejor.2013.02.034

Mauer, I. E., M. (2006). Dynamics of Social Capital and their performance implications: Lessons from biotechnology start-ups. Administrative Science Quarterly, 51(June), 262-291.

Maurer, I., \& Ebers, M. (2006). Dynamics of Social Capital and Their Performance Implications: Lessons from Biotechnology Start-Ups. Administrative Science Quarterly, 51(2), 262-292. doi: $10.2307 / 20109873$

McEvily, B., \& Zaheer, A. (1999). BRIDGING TIES: A SOURCE OF FIRM HETEROGENEITY IN COMPETITIVE CAPABILITIES. Strategic Management Journal, 20(12), 1133-1156.

Meyer, Gregory (2013) URL: FT.com 02-05. Commodities trading becoming more complex. FT.com. Retrieved from the internet 23 August 2014. 
Michelfelder, I., \& Kratzer, J. (2013). Why and How Combining Strong and Weak Ties within a Single Interorganizational R\&D Collaboration Outperforms Other Collaboration Structures. Journal of Product Innovation Management, 30(6), 1159-1177. doi: 10.1111/jpim.12052

MPOB. (2014). URL: http://www.mpob.gov.my. Retrieved 21 August, 2014

Müller-Seitz, G. (2012). Leadership in Interorganizational Networks: A Literature Review and Suggestions for Future Research. International Journal of Management Reviews, 14(4), 428-443. doi: 10.1111/j.14682370.2011.00324.x

Murphy, S. B., David; Clapp, Jennifer. (2012). Cereal Secrets. OXFAM RESEARCH REPORTS, 80.

Musteen, M., Francis, J., \& Datta, D. K. (2010). The influence of international networks on internationalization speed and performance: a study of Czech SMEs. Journal of world business, 45(3), 197-205.

Nahapiet, J., \& Ghoshal, S. (1998). Social Capital, Intellectual Capital, and the Organizational Advantage. The Academy of Management Review, 23(2), 242-266. doi: 10.2307/259373

Narayanan, V. K., \& Fahey, L. (2005). The Relevance of the Institutional Underpinnings of Porter's Five Forces Framework to Emerging Economies: An Epistemological Analysis. Journal of Management Studies, 42(1), 207-223. doi: 10.1111/j.1467-6486.2005.00494.x

Nelson, R. E. (1989). THE STRENGTH OF STRONG TIES: SOCIAL NETWORKS AND INTERGROUP CONFLICT IN ORGANIZATIONS. Academy of Management Journal, 32(2), 377-401. doi: 10.2307/256367

Nummela, N., Saarenketo, S., \& Puumalainen, K. (2004a). A Global Mindset - A Prerequisite for Successful Internationalization? Canadian Journal of Administrative Sciences, 21(1), 51-64.

Nummela, N., Saarenketo, S., \& Puumalainen, K. (2004b). A Global Mindset--A Prerequisite for Successful Internationalization? Canadian Journal of Administrative Sciences (Canadian Journal of Administrative Sciences), 21(1), 51-64.

Osarenkhoe, A. (2010). A study of inter-firm dynamics between competition and cooperation - A coopetition strategy. Journal of Database Marketing \& Customer Strategy Management, 17(3/4), 201-221. doi: $10.1057 / \mathrm{dbm} .2010 .23$

PAK'nSAVE, (2014). URL: http://www.paknsave.co.nz. Retrieved 28 August, 2014

Pelupessy, W., \& Van Kempen, L. (2005). The Impact of Increased ConsumerOrientation in Global Agri-food Chains on Smallholders in Developing Countries. Competition and Change, 9(4), 357-381. doi: http://www.ingentaconnect.com/content/maney/com

Perlmutter, H. V. (1969). The Tortuous Evolution of the Multinational Corporation. Columbia Journal of World Business, 4(1), 9.

Pett, T. L., \& Dibrell, C. C. (2001). A process model of global strategic alliance formation. Business Process Management Journal, 7(4), 349-364.

Podsakoff, P. M. M., S.B.; Lee, J.Y.; Podsakoff, N.P. (2003). Common method biases in behavioral reearch: A critical review of the literature and recommended remediies. Journal of Applied Psychology, 88(5), 879-903.

Porter, M. E. (1979). How Competitive Forces Shape Strategy. Harvard Business Review, March-April. 
Porter, M. E. (1980). Competitive Strategy: FREE PRESS.

Porter, M. E. (1990). Competitive Advantage: Creating and Sustaining Superior Performance: THE FREE PRESS.

Porter, M. E. (2008). THE FIVE COMPETITIVE FORCES THAT SHAPE STRATEGY. Harvard Business Review, 86(1), 78-93.

Pringle, J., \& Huisman, J. (2011). Understanding Universities in Ontario, Canada: An Industry Analysis Using Porter's Five Forces Framework. The Canadian Journal of Higher Education, 41(3), 36-58.

Quadra Commodities (2014) URL: http://www.quadra.com. Retrieved 23 August 2014.

Raman, R., Chadee, D., Roxas, B., \& Michailova, S. (2013). Effects of Partnership Quality, Talent Management, and Global Mindset on Performance of Offshore IT Service Providers in India. Journal of International Management(0). doi: http://dx.doi.org/10.1016/j.intman.2013.03.010

Rhinesmith, S. H. (1992). Global Mindsets Global Managers. Training \& Development, 46(10), 63.

Rhinesmith, S. H. (1995). Open the door to a global mindset. Training \& Development, 49(5), 35.

Rost, K. (2011). The strength of strong ties in the creation of innovation. Research Policy, 40(4), 588-604. doi: 10.1016/j.respol.2010.12.001

Schrag, F. (1992). In Defense of Positivist Research Paradigms. Educational Researcher, 21(5), 5-8. doi: 10.2307/1176838

Seth, A. (1894). Epistemology and Ontology. The Philosophical Review, 3(5), 568-582. doi: $10.2307 / 2175689$

Shah, R. H., \& Swaminathan, V. (2008). Factors influencing partner selection in strategic alliances: the moderating role of alliance context. Strategic Management Journal, 29(5), 471-494. doi: 10.1002/smj.656

Shipilov, A. V., \& Li, S. X. (2008). Can You Have Your Cake and Eat It Too? Structural Holes' Influence on Status Accumulation and Market Performance in Collaborative Networks. Administrative Science Quarterly, 53(1), 73-108.

Sowinski, L. L. (2012). The Global Food Supply Chain. Food Logistics(136), 14$14,16,18,20$.

Sparrowe, R. T., Liden, R. C., Wayne, S. J., \& Kraimer, M. L. (2001). SOCIAL NETWORKS AND THE PERFORMANCE OF INDIVIDUALS AND GROUPS. Academy of Management Journal, 44(2), 316-325. doi: $10.2307 / 3069458$

Sparrowe, R. T. M. K. J. (2011). PUBLISHING IN AMJ--PART 4: GROUNDING HYPOTHESES. Academy of Management Journal, 54(6), 1098-1102. doi: 10.5465/amj.2011.4001

Stam, W., Arzlanian, S., \& Elfring, T. (2014). Social capital of entrepreneurs and small firm performance: A meta-analysis of contextual and methodological moderators. Journal of Business Venturing, 29(1), 152173. doi: http://dx.doi.org/10.1016/j.jbusvent.2013.01.002

Story, J. S. P., \& Barbuto, J. E. (2011). Global Mindset: A Construct Clarification and Framework. Journal of Leadership \& Organizational Studies, 18(3), 377-384.

Street, C. T., \& Cameron, A.-F. (2007). External Relationships and the Small Business: A Review of Small Business Alliance and Network Research*. 
Journal of Small Business Management, 45(2), 239-266. doi: 10.1111/j.1540-627X.2007.00211.x

Tiwana, A. (2008). Do bridging ties complement strong ties? An empirical examination of alliance ambidexterity. Strategic Management Journal, 29(3), 251-272.

Tser-Yieth, C., Hsiang-Hsi, L. I. U., \& Wei-Lan, H. (2009). The Influence of Partner Characteristics and Relationship Capital on the Performance of International Strategic Alliances. Journal of Relationship Marketing, 8(3), 231-252. doi: 10.1080/15332660902991148

Turnbull, P., \& Ford, D. (1996). Interaction, relationships and networks in business markets: An evolving perspective. Journal of Business \& Industrial Marketing, 11(3/4), 44.

UNIDO. (2009). Agro-value chain analysis and development. The UNIDO Approach Working Paper.

USDA. (2014). Foreign Agricultural Services. http://apps.fas.usda.gov/psdonline/psdQuery.aspx

Vissa, B., \& Chacar, A. S. (2009). Leveraging ties: the contingent value of entrepreneurial teams' external advice networks on Indian software venture performance. Strategic Management Journal, 30(11), 1179-1191.

Vogelgesang, G., Clapp-Smith, R., \& Osland, J. (2014). The Relationship Between Positive Psychological Capital and Global Mindset in the Context of Global Leadership. Journal of Leadership \& Organizational Studies, 21(2), 165-178.

Walmart. (2014). http://corporate.walmart.com/global-responsibility/ethicalsourcing/.

Williamson, O. (1998). Transaction Cost Economics: How It Works; Where It is Headed. De Economist, 146(1), 23-58. doi: 10.1023/A:1003263908567

Williamson, O. E. (2010). Transaction Cost Economics: The Natural Progression. The American Economic Review, 100(3), 673-690. doi: $\mathrm{http}: / / \mathrm{dx}$.doi.org/10.1257/aer.100.3.673

Wilmar Intl, (2014) URL: http://www.wilmar-international.com. (2014). Retrieved 23 August, 2014

Yu, Sui-Hua., \& Chiu, Wei-Ting. (2013). Social Networks and Corporate Performance: The Moderating Role of Technical Uncertainty. Journal of Managerial Issues, 25(1), 26-45.

Zaheer, A., \& Bell, G. G. (2005). Benefiting from Network Position: Firm Capabilities, Structural Holes, and Performance. Strategic Management Journal, 26(9), 809-825. doi: 10.2307/20142270

Zhang, Y. J. D. (2012). FROM THE EDITORS: PUBLISHING IN AMJ-PART 5: CRAFTING THE METHODS AND RESULTS. Academy of Management Journal, 55(1), 8-12. doi: 10.5465/amj.2012.4001

Zhou, L., Wu, W.-p., \& Luo, X. (2007). Internationalization and the performance of born-global SMEs: the mediating role of social networks. Journal of International Business Studies, 38(4), 673-690. doi: http://dx.doi.org/10.1057/palgrave.jibs. 8400282 